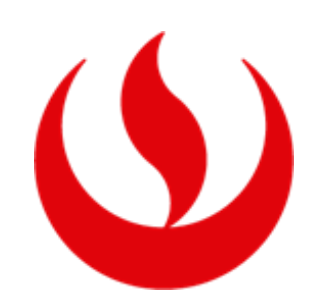

UNIVERSIDAD PERUANA DE CIENCIAS APLICADAS

FACULTAD DE NEGOCIOS

CARRERA DE MARKETING

\title{
APERBIRD EXPEDITION
}

\author{
TRABAJO DE INVESTIGACIÓN
}

Para obtener el grado académico de Bachiller en Marketing

\author{
$\operatorname{AUTOR}(\mathrm{ES})$ : \\ CASTILLA ESCOBAR, Rocío (0000-0002-3986-1292) \\ FLORES FUENTES DÁVILA, Claudia Alexandra (0000-0003-4950-5037) \\ SACO MEDINA, Luis Alfredo (0000-0002-8691-2208) \\ YRAJA NISHIKI, Patricia (0000-0002-9789-6207)
}

ASESOR:

GAVIRIA CLEMENTE, Juan Francisco (0000-0001-6435-0307)

Lima, 15 de julio de 2018 


\section{Resumen}

El Perú es un país increíble y mega biodiverso. Si hablamos de especies de aves, el Perú tiene el 3er lugar en el mundo, con más de 1800 especies, y es el 2 do en endémicas con 104 especies. Con este recurso podemos atraer a un nicho de turismo especializado: Los Birdwatchers: Personas cuyo único interés es apreciar la belleza natural de las aves y completar su "check list". Cabe mencionar que PROMPERU en el 2014 realizó un estudio de dicho mercado, identificando a 2, 419,839 personas interesadas en visitar el Perú.

El trabajo propone la implementación de un albergue especializado para birdwatchers en Tambopata, con un enfoque de desarrollo sostenible, la propuesta de valor se resume en: Rutas turísticas de observación de aves con base científica, una característica muy importante ya que nuestro potencial cliente valora y prioriza la selección de un destino por la cantidad de especies que podría avistar. Cabe resaltar que el Birdwatcher es una actividad que no hace uso tangible del recurso, por el contrario, recrea la experiencia a través del avistamiento de aves. Con esta iniciativa se promueve la conservación de los bosques, empleo local, lucha contra la tala y minería ilegal, problemas sociales latentes en esta región.

El equipo es multidisciplinario, ya que, cuenta con profesionales con experiencia en marketing, gestión comercial, administración y proyectos turísticos. Según lo proyectado tendremos una ganancia de S/ 460799.20 a los 5 años de implementado el proyecto, siendo la inversión total de S/ 656976.62.

Palabras claves: Aves, observadores de aves, albergue, Tambopata, ecoturismo, turismo especializado, investigación en aves, naturaleza. 


\begin{abstract}
Peru is an amazing and biodiverse country. There are over 1800 bird species in Peru, making it the third country with most species and 104 of these can only be seen there. With these resources we can attract a specialized kind of tourists: Birdwatchers, these are people interested in watching the natural beauty of birds and this way finish their "checklist ". PROMPERU made an investigation on this subject in 2014 and identified almost 2.5 million people interested in coming to Peru.

The current paper proposes the implementation of a specialized birdwatching shelter in Tambopata with and environmental development. The project consists in touristic birdwatching routes with a scientific base because our target values the possibility of watching different species when they select their destination. It's important to mention that this activity does not make tangible use of the resources so they are not exposed to any danger (the birds). Considering this, birdwatchers promote forest preservation, local employment and fight against deforestation and any social problems around bird's environment.
\end{abstract}

This is a multidisciplinary team with professionals with experience on marketing, management and touristic projects. According to our forecast we will make a 5 years profit of S/ 460799.20 with an initial investment of S/ 656976.62.

Keywords: Birds, birdwatchers, shelter, Tambopata, ecotourism, specialized tourism, research on birds, nature. 


\section{Tabla de Contenido}

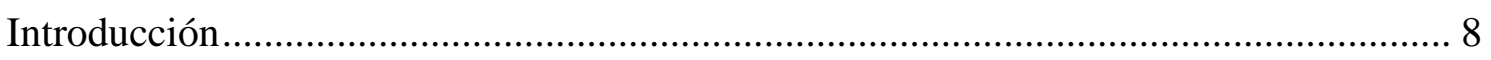

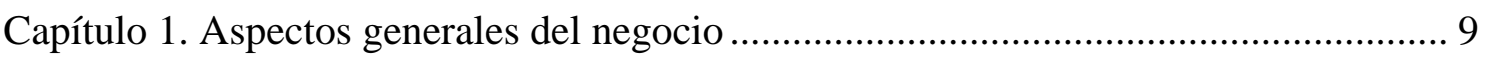

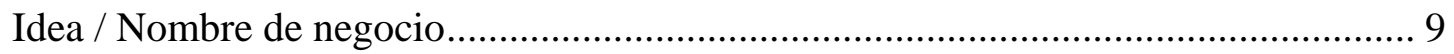

Descripción del producto o servicio a ofrecer ............................................................. 9

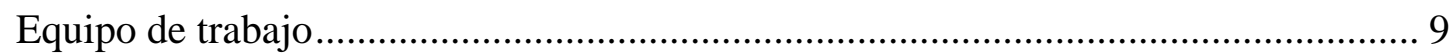

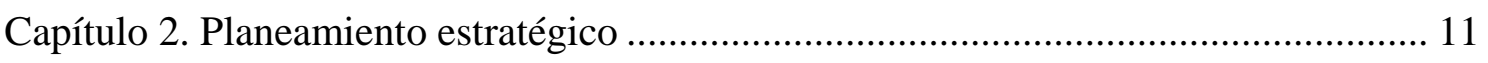

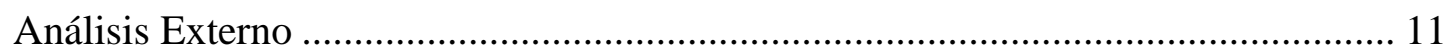

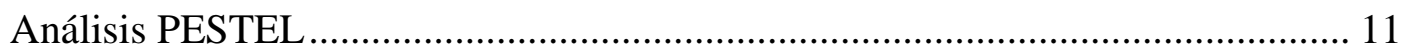

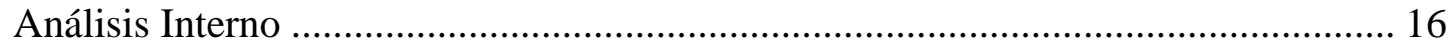

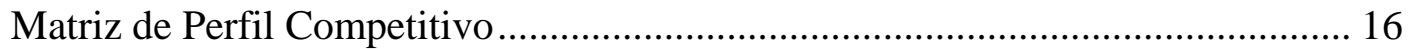

Análisis de las 5 Fuerzas de Porter ...................................................................... 16

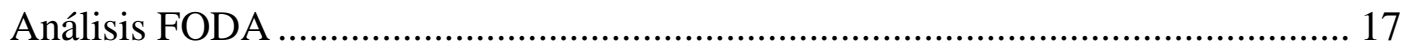

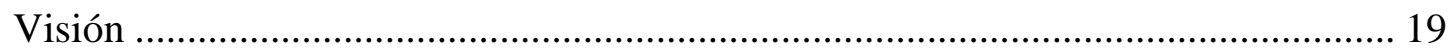

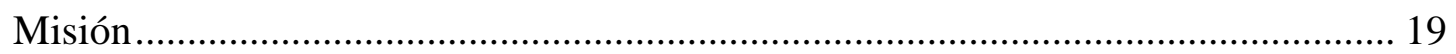

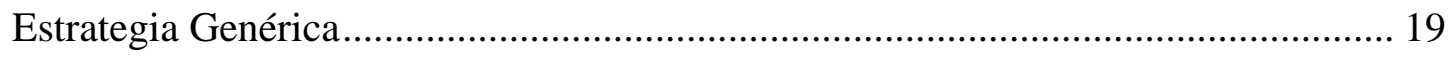

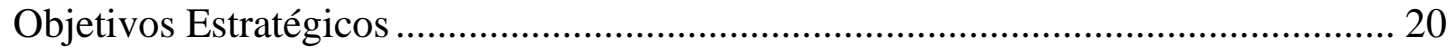

Capítulo 3. Investigación / Validación del mercado........................................................ 21

Diseño metodológico de la investigación / metodología de validación de hipótesis . 21

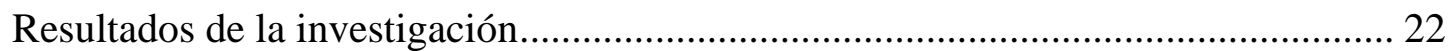

Informe final: Elaboración de tendencias, patrones y conclusiones.......................... 23

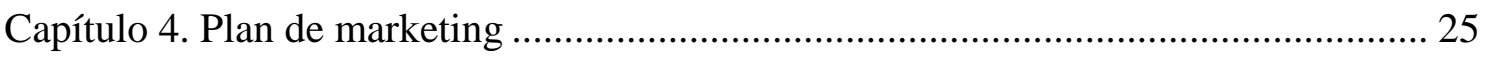

Planteamiento de objetivos de marketing ............................................................ 25

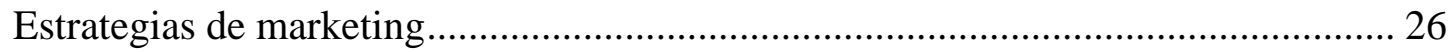

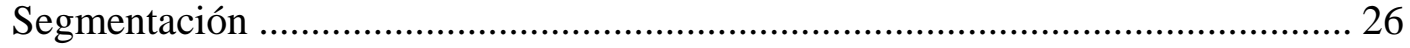

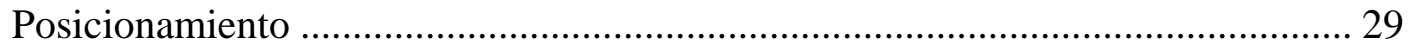

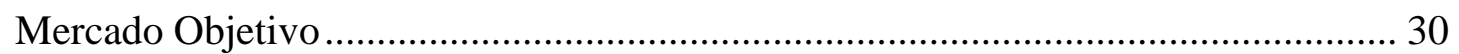

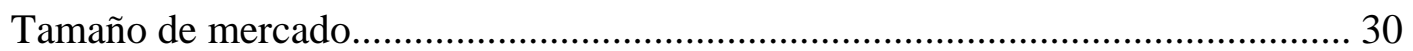

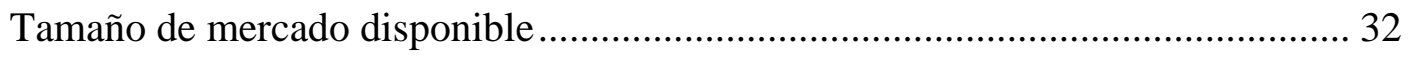

Tamaño de mercado operativo (Target) ….......................................................... 32

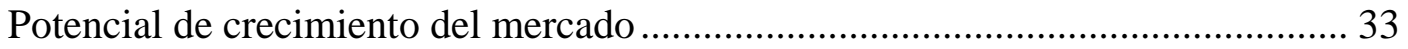




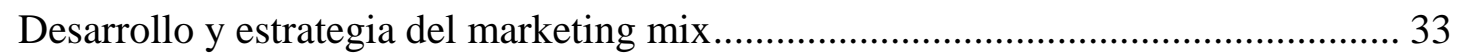

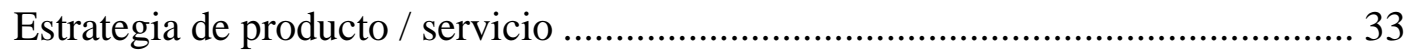

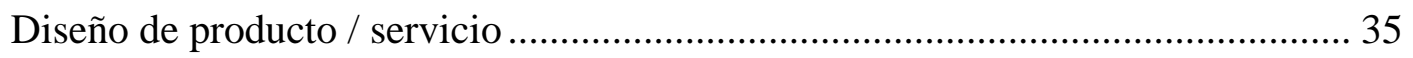

Estrategia de precios (Análisis de costos, precios de mercado) ............................ 38

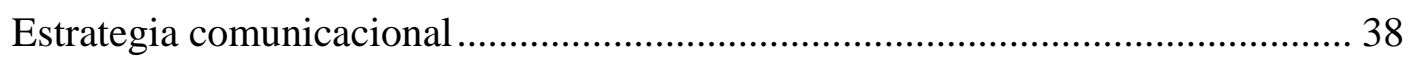

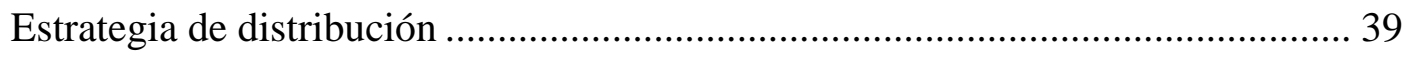

Plan de Ventas y Proyección de la Demanda ............................................................. 41

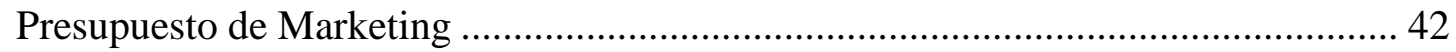

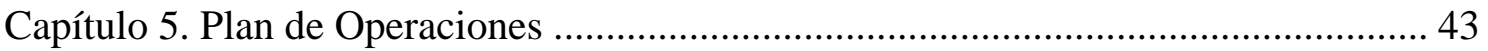

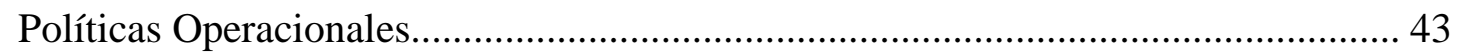

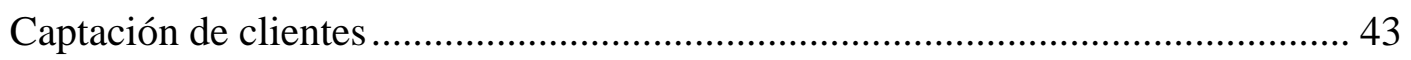

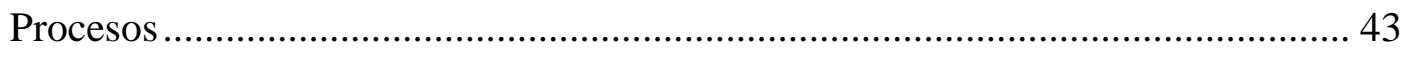

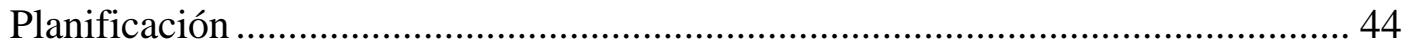

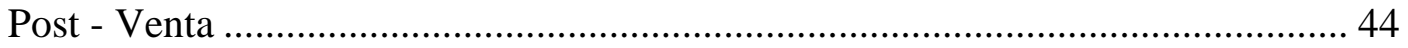

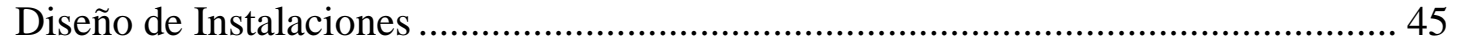

Localización de las instalaciones............................................................................ 45

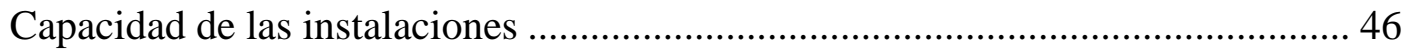

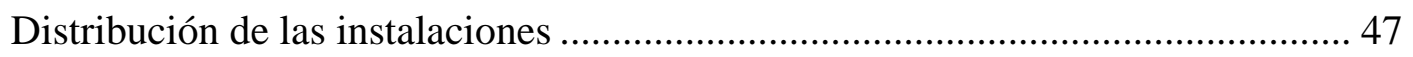

Especificaciones Técnicas del Producto / servicio .................................................... 51

Mapa de Procesos y PERT ……....................................................................... 52

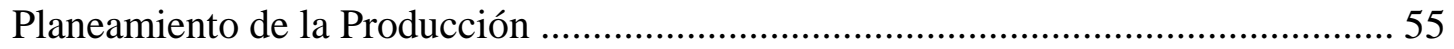

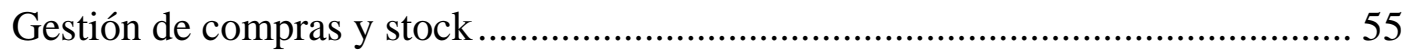

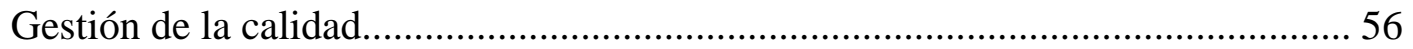

Inversión en activos fijos vinculados al proceso productivo ..................................... 57

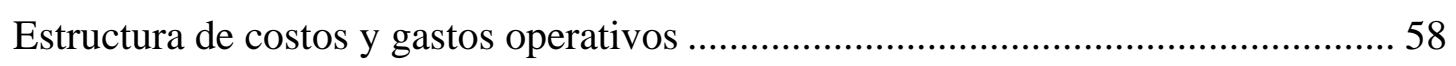

Capítulo 6. Estructura organizacional y recursos humanos......................................... 59

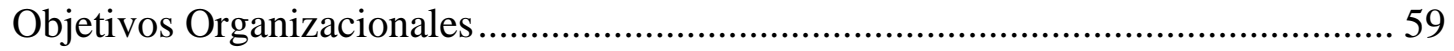

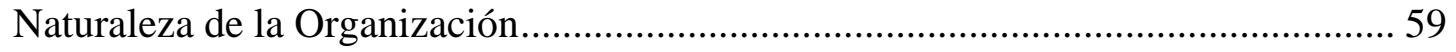

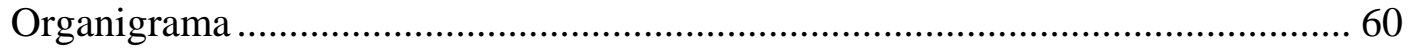

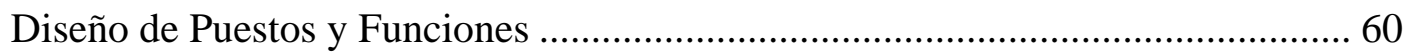

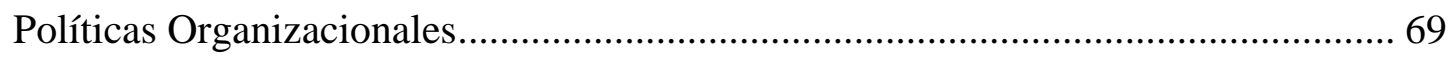

Gestión Humana ............................................................................................... 70

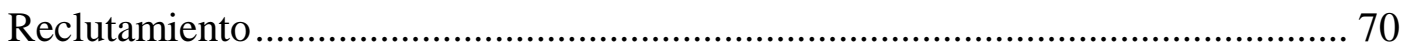

Selección, contratación e inducción .................................................................... 70 
Capacitación, desarrollo y evaluación del desempeño ......................................... 71

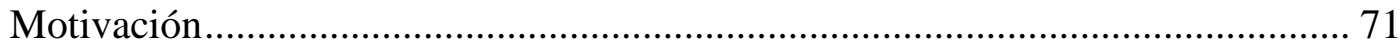

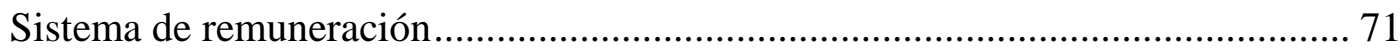

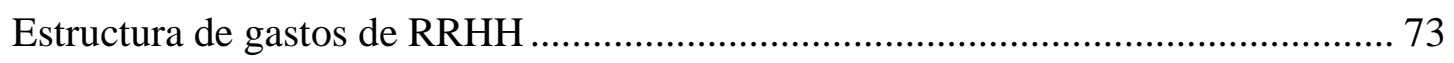

Capítulo 7. Plan económico-financiero ……........................................................... 74

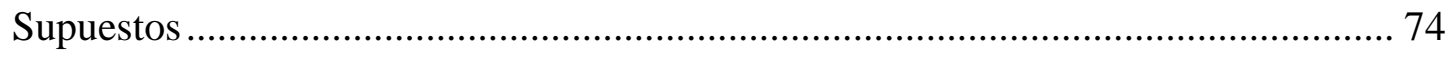

Inversión en activos (fijos e intangibles) y depreciación ........................................... 74

Proyección de ventas …...................................................................................... 75

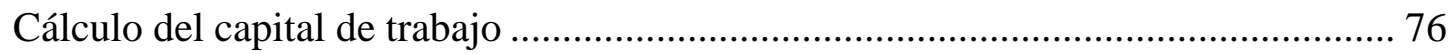

Estructura de financiamiento: Tradicional y no tradicional ....................................... 76

Estados Financieros (Balance General, Estado de GGPP, Flujo de Caja) .................. 77

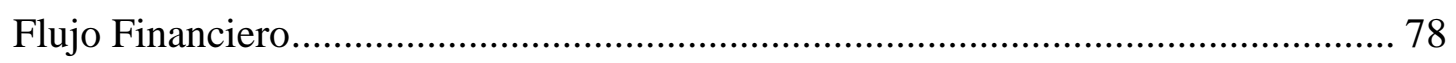

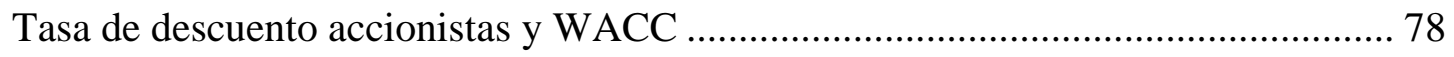

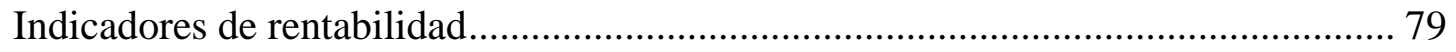

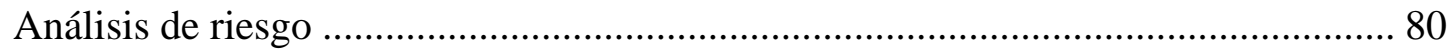

Análisis de sensibilidad y escenarios (por variables) …......................................... 80

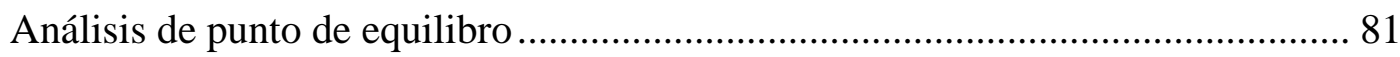

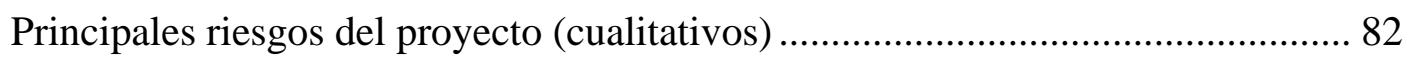

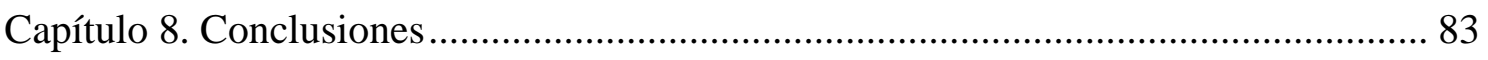

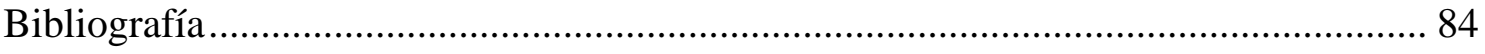




\section{Índice de Tablas}

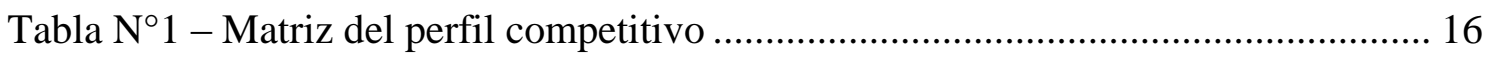

Tabla N² Tamaño de mercado según capacidad instalada ........................................ 32

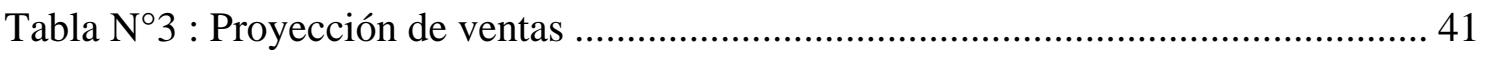

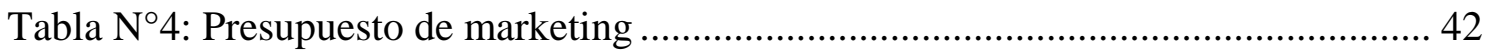

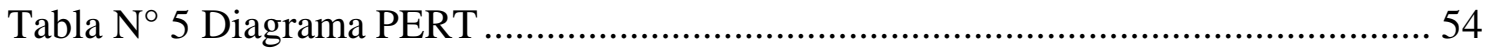

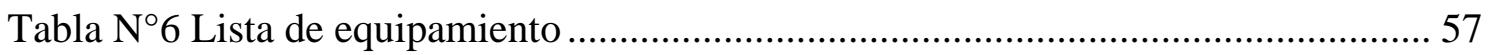

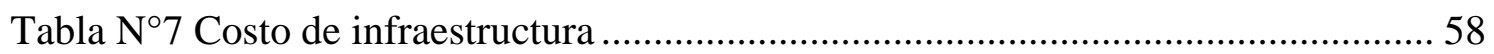

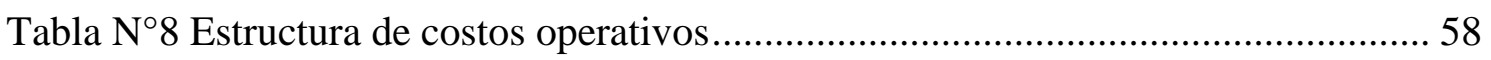

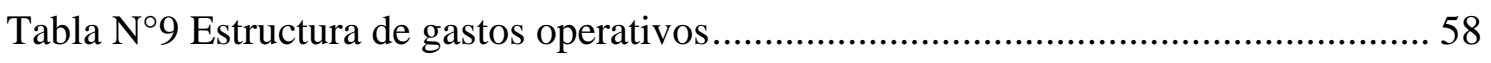

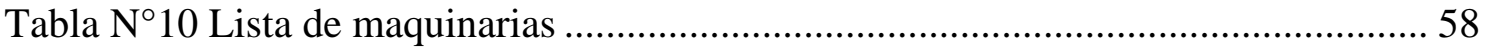

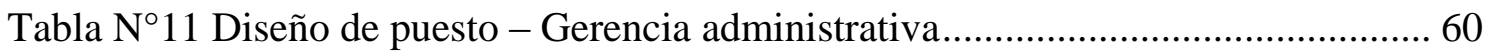

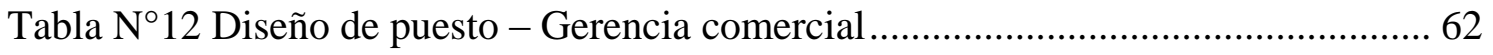

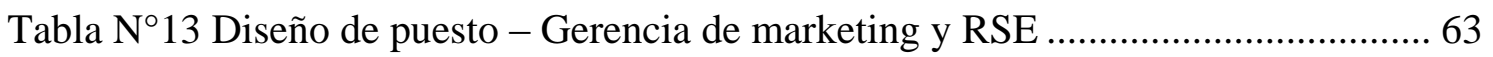

Tabla N${ }^{\circ} 4$ Diseño de puesto - Gerencia de Planeamiento e Investigación................... 65

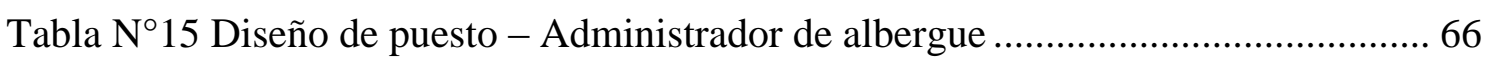

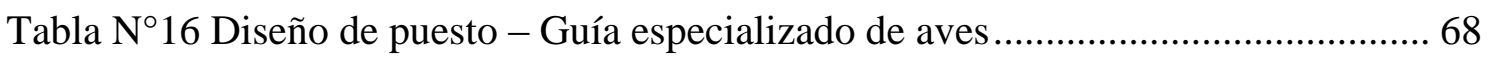

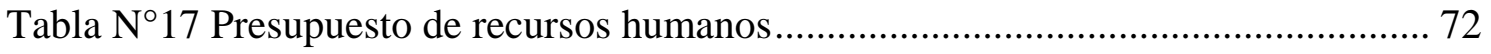

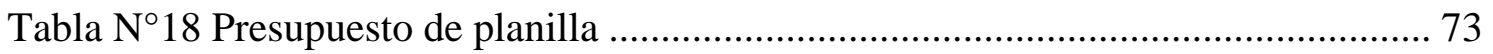

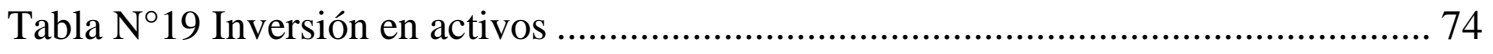

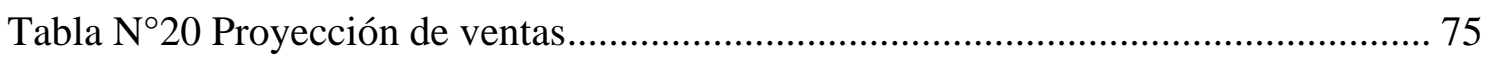

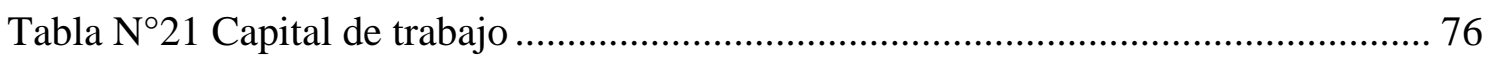

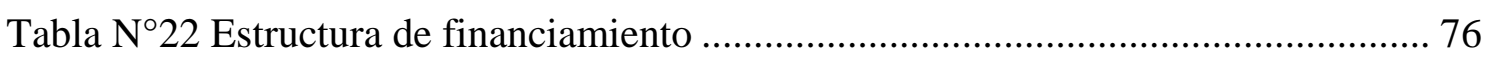

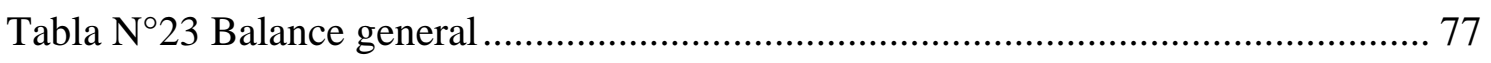

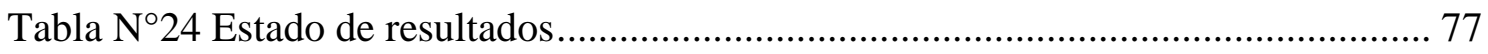

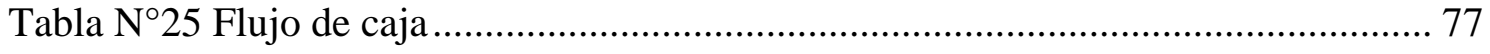

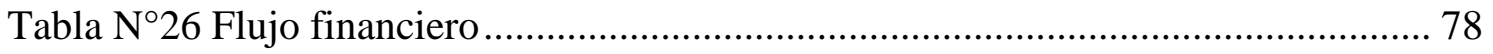

Tabla $\mathrm{N}^{\circ} 27$ Tasa de descuento accionistas y WACC ................................................... 78

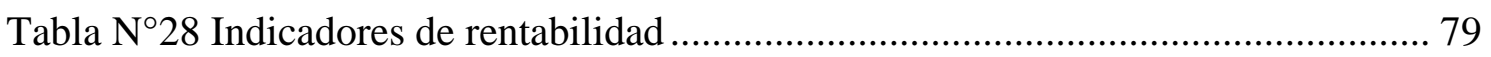

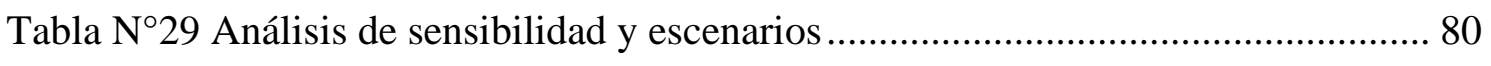

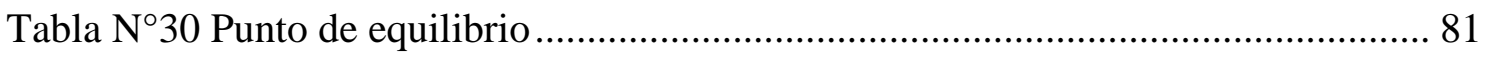




\section{Índice de figuras}

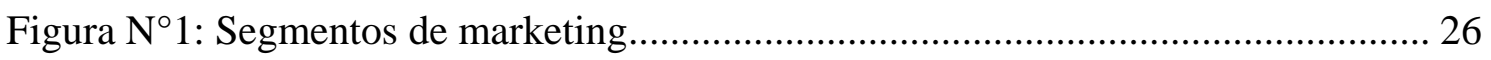

Figura $\mathrm{N}^{\circ} 2$ : Mercado potencial de Birdwatchers …................................................ 31

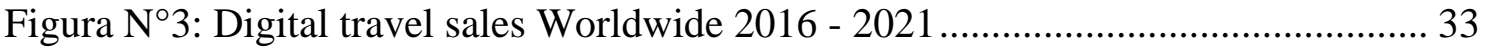

Figura $\mathrm{N}^{\circ} 4$ Ciclo de vida de un producto en el mercado .............................................. 34

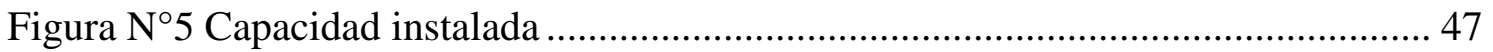

Figura $\mathrm{N}^{\circ} 6$ Mapa de procesos - Cliente Directo ........................................................... 52

Figura $\mathrm{N}^{\circ} 7 \mathrm{Mapa}$ de procesos - Intermediario ....................................................... 53

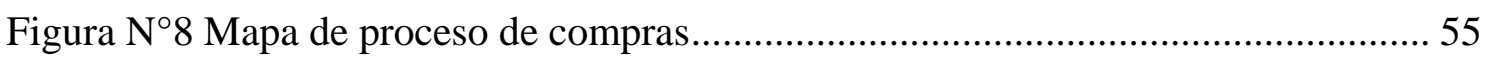

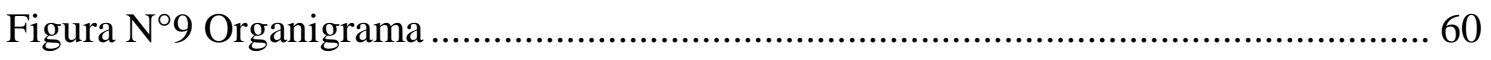




\section{Introducción}

La actividad del turismo se viene desarrollando en un constante crecimiento en cuanto a llegadas internacionales e ingresos por divisas; así mismo se están dando cambios en las motivaciones del turismo que obliga a los destinos a innovar y crear productos turísticos para satisfacer a la demanda tal como lo señala la Organización Mundial del Turismo (OMT).

De acuerdo al Plan Estratégico Nacional del Turismo (PENTUR 2012 -2021) lo que se busca es diversificar la oferta turística para atender a los nuevos segmentos. En este marco, a fines del 2012 se llevó a cabo en el Perú en la ruta de Madre de Dios y Cusco, la primera competencia de observadores de aves en Sudamérica teniendo como nombre “Birding Rally Challenge 2012”. En ella se convocó a los más renombrados observadores de aves a nivel mundial; competidores fueron seleccionados de los principales mercados emisores como Reino Unido, EE.UU., España, Brasil y Sudáfrica. Los resultados de este evento nos motivaron a proponer la implementación de un albergue dirigido a este nicho especializado.

Lo que buscamos es generar ingresos a través del valor de los recursos naturales (avistamiento de aves) y sensibilizar al público en general sobre la importancia y valor que tienen nuestros recursos, además de beneficiar a las poblaciones locales.

Para la realización del trabajo usamos fuentes secundarias tal como el estudio de PromPerú del año 2014 en el cual se determina que existe un interés de este nicho de mercado en visitar el Perú. Así mismo, se utilizó una fuente primaria que fue desarrollada por el equipo de trabajo que consta de una investigación de tipo exploratoria la cual se realizó a través de entrevistas de profundidad a expertos, guías locales y clientes potenciales. Dicha investigación respalda la idea de negocio. El presente trabajo busca llegar al mercado de birdwatchers de Europa, EE.UU. y Latinoamérica, así como también a los expertos de aves en el Perú, los cuales actuarán de intermediarios, ya que, la gran mayoría del negocio se mueve por recomendaciones.

Finalmente, en base a las investigaciones y por la variedad de aves, la zona elegida para iniciar el proyecto es Tambopata, allí se implementarán rutas con base científica con ayuda de las comunidades locales. El periodo de tiempo inicial para el desarrollo del modelo de negocio es de 10 años y se busca crecer solo dentro del Perú. 


\section{Capítulo 1. Aspectos generales del negocio}

\section{Idea / Nombre de negocio}

Se ha identificado que existen más de 2 millones de Birdwatchers interesados en viajar al Perú para practicar su afición y no cuentan con opciones de servicios turísticos especializados. Nuestro país ocupa el tercer lugar en el mundo en concentrar el mayor número de aves. Tiene registradas 1,816 especies, de las cuales 104 son endémicas. Esa riqueza ornitológica es el principal elemento que un $79 \%$ de los observadores de aves toma en cuenta para elegir un país a visitar. Es por ello que para atender este nicho decidimos desarrollar un modelo de negocio:

Albergue en la Amazonía Peruana dirigido a Birdwatchers.

- APERBIRD Expedition

\section{Descripción del producto o servicio a ofrecer}

Servicio especializado de observación de aves que incluye: Guiado, alojamiento, alimentación, material de campo, traslados y servicio de alquiler de equipos.

\section{Equipo de trabajo}

Patricia Yraja Nishiki - ORCID 0000-0002-9789-6207

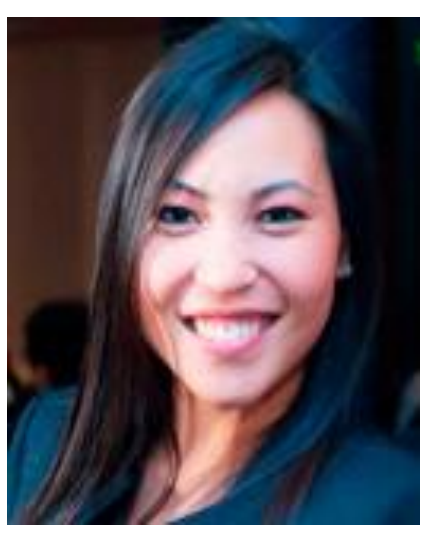

Especializada en Administración en Turismo (Cenfotur) y proyectos de inversión pública (Universidad del Pacífico). Tiene experiencia en el sector público y privado, y actualmente trabaja como coordinadora de proyectos de innovación y desarrollo sostenible para las zonas de influencia de Inkaterra. En el 2012 apoyo en la organización del Birding Rally Challenge, evento co organizado por PROMPERU, MINCETUR e Inkaterra. 


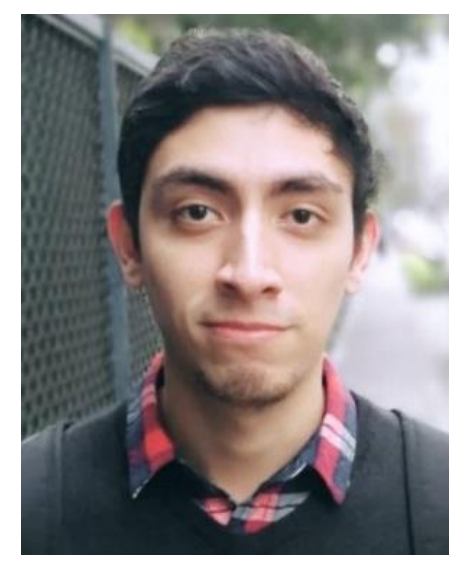

Técnico en diseño gráfico y futuro egresado de la carrera de marketing de la UPC. Experiencia en el sistema privado de pensiones por más de 5 años, actualmente analista de servicio al cliente, responsable de la evaluación de calidad de servicio, y de la creación de guiones para nuevas campañas.

Rocío Castilla - ORCID 0000-0002-3986-1292

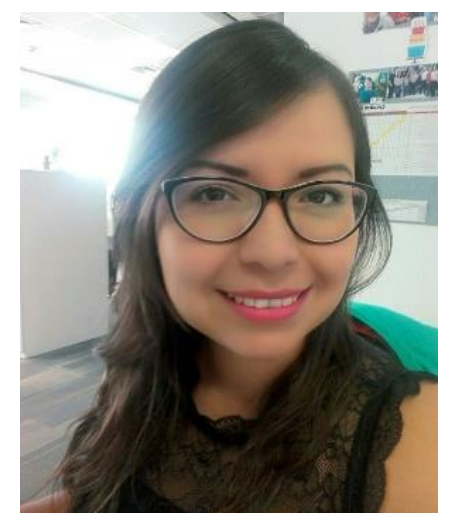

Más de 10 años de experiencia en marketing off y on-line, imagen corporativa, trade marketing y atención al cliente. Actualmente trabaja como asistente de marketing en Corporación Romero - PECSA en desarrollo de estrategias en el sector de negocio Industrial, GLP envasado y C-stores.

Claudia Flores - ORCID 0000-0003-4950-5037

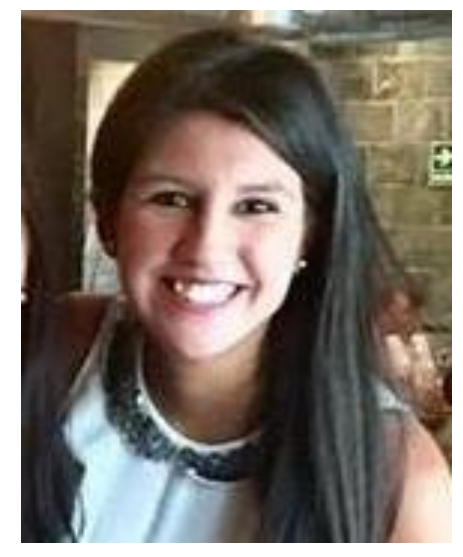

Estudios de Aviación Comercial (AVIA) y experiencia de 11 años como Tripulante de Cabina en aerolíneas del medio. Actualmente se desempeña como Jefa de Servicio abordo en Latam Airlines. Manejo del idioma ingles y estudiante de último ciclo de la carrera de Marketing. 


\title{
Capítulo 2. Planeamiento estratégico
}

\author{
Análisis Externo
}

Análisis PESTEL

\section{Político}

\section{Ministerio de Comercio Exterior y Turismo}

- El panorama internacional es muy promisorio para el Perú. Se vienen desarrollando actividades de promoción a través de la marca Perú que comprenden diversas campañas publicitarias y estrategias de mercadeo que han contribuido al posicionamiento de la imagen del país.

- Sumado a este esfuerzo, los acuerdos comerciales como los Tratados de Libre Comercio o el más reciente Acuerdo de Negociación Transpacífico (TPP), y una participación activa en los principales foros de organismos internacionales como la Organización Mundial del Turismo (OMT), Alianza del Pacifico (AP), Organización de los Estados Americanos (OEA), Foro de Cooperación Asia-Pacifico (APEC), Organización de Tratados de Cooperación Amazónica (OTCA), Foro Económico Mundial (WEF), han fortalecido la consolidación del país como un destino atractivo para el turismo y las inversiones.

- MINCETUR estima alcanzar para este año 2018, los 4,4 millones de turistas internacionales.

\section{La Organización de las Naciones Unidas - ONU}

- Reconoce al turismo como uno de los diez sectores capaces de propiciar el cambio hacia una economía verde.

\section{Ministerio del Ambiente}

- La Estrategia Nacional de Diversidad Biológica (ENDB), de acuerdo con la Ley N²6839, Ley sobre la Conservación y Aprovechamiento sostenible de la Diversidad Biológica, es el principal instrumento para la gestión de la biodiversidad en el Perú. El cual tiene establecido los siguientes objetivos: 
- O1: Mejorar el estado de la biodiversidad y mantener la integridad de los servicios ecosistémicos que brinda.

- O2: Incrementar la contribución de la biodiversidad al desarrollo nacional mejorando la competitividad del país y la distribución equitativa de beneficios.

- O3: Reducir las presiones directas e indirectas para la diversidad biológica y sus procesos ecosistémicos.

- O4: Fortalecer las capacidades de los tres niveles de gobierno para la gestión sostenible de la biodiversidad.

- O5: Mejorar el conocimiento y las tecnologías para el uso sostenible de la biodiversidad, así como la revalorización de los conocimientos tradicionales vinculados con la biodiversidad de los pueblos indígenas.

- O6: Fortalecer la cooperación y participación de todos los sectores de la población para la gobernanza de la diversidad biológica.

\section{Programa Innóvate Perú (Ministerio de la Producción)}

- El Programa Nacional de Innovación para la Competitividad y Productividad (Innóvate Perú) del Ministerio de la Producción fue creado el 24 de julio de 2014 mediante Decreto Supremo N$^{\circ} 003-2014-P R O D U C E$, como Unidad Ejecutora del Ministerio de la Producción, con autonomía económica, administrativa, financiera y técnica.

- El programa busca incrementar la productividad empresarial a través del fortalecimiento de los actores del ecosistema de la innovación (empresas, emprendedores y entidades de soporte) y facilitar la interrelación entre ellos.

- Tiene como objetivos específicos:

1. Incrementar la innovación en los procesos productivos empresariales.

2. Impulsar el emprendimiento innovador.

3. Facilitar la absorción y adaptación de tecnologías para las empresas.

\section{Gobierno Regional Madre de Dios}

- La región atraviesa por un problema muy grande de deforestación y pérdida de biodiversidad por la falta conectividad de sus bosques a consecuencia de la minería y 
tala ilegal principalmente. Las políticas y prioridades del Gobernador actual (Luis Otsuka) no están enfocadas en solucionar dichos problemas.

\section{Económico}

- El creciente impacto económico del turismo en el mundo presenta un buen panorama. Actualmente, su contribución al PBI mundial llega al 9\% (US\$ 6.6 billones), lo que crea alrededor de 260 millones de empleos. Es decir, 1 de cada 11 empleos es generado por el turismo. Así, se estima que en 2023 represente el 10\% del PBI mundial, con un valor de US\$ 10.5 billones y 340 millones de empleos generados.

- El turismo internacional representa el 30\% de las exportaciones de servicios a escala mundial y el $6 \%$ de las exportaciones globales de bienes y servicios. Ocupa el cuarto puesto en categoría de exportación a escala mundial, por detrás de combustibles, productos químicos y alimentación. En muchos países en desarrollo el turismo ocupa incluso el primer puesto.

- En el 2017 se alcanzó un total de 3,7 millones de turistas internacionales, lo que significa un crecimiento de $7,5 \%$ respecto al 2016.

- En el año 2017 se logró un ingreso de divisas de más de US\$ 4151 millones, equivalente a un incremento de 6,2\% con relación al 2016.

- El Fondo Monetario Internacional (FMI) en su último análisis estimó un crecimiento de 3.8\% para el Perú en el 2018. "Se espera que la mayor inversión pública genere más dinamismo".

- Banco Central de Reserva indica que la inflación sería del $2.8 \%$ en el 2018 y del $2.7 \%$ en el 2019.

- Según el informe anual de la Sociedad Hoteles del Perú (SHP), el futuro se muestra positivo para el sector, con la ejecución de 102 proyectos que suman una inversión aproximada de US\$1,211 millones. Esto implica 7,676 habitaciones nuevas que se sumarán a la oferta actual en hoteles de 3, 4 y 5 estrellas entre los años 2015 y 2018.

\section{Social}

\section{Mercado}

- Según la Organización Mundial del Turismo, los 25 millones de personas que viajaban por ocio en 1950 se han multiplicado hasta llegar a 1184 millones en el 
2015. Asimismo, en el mismo año se registró un aumento de 4,4\% en comparación con el 2014, manteniendo la tendencia positiva pese a las dificultades geopolíticas, económicas y sanitarias presentes en algunas zonas del mundo.

- Perú recibe: Mercado Anglosajón (20\%) y el mercado europeo (15\%).

- En el Perú la mayoría de viajeros extranjeros que recibimos son personas mayores, jubiladas de alto poder adquisitivo y con un alto grado académico. Además, están interesados en visitar lugares relacionados a la cultura, un claro ejemplo es Machu Picchu como ícono y principal atractivo turístico de nuestro país, sin embargo, hay otro grupo de viajeros no convencionales que buscan experiencias específicas como, por ejemplo: Turismo rural comunitario, turismo de aventura, turismo de naturaleza, turismo educacional, entre otros.

\section{Comunidades en la zona de intervención}

- Madre de Dios: Comunidad Ese 'ja y comunidades asentadas provenientes de la sierra y del VRAEM. Existe mucho tráfico de terrenos, inseguridad e invasiones.

\section{Tecnológico}

\section{Compras por internet de los viajeros}

Más del $60 \%$ de viajeros o turistas receptivos independientes de su país de residencia utilizan smartphones, tabletas o cualquier herramienta para informarse, compartir experiencias y resolver problemas durante su viaje. Utilizan las aplicaciones que estos dispositivos ofrecen y que hacen su viaje más sencillo: el traductor de idiomas, el lector, la guía de calles, las audio-guías, entre otras.

\section{Tecnología de apoyo para la investigación y plataformas comerciales}

Podemos indicar que el uso de drones, cámaras trampa, equipos bio acústicos, apps para el registro de especies de aves (EBird), streaming y otros es la tecnología que se está utilizando en el mundo como apoyo a la investigación científica.

Además, el uso de plataformas logísticas, ventas, reservas, etc. Son mejoradas cada año.

\section{Ecológico}

- Perú participa de las COP (Conferencia del Cambio Climático)

- Las certificaciones de Desarrollo Sostenible como la de Rainforest Alliance, Control Unión y otros son importantes en este sector ya que te certifican en el uso adecuado de los recursos, por ejemplo, uso adecuado del agua, de la luz, impacto reducido en 
la biodiversidad, políticas de inclusión social, políticas de reciclaje y manejo de residuos en general)

- La Estrategia Nacional de Diversidad Biológica (ENDB), de acuerdo con la Ley N²6839, Ley sobre la Conservación y Aprovechamiento sostenible de la Diversidad Biológica, es el principal instrumento para la gestión de la biodiversidad en el Perú.

\section{Legal}

Existen leyes a tomar en cuenta, como:

- "Ley No30641"

Ley que fomenta la exportación de servicios y el turismo

- “Ley General del Turismo”, Ley No29408.

Ley a nivel nacional a todos los niveles de gobierno, entidades e instituciones públicas $\mathrm{y}$ privadas vinculadas a la actividad turística y a los proveedores de servicios turísticos.

- "Ley de Promoción de la Inversión en la Amazonía", Ley N. ${ }^{\circ 27037,}$

El objetivo de esta ley es promover el desarrollo sostenible e integral de la Amazonia, estableciendo las condiciones para la inversión pública y la promoción de la inversión privada. El Estado fomenta el desarrollo sostenible de la Amazonía con una legislación orientada a promover la conservación de la diversidad biológica y de las áreas naturales protegidas. El territorio comprende los departamentos de Loreto, Madre de Dios, Ucayali, Amazonas y San Martín. 


\section{Análisis Interno}

\section{Matriz de Perfil Competitivo}

Tabla $\mathrm{N}^{\circ} 1$ - Matriz del perfil competitivo

\begin{tabular}{|c|c|c|c|c|c|c|c|c|c|}
\hline \multirow{3}{*}{ Atributos } & \multicolumn{3}{|c|}{ Nosotros } & \multicolumn{3}{|c|}{ Competencia 1} & \multicolumn{3}{|c|}{ Competencia 2} \\
\hline & \multicolumn{3}{|c|}{ APERBIRD - PERÚ } & \multicolumn{3}{|c|}{ CRISTALINO LOUDGE - BRASIL } & \multicolumn{3}{|c|}{ ECOMANU EXPEDITION - PERÚ } \\
\hline & Porcentaje & Calificación & Ponderado & Porcentaje & Calificación & Ponderado & Porcentaje & Calificación & Ponderado \\
\hline $\begin{array}{l}\text { Aves endémicas del País } \\
\text { (albergue) }\end{array}$ & $30 \%$ & 5 & 1.5 & $30 \%$ & 4 & 1.2 & $30 \%$ & 5 & 1.5 \\
\hline $\begin{array}{l}\text { Investigación Científica } \\
\text { de base }\end{array}$ & $25 \%$ & 4 & 1.2 & $25 \%$ & 2 & 0.6 & $25 \%$ & 2 & 0.6 \\
\hline Servicio Especializado & $25 \%$ & 4 & 1.2 & $25 \%$ & 2 & 0.6 & $25 \%$ & 3 & 0.9 \\
\hline $\begin{array}{l}\text { Guía experimentado } \\
\text { personal de la zona }\end{array}$ & $20 \%$ & 3 & 0.9 & $20 \%$ & 3 & 0.9 & $20 \%$ & 4 & 1.2 \\
\hline & $100 \%$ & & 4.8 & $100 \%$ & & 3.3 & $100 \%$ & & 4.2 \\
\hline
\end{tabular}

Sustento APERBIRD:

- Más 1,800 especies de aves en el Perú y 300 aves endémicas.

- Internamiento en la zona de Tambopata, inventario de aves, ciclo de vida, dibujo de cada ave con un especialista de la zona, descripción y detalle de cada especie.

- Personal de guiado de la zona, específicamente de las comunidades de Tambopata.

\section{Análisis de las 5 Fuerzas de Porter}

\section{Amenaza de nuevos competidores}

La entrada de nuevos competidores se vería afectada por las barreras que presenta el sector como son la obtención de permisos para la operación turística y los reglamentos nacionales relacionados a las áreas naturales protegidas. Así mismo, se requiere un capital elevado, ya que, la inversión en infraestructura de los hoteles de lujo es alta.

Por otro lado, el acceso a ecosistemas y zonas protegidas no es para nada sencillo, se requiere conocimiento y buenas relaciones con las comunidades nativas y locales.

\section{Rivalidad entre competidores}

El sector está en constante crecimiento, se vienen desarrollando actividades de promoción a través de la marca Perú que comprenden diversas campañas publicitarias y estrategias de mercadeo que han contribuido al posicionamiento de la imagen del país en los 22 mercados priorizados con énfasis en Asia y Latinoamérica. Por otro lado, nuestra 
competencia directa son albergues en Costa Rica, Brasil y Colombia principalmente, como, por ejemplo: Paquare Lodge (Costa Rica) y Cristalino Lodge (Brasil).

\section{Poder de negociación de los proveedores}

Al ser una empresa de ecoturismo que brinda servicios de alojamiento, alimentación y excursiones turísticas tiene proveedores en distintos rubros, a continuación, detallaremos algunos:

- Abarrotes

- Carnes

- Pollo

- Bebidas

El poder de negociación de los proveedores es baja en la mayoría de los casos, sobre todo en insumos para los restaurantes ya que se cuenta con varias opciones de proveedores. A su vez, los proveedores no tienen intención de incursionar en el negocio que ofrecemos.

\section{Poder de negociación de los clientes}

La empresa tiene dos tipos de clientes, el primero y de mayores volúmenes de compra son los intermediarios que son los expertos de aves en el Perú como y el segundo es el cliente directo que es el viajero proveniente de Europa, EEUU y Latinoamérica. El poder de negociación de nuestros clientes es bajo, ya que el producto que ofreceremos tiene una propuesta de valor diferenciada.

\section{Productos sustitutos}

Los productos sustitutos son empresas que brindan servicios de relajación, ocio, disfrute de la naturaleza, entre otros. Por ejemplo: Parques Nacionales en otros países (Ejemplo: Parque Nacional Kruger en África).

\section{Análisis FODA}

\section{Fortalezas:}

- Conocimiento del sector turístico.

- Recurso Humano con experiencia y visión Holística

- Operación Turística con base científica 
- Conocimiento de la gestión pública y cooperación técnica en el país para captar fondos no reembolsables con lo cual se podría financiar los programas de investigación.

- Se cuenta con red de contactos para establecer alianzas estratégicas con otras empresas privadas, gobiernos locales, gremios, asociaciones, instituciones académicas nacionales e internacionales, entre otros) para desarrollar acciones que aporten a la oferta / desarrollo de producto o acercamiento del mercado / demanda.

\section{Debilidades}

- Falta de financiamiento.

- Falta de Infraestructura de apoyo para investigación y expediciones turísticas, por ejemplo: Red de puentes colgantes en la copa de los árboles, trochas, laboratorios, centros de interpretación, entre otros.

- Pocos guías especializados en aves en el Perú.

\section{Oportunidades}

- El Perú tiene en promedio 1800 especies de aves y está considerado dentro de los 3 países con mayor cantidad de especies de aves en el mundo. Más de 100 especies endémicas.

- La gran ventaja del país es su ubicación cerca de la línea ecuatorial y además cuenta con los Andes, Amazonia y la zona costera.

- El mercado crece cada año, más personas viajan (Según la OMT).

- Nichos de mercado poco atendidos en el país.

- Como parte del turismo de naturaleza, se sabe que existe un nicho de mercado potencial de observadores de aves o lo que en el mundo se conoce como “birdwatchers". Tal es así que PROMPERU en el año 2014 realizó un estudio de dicho mercado, identificando a 9, 171, 615 personas asociadas a 53 organizaciones internacionales que practican esta afición. De ellas, 6, 236,698 personas manifestaron estar dispuestas en viajar fuera de su país en busca de nuevas especies de aves, y 2 , 419,839 personas han expresado su interés en visitar el Perú

- Tendencias a nivel nacional e internacional respecto al cuidado del medio ambiente y valor de los recursos naturales. 
- Uso de la tecnología para: Contactar, concretar la venta y como apoyo de las actividades de investigación y conservación.

- Mayores oportunidades de alianzas estratégicas y convenios de cooperación.

- Oportunidades de financiamientos no reembolsables para proyectos de investigación y conservación de la biodiversidad (Banco mundial, Innóvate Perú, Fondo de las Américas, otros.)

\section{Amenazas}

- Presiones sociales de las comunidades aledañas.

- Huelgas y paros (Ejemplo: Bloqueo de carreteras, aeropuertos, vías férreas, entre otros).

- Depredación de los recursos naturales.

- Migración / Extinción de las especies.

- Mala gobernanza en Madre de Dios.

- Legislación de Áreas Naturales Protegidas, en cuanto a restricciones.

- Condiciones climáticas (Cambio climático, Fenómeno del Niño, otros.)

- Tala y minería ilegal en Madre de Dios. Inseguridad, invasiones

\section{Visión}

Convertirse en una organización peruana líder especializada en turismo y conservación a nivel regional (América Latina) en los próximos 5 años.

\section{Misión}

Acercar a las personas a vivir su pasión por la naturaleza, proporcionando un servicio de excelencia basado en la investigación científica.

\section{Estrategia Genérica}

La estrategia es de diferenciación, ya que, nos especializamos en el nicho de birdwatchers dándoles todos los servicios necesarios para que disfruten de una experiencia de una manera integral. 


\section{Objetivos Estratégicos}

- Crear un nuevo albergue en una zona con mucha variedad de aves.

- Invertir en soluciones tecnológicas e incentivar la mejora continua de los procesos para desarrollar las actividades diarias.

- Forjar lazos estratégicos con más guías especializados para mayor recomendación.

- Capacitar al personal continuamente para generar constantemente un mejor servicio.

- Desarrollar programas de responsabilidad social y promover la conservación de los bosques a través del desarrollo sostenible. 


\section{Capítulo 3. Investigación / Validación del mercado}

\section{Diseño metodológico de la investigación / metodología de validación de hipótesis}

El método que se utilizará será exploratorio, a través de entrevistas de profundidad. Esto debido a que se trata de un nicho especializado, que es difícil de contactar de forma presencial. Así mismo, por ser un rubro que se maneja a través de recomendaciones también se tomaran en cuenta en la muestra a los expertos locales en observación de aves.

\section{Guion de entrevista}

Público Objetivo: Birdwatcher con residencia en USA, Europa y Latinoamérica Validación: Cliente - Problema

\section{Apertura}

Presentación del entrevistador

Breve descripción del porqué de la entrevista:

El objetivo de esta entrevista

\section{Perfil}

¿En sus vacaciones prefiere los destinos de sol y playa, aventura o los de naturaleza?

¿Visitó el Perú alguna vez? ¿Con qué fin?

¿Practica o es aficionado a la observación de aves? ¿Por influencia de terceros o por interés propio?

¿Cuál es su país de residencia?

*En este punto el entrevistado debería de confirmar o validar si es nuestro perfil de cliente (Birdwatcher).

\section{Historia}

En el Rally de Aves en el 2012 (Competencia Mundial de Observación de Aves organizado por la empresa Inkaterra y PROMPERU) uno de los competidores indico que cuando eligió visitar Colombia para avistar aves le sucedieron algunos problemas en 
cuanto a los servicios turísticos (Servicio de alojamiento, alimentación, guía local, logística y otros)

\section{Problema}

Cuénteme. ¿Cuál fue el destino que visitó en sus últimas vacaciones con el fin de observar aves?

¿Cómo suele organizar sus viajes de observación de aves? ¿Qué problemas suele enfrentar en el momento de la organización? ¿Le es fácil encontrar servicios adecuados? Coméntenos sobre su experiencia para encontrar/buscar los servicios necesarios que requiere para esta actividad.

¿Le ocurren los mismos problemas en todos los destinos al que ha ido con este mismo fin (Observar Aves)? ¿Cuál de todos los problemas considera que son los más críticos (Puede ser más de 1)? ¿Por qué cree que suceden?

¿Cómo suele resolverlos?

¿Qué solución le gustaría que hubiera para este problema?

¿Ya visitó el Perú? De ser así, coméntenos sobre la experiencia de su viaje.

\section{Ranking}

En este momento se ordenará de mayor a menor los problemas que se han identificado. ¿Qué es lo más crítico de estos problemas?

\section{Cierre}

Muchas gracias por su tiempo y colaboración ¿Le gustaría tener información de los resultados del análisis de la investigación? ¿A quién recomendaría contactar para la misma entrevista?

\section{Documentación}

Escribir todos los aspectos: Verbales y no verbales (Expresiones, gestos, risas, etc.)

\section{Resultados de la investigación}

Tenemos 2 canales para llegar a nuestro mercado objetivo. El primer canal es a través de los especialistas en aves y guías locales, que realizan la labor de intermediarios recomendando las zonas de observación de aves en base a sus experiencias y servicios de guiado. El segundo canal llega directo al consumidor final, los birdwatchers. 
Hemos realizado una encuesta y entrevistas como muestra al canal de los especialistas en aves obteniendo como resultado una validación exitosa con un $86 \%$ de aceptación del modelo de negocio.

\section{Informe final: Elaboración de tendencias, patrones y conclusiones}

De acuerdo con nuestras las experiencias relatadas de los intermediarios (especialistas) hemos llegado a las siguientes conclusiones:

- Las personas que ven aves de por sí son personas que disfrutan de la naturaleza

- Gran parte de entrevistados visitó Tambopata, en la selva peruana, para observar aves con fines de trabajo, como también por participación del Birding Rally Challengers, que fue una competencia sobre observación de aves que se llevó a cabo el 2012 y 2013 que tuvo como objetivo posicionar a Perú como destino ideal para la observación de aves.

- Podemos distinguir a dos tipos de observadores: los aficionados y los investigadores.

- Casi el total de especialistas encuestados realizan sus visitas por sí mismos y llegan a las zonas de observación de aves por contacto de otros guías u observadores locales siendo este último la fuente más rica y confiable de observación.

- El principal problema es la falta de información accesible sobre los lugares con mayor diversidad de aves y la falta de servicios de hospedaje y guiado para realizar la observación de aves.

- La mayoría de hoteles o servicios se encuentran muy alejados de las zonas por lo que los birdwatcher pierden mucho tiempo en trasladarse de un lugar a otro.

- Todos los especialistas/observadores son respetuosos del medio ambiente por lo que no les incomoda acampar ante la falta de infraestructura o servicios de observación de aves, como tampoco les afecta la falta de comodidad de estos servicios, sino por el contrario de haber estos puntos de descanso prefieren que los ambientes en estas zonas se encuentren en armonía con la flora o fauna sin afectar o alterar el ecosistema.

- Existen problemas secundarios expuestos por los especialistas como la movilidad para llegar a los puntos de observación, la falta de infraestructura adecuada en estas zonas 
y la ausencia sobre el trato de cuidado para con el medio ambiente de los prestadores de servicios (hospedajes/ hoteles/ servicios de turismo).

- Todos han visitado Perú y están totalmente dispuestos a regresar para realizar la observación de aves por la inmensa variedad que tenemos. 


\section{Capítulo 4. Plan de marketing}

\section{Planteamiento de objetivos de marketing}

A corto plazo:

- Ser reconocidos como el primer albergue especializado de Birdwatchers en el Perú.

- Incrementar de manera progresiva la cantidad de socios estratégicos y marcas locales que estén dispuestos a ofrecer nuestros productos.

- Obtener un incremento constante de las ventas en $14 \%$ en los siguientes dos años de operaciones

- Posicionarse como la mejor alternativa de observación de aves en la Región.

A mediano plazo:

- Crear un programa de fidelización entre nuestros clientes potenciales (intermediarios).

- Cumplir con una eficiencia de marca traducida en 95\% de clientes satisfechos.

- Insertar en nuestra página publicidad de nuestros principales socios estratégicos, los cuales tengan la posibilidad de hacer conocido sus productos e incrementar sus ventas y por ende las nuestras.

A Largo plazo:

- Mantener nuestra estrategia genérica de diferenciación lo cual nos permita generar más valor de marca.

- Incrementar nuestra presencia en territorio nacional a través de la expansión en otras áreas geográficas. 


\section{Estrategias de marketing}

\section{Segmentación}

Como parte del turismo de naturaleza, se sabe que existe un nicho de mercado potencial de observadores de aves o lo que en el mundo se conoce como "birdwatchers". Tal es así que PROMPERU en el año 2014 realizó un estudio de dicho mercado, identificando a 9, 171, 615 personas asociadas a 53 organizaciones internacionales que practican esta afición. De ellas, 6, 236,698 personas manifestaron estar dispuestas en viajar fuera de su país en busca de nuevas especies de aves, y 2, 419,839 personas han expresado su interés en visitar el Perú. Básicamente los birdwatchers buscan rutas y destinos que concentren la mayor diversidad de aves. Su afición es la de avistar aves y si tienen la oportunidad, la fotografían.

Figura $\mathrm{N}^{\circ} 1$ : Segmentos de marketing
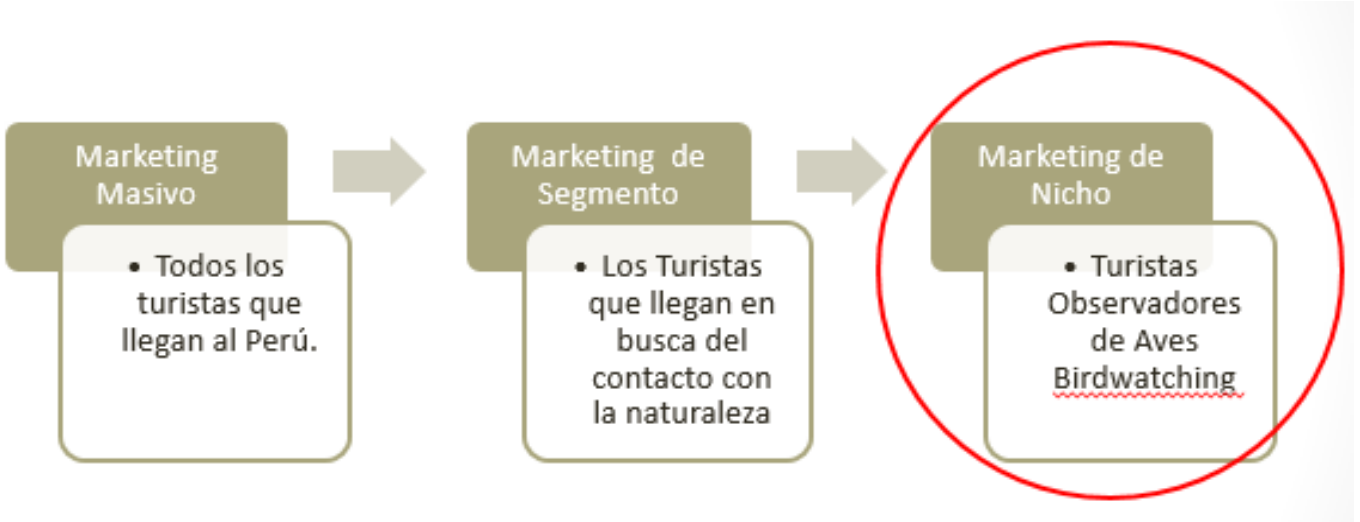

Los "Birdwatchers" son personas que practican la actividad de "Observar Aves" ya sea por influencia de terceras personas (familia y amigos) o por interés propio, personal. Las palancas motivacionales de la actividad son de tipo hedónico (disfrute, contemplación, belleza natural, etc.) y de tipo ambientalista (ecología, conocimiento, hábitats, conservacionismo, etc.). Una vez introducidos en la observación de aves, el interés se extiende generalmente a todo tipo de actividades relacionadas con su práctica, siendo la observación con ayuda de medios ópticos la que más se practica. De los resultados por segmentos se deduce que los más activos dentro del colectivo de aficionados a la observación de aves son: los hombres, los menores de 25 años o ya mayores de 50 o 60 años, las personas sin hijos o con hijos independientes y con niveles de estudios y de renta 
medios o superiores, además de quienes tienen más tiempo propio disponible (estudiantes, jubilados, trabajadores por cuenta propia). La mayoría de los aficionados a la observación de aves hace algún viaje de más de una noche (11 días en promedio) y viaja fuera de su país por tal motivo (6 viajes en promedio en los últimos 3 años).

Los birdwatchers más activos son los residentes de países europeos, seguidos por norteamericanos y otros países de origen anglosajón. El Perú es considerado un país interesante para observar aves. Generalmente, lo habitual es dedicar más del $40 \%$ del tiempo de viaje a la observación de aves. El destino se decide en función de la riqueza de la fauna ornitológica del lugar. Una vez allí, los birdwatchers se centran en la observación de aves y en las actividades más íntimamente ligadas a ello: visitar áreas protegidas, observar flora, mariposas o insectos y hacer trekking; en un segundo plano de interés habría que hablar de actividades de tipo cultural; el resto apenas tiene importancia para estos viajeros.

Actualmente, la fuente de información principal es la recomendación de expertos locales para planificar los viajes de observación de aves. También son importantes las publicaciones especializadas. La mayoría opta por organizar sus viajes por cuenta propia; no obstante, conforme aumenta la edad crece la proporción de quienes compran paquetes. Por ello, es totalmente frecuente la compra por internet de pasajes aéreos y alojamiento. Aunque el precio siempre tiene su importancia, la elección depende del perfil de viajero: hay quien prefiere un alojamiento típico del destino y hay quien no le da importancia con tal de estar cerca del punto de observación. Es poco habitual viajar solos, lo normal es hacerlo con personas que comparten la afición, sean familiares o no. 
Lo que piensa y siente:

- Disfruta, contempla, admira la naturaleza

- Encuentra interesante la ecología de las aves.

- Siente placer al ver un ave por primera vez. Ellos lo llaman "Lifer"

- Piensa que será reconocido por la mayor cantidad de especies de ave que tenga en su check list.

\section{¿Qué oye?:}

A sus amigos pajareros en el gremio al que pertenece.

- Consulta con pajareros locales en cada país.

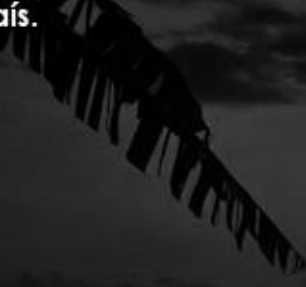

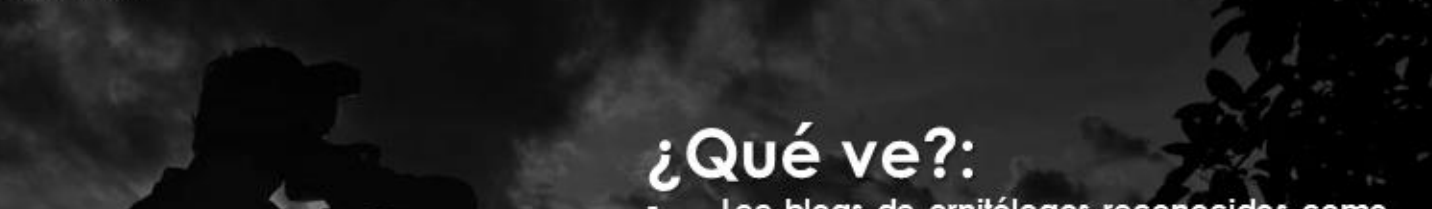

Lee blogs de ornitólogos reconocidos como Tom Shulenberg, escritor del Libro "Aves del Perú"

Revisa las páginas de expertos y aficionados a la observación de aves en redes sociales. Revisa los registros de aves en el aplicativo "E Bird"

\section{¿Qué dice y hace?:}

- Es coherente con lo que dice y hace.

- Aplican un código de honor al registrar las especies de aves avistadas en su check list.

- Son respetuosos con la naturaleza

- Se preocupan por la conservación de les eves y de causar el menor impacto posible al realizar la acfivided (Observación de aves).

- Participa en las ferias especializades. Por ejemplo "Bird Fair" en Rutland Inglaterra. 


\section{Posicionamiento}

La estrategia que usaremos es "Más por Más", es decir se les cobrará un precio alto por un producto de alta calidad.

\section{La propuesta de valor del servicio:}

Nuestra propuesta de valor tiene 2 pilares importantes:

- Rutas con base científica: Trabajaremos con una serie de metodologías que aplican los ornitólogos como: Puntos de conteo, cámaras trampa, anillamiento de aves, bio acústica, entre otros para obtener el inventario de especies de aves en nuestra zona de intervención. El programa de investigación se realizará de forma permanente para poder analizar resultados y obtener frecuencia y temporadas de avistamiento de ciertas especies, por ejemplo. Con ello, podemos diseñar paquetes turísticos a la medida según los requerimientos de nuestro cliente, ya que podemos ofrecerles la probabilidad de avistar un ave específica con probabilidades de entre 50 - 60\%.

Se considera que este es un paso muy importante ya que nuestro potencial cliente valora y tiene como prioridad al seleccionar un destino turístico la cantidad de especies que podría avistar.

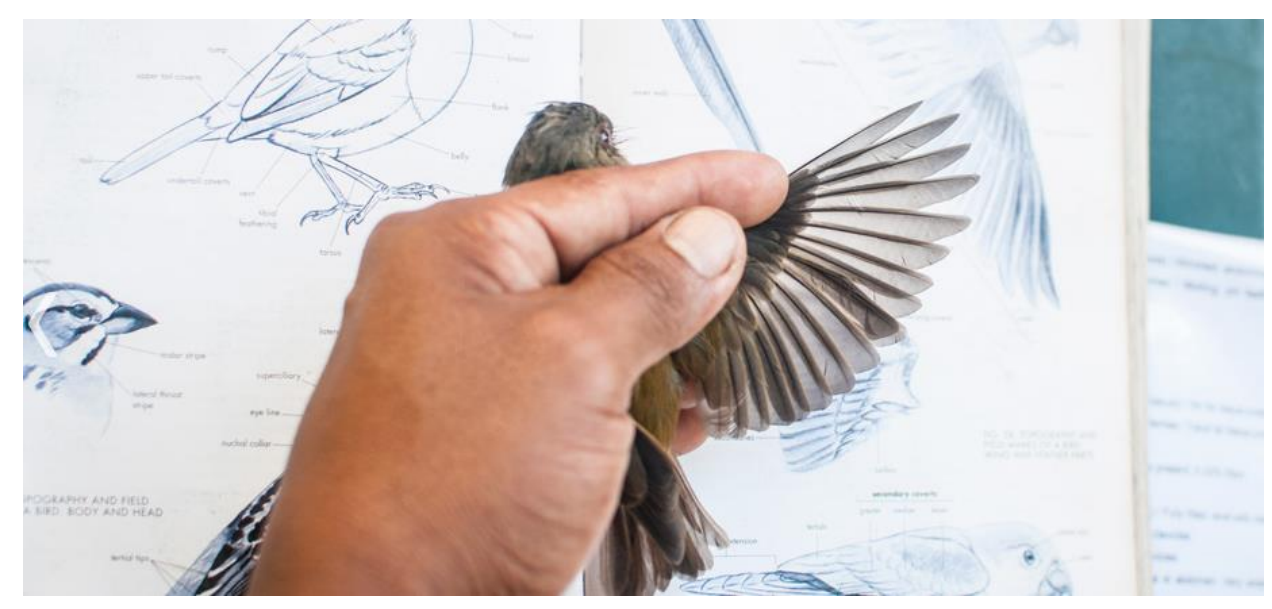

Imagen: Inka Terra Asociación

- Modelo Replicable de Desarrollo Sostenible: Cabe resaltar que el Birdwatcher es una actividad que NO hace uso tangible del recurso, por el contrario, recrea la experiencia a través de la contemplación de las aves. Con esta iniciativa es posible promover la conservación de los bosques, generar empleo local, luchar contra la tala y minería ilegal, problemas sociales latentes en esta región. 


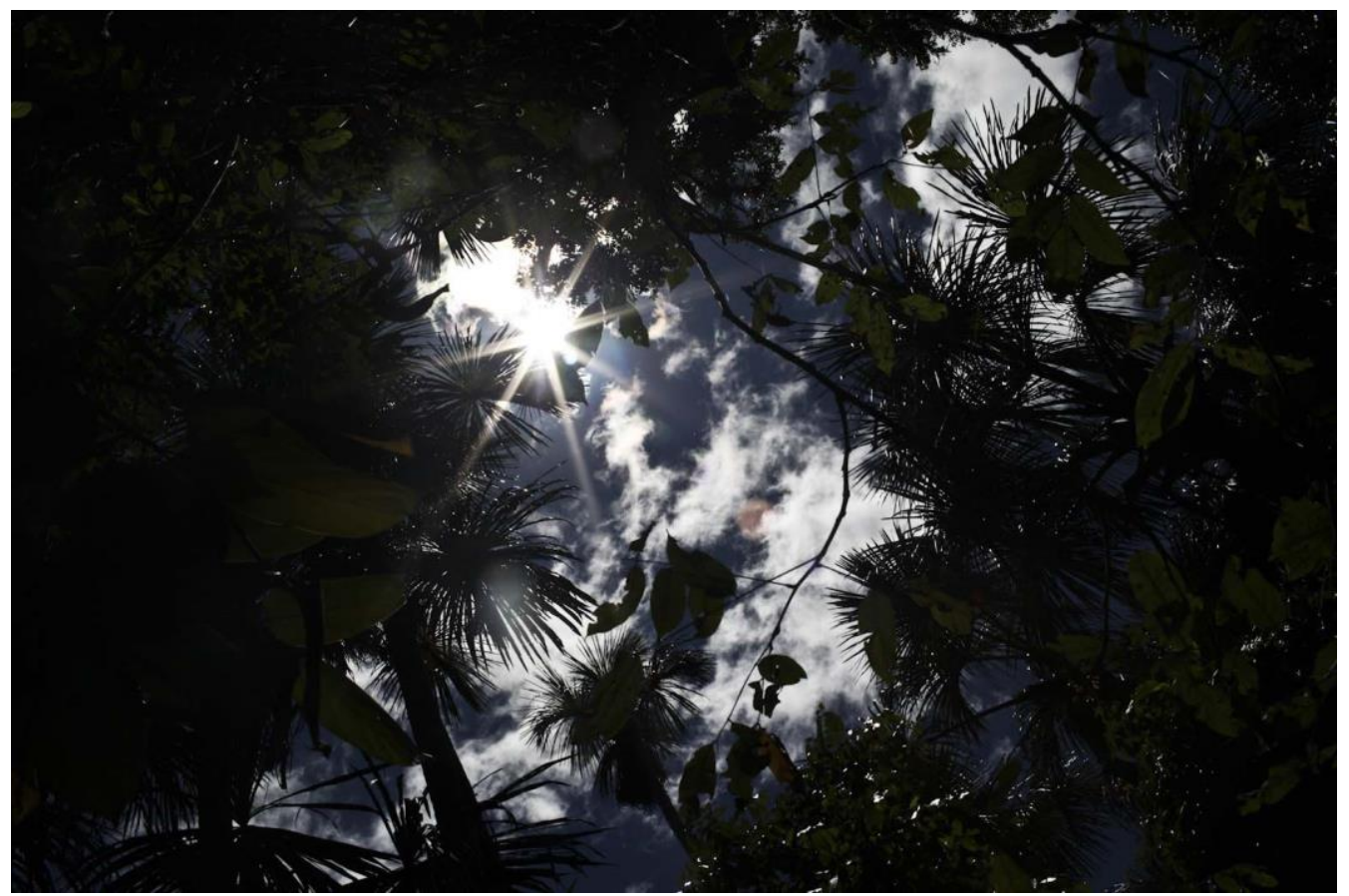

Imagen: Inka Terra Asociación

Declaratoria de posicionamiento:

Para los Observadores de Aves más exigentes, quienes buscan la mayor cantidad de especie con un servicio de calidad, APERBIRD ofrece paquetes hechos a la medida y con base científica.

\section{Mercado Objetivo}

\section{Tamaño de mercado}

PROMPERU en el año 2014 publicó los resultados de un estudio de mercado de los birdwatchers en el mundo, identificando a 9, 171, 615 personas asociadas a 53 organizaciones internacionales que practican esta afición. De ellas, 6, 236,698 personas manifestaron estar dispuestas en viajar fuera de su país en busca de nuevas especies de aves, y 2, 419,839 personas han expresado su interés en visitar el Perú. 
Figura $\mathrm{N}^{\circ}$ 2: Mercado potencial de Birdwatchers

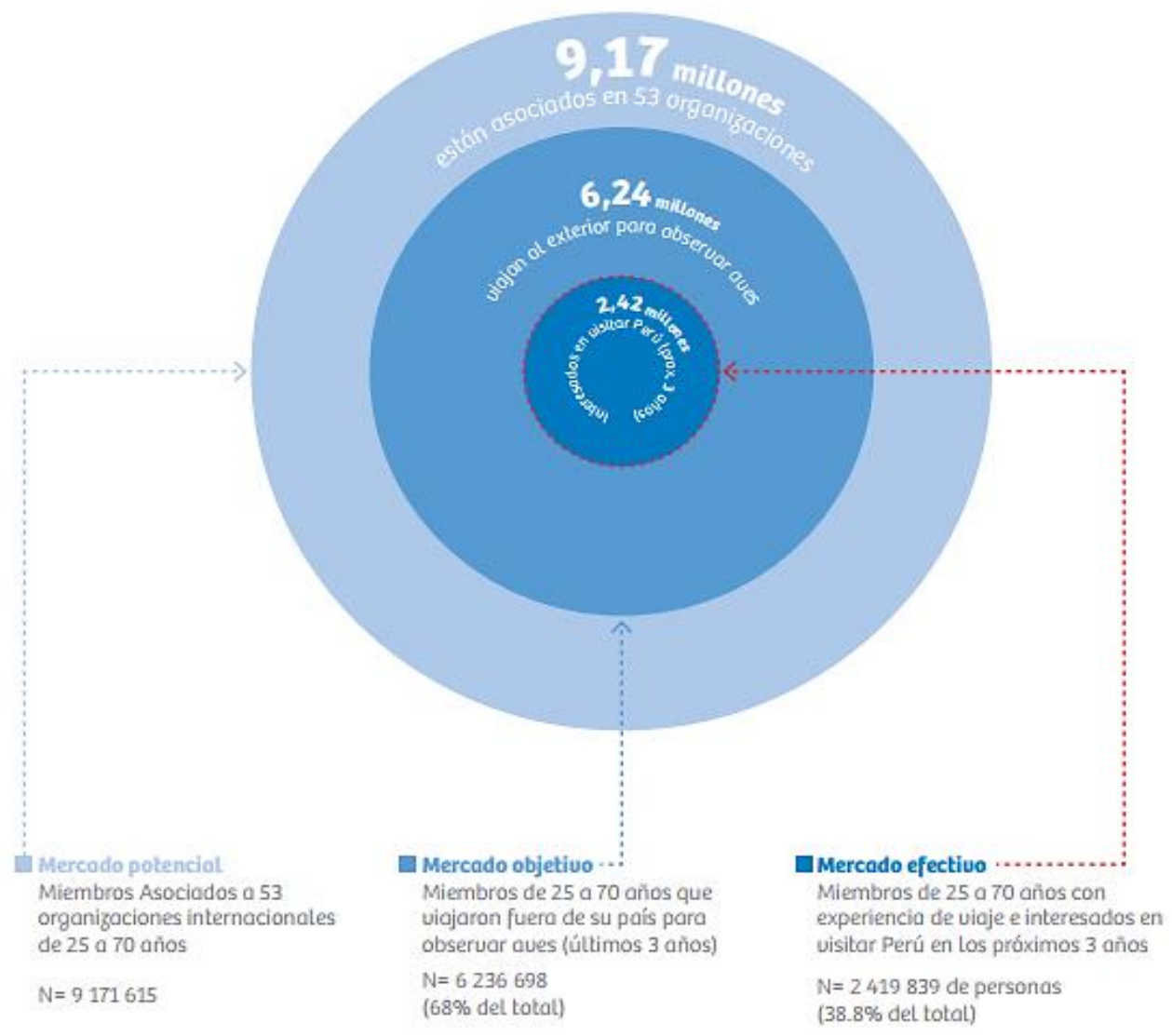

Imagen: PROMPERÚ

Al tratarse de una actividad muy especializada, los observadores de aves suelen estar asociados en agremiaciones en las que comparten su experiencia. Estas asociaciones se encuentran principalmente en EE. UU. y Reino Unido, aunque en Suecia existe un gremio con 450,000 observadores de aves.

En conclusión, el tamaño de mercado potencial real es de 6,24 millones de observadores de aves que viajan al exterior para practicar su afición y están asociados a un gremio, ya que según estudios de PROMPERU, indican que solo 7 asociaciones concentran el $98 \%$ del mercado de consumidores de esta actividad.

Sin embargo, consideraremos la siguiente segmentación para poder aterrizar con mayor facilidad en nuestro mercado potencial mediante las actividades de marketing. De los 2,42 millones de interesados en visitar el Perú en los próximos años:

- Hardcore (Coleccionista, el 100\% de su tiempo en un destino lo ocupa viendo aves): Representa 0.9 millones. 
- Softcore (Cada vez que pueda y combina con otras actividades): = Representa 1.1 millones.

- Ocasionales (Ver aves es un pasatiempo fenomenal): Representa 0.5 millones.

De estos tres sub segmentos consideraremos como mercado potencial el segmento Hardcore con 0.9 millones de birdwatchers y el segmento softcore con 1.1 millones de personas.

\section{Tamaño de mercado disponible}

$\mathrm{MD}=23 \% * \mathrm{MP}$

$\mathrm{MD}=23 \% * 2$ millones

$\mathrm{MD}=460,000$ personas

$23 \%$ es nuestra tasa de conversación, resultado de la validación que se realizó en DN1.

\section{Tamaño de mercado operativo (Target)}

Considerando la capacidad instalada (10 cabañas de 4 camas cada una) y los dos tipos de paquetes que se tendría en un inicio, se podría atender a 212 personas cada mes, es decir máximo 2544 personas cada año.

Tabla №2 Tamaño de mercado según capacidad instalada

\section{Tamaño de mercado objetivo según capacidad instalada del albergue mensual}

\begin{tabular}{|l|c|}
\hline \multicolumn{1}{|c|}{ Paquetes de turismo especializado } & Personas \\
\hline $\begin{array}{l}\text { Paquetes de turismo especializado - Estándar, incluye } \\
\text { un guía local especializado en la observación de } \\
\text { aves. Dirigido al segmento de los Softcore. 5D - 4N }\end{array}$ & 192 \\
\hline $\begin{array}{l}\text { Paquetes de turismo especializado - Superior, incluye } \\
\text { un guía investigador, cientifico experto en la } \\
\text { observación de aves. } \\
\text { Dirigido al segmento de los Hardcore. } \\
\text { 12D - 11N }\end{array}$ \\
\hline \multicolumn{1}{|c|}{ Total personas } \\
\hline
\end{tabular}

Consideramos que el paquete especializado estándar podría tener una acogida del $80 \%$ mientras que el paquete especializado superior podría tener solo el $20 \%$ de acogida. (Capacidad máxima por día * 30 días) *\% de venta por tipo de paquete / Días de estadía 


\section{Potencial de crecimiento del mercado}

La industria de Viajes y Turismo registra un crecimiento promedio anual del $10 \%$ en las ventas online a nivel mundial. En los países a los que nos dirigimos, estas cifras superan el $30 \%$ de la cuota de ventas. Y existe una tendencia del consumidor a realizar la compra directamente con el operador, en la web de hotel o la aerolínea, eliminándose los intermediarios.

Figura $N^{\circ} 3$ : Digital travel sales Worldwide 2016 - 2021

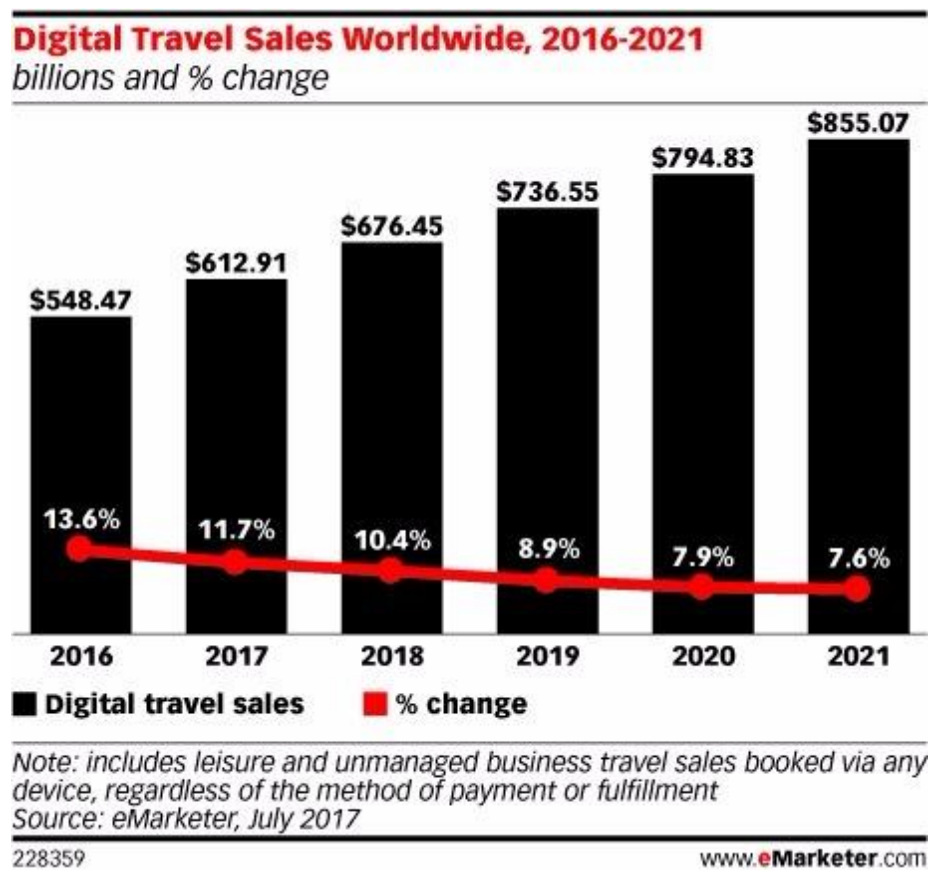

Tomando en cuenta estas cifras, se considera que nuestro mercado tendrá un potencial de crecimiento de $15 \%$.

\section{Desarrollo y estrategia del marketing mix}

\section{Estrategia de producto / servicio}


Figura $\mathrm{N}^{\circ} 4$ Ciclo de vida de un producto en el mercado

\section{CICLO DE VIDA DE UN PRODUCTO EN EL MERCADO}

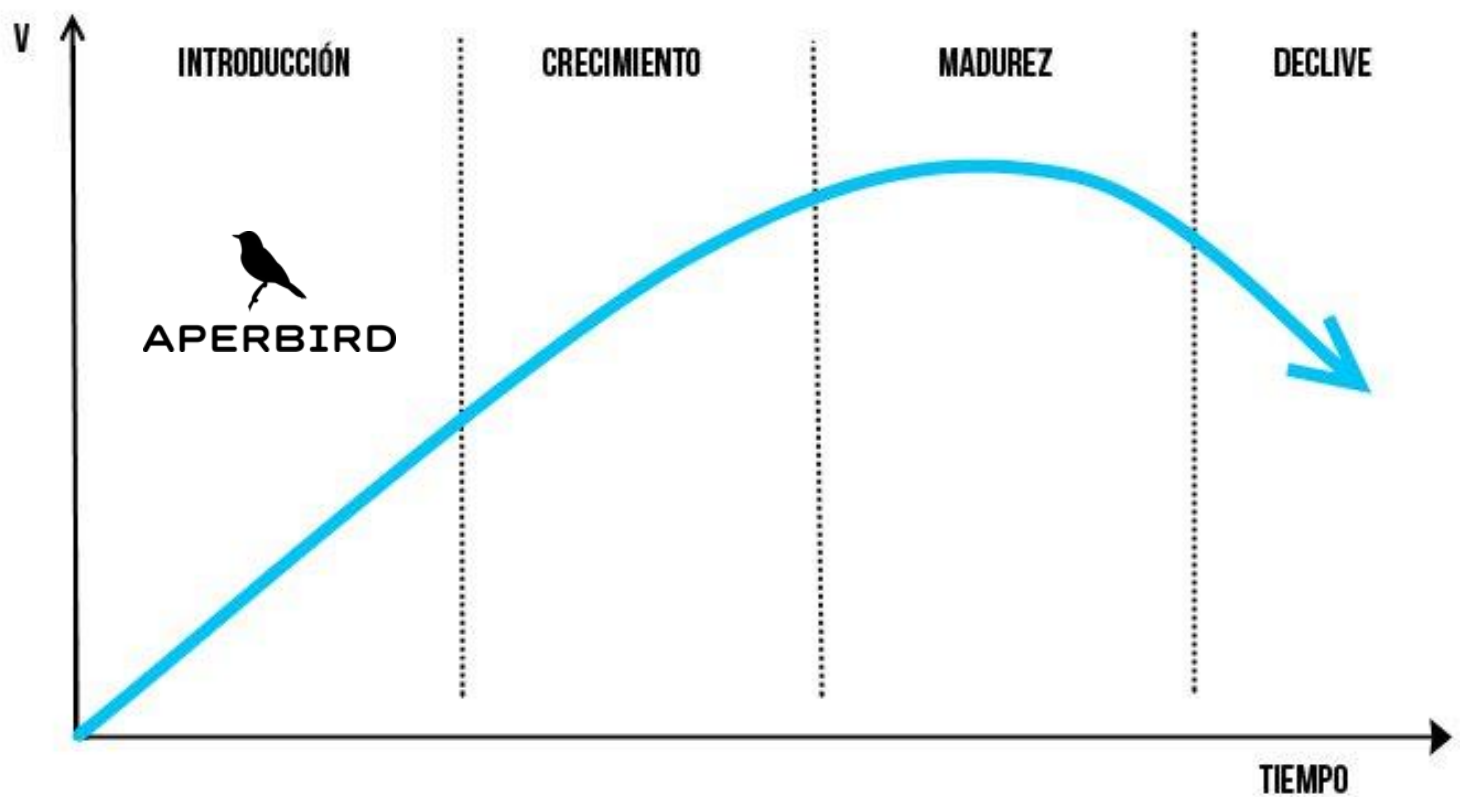

APERBIRD es una organización que recién se crea, y que pretende innovar a través de especialización de los servicios ofrecidos en un mercado ya desarrollado.

Según la Matriz de Ansoff, APERBIRD se ubica en el cuadrante de Desarrollo de Producto. Por tal motivo, se trabajará esta estrategia desarrollando paquetes turísticos especializados para la Observación de Aves. Estos paquetes buscan la diversificación de oferta turística en el Perú sabiendo el potencial que existe en este nicho de mercado. El producto permite conocer, observar y explorar nuevas especies de aves para su estudio o distracción, dentro de ambientes exóticos disfrutando al mismo tiempo de paisajes naturales en grupos con intereses en común. Cuenta con todas las normas y estándares establecidos para satisfacer la seguridad y bienestar de nuestros clientes. 


\section{Diseño de producto / servicio}

\section{Traslados}

Los traslados se realizarán desde el aeropuerto, teniendo un monitoreo oportuno de los vuelos para luego llevarlos por rio hasta Tambopata donde se encuentra el albergue. Todos los transportes cuentan con las medidas de seguridad necesarias para los pasajeros y sus equipajes.

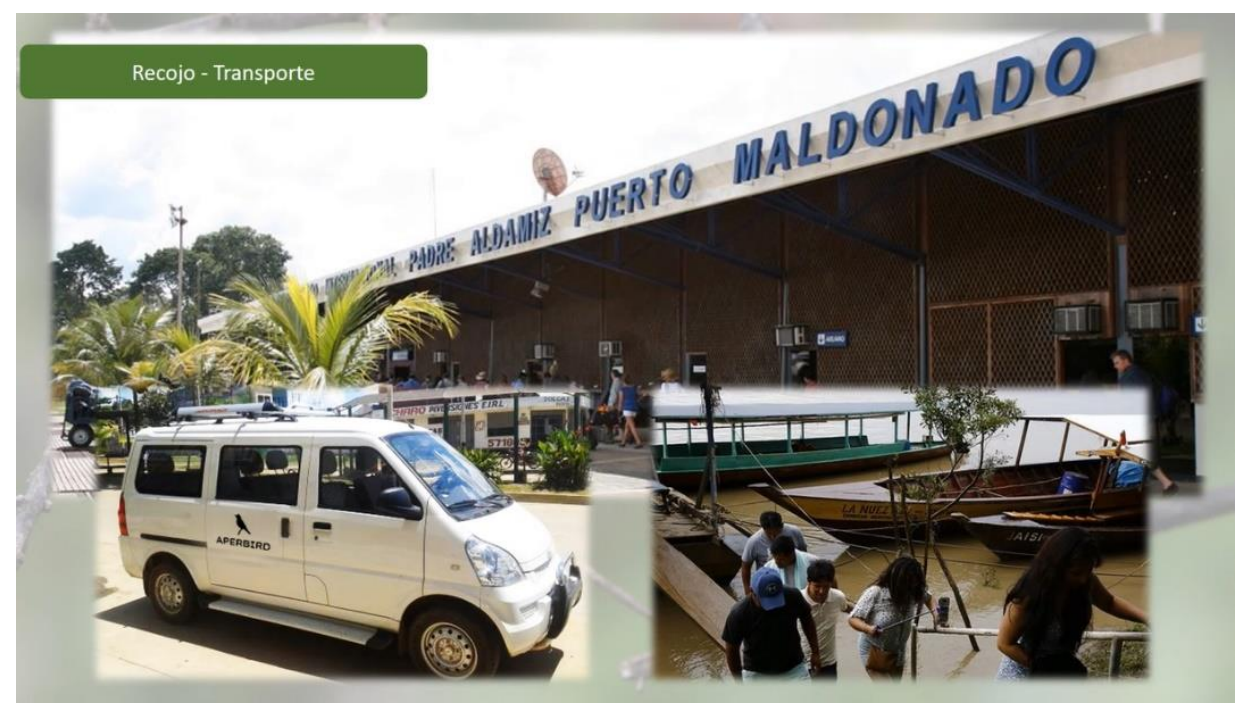

Imagen: Internet

\section{Alojamiento}

La estadía será en cabañas de 4 personas que cuentan con todos los servicios necesarios para este tipo de viajero. Siempre manteniendo un estricto cuidado del medio ambiente, tanto en los materiales utilizados como en su conservación.

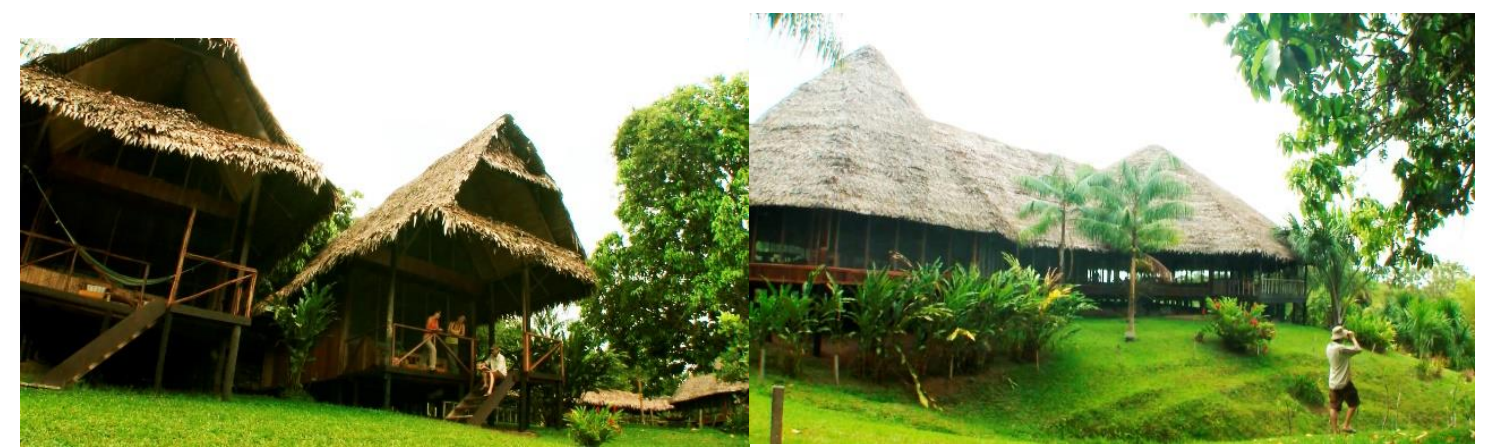

Imagen: Internet 


\section{Alimentación completa:}

La alimentación se ofrecerá en estilo buffet. Se contará con platos de gastronomía local e internacional, preparados en base a productos de la región y de la estación. Además de ofrecer diversos acompañamientos de frutas y vegetales.

El servicio estará disponible en los siguientes horarios:

Desayuno 05:00-08:30

Almuerzo 12:00-15:00

Cena 19:00-22:00

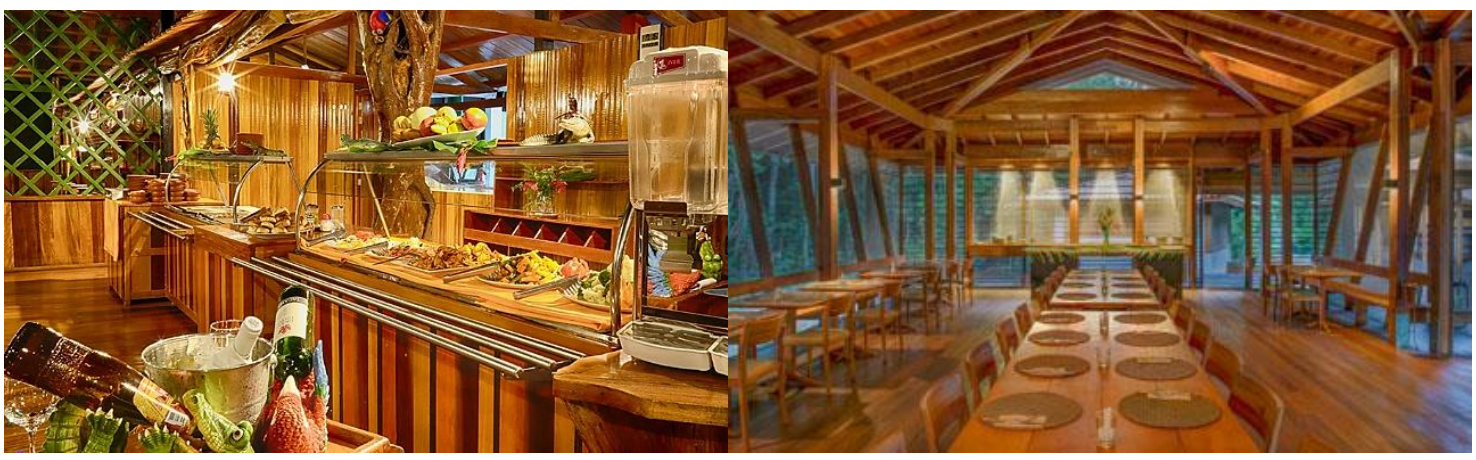

Imagen: Internet

\section{Guía local especializado}

El guiado será realizado por expertos locales los cuales han sido previamente capacitados por los expertos más reconocidos del país en observaciones de aves. Estos guiados serán realizados en rutas y trochas con validación científica.

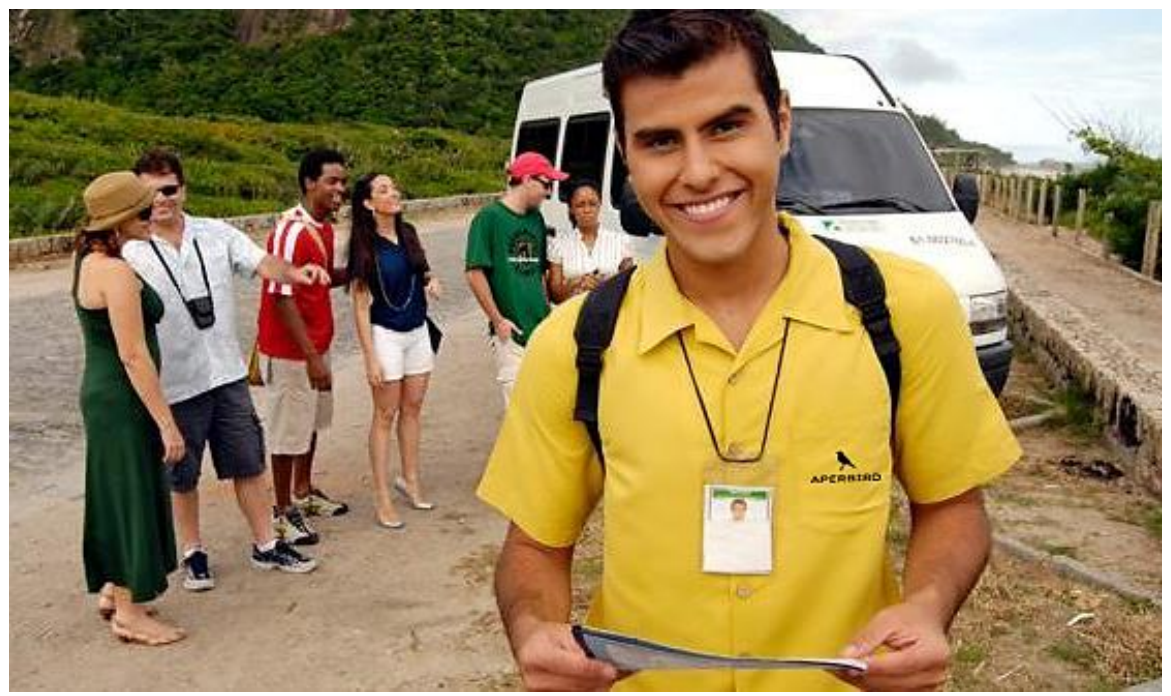

Imagen: Internet 


\section{Entradas a áreas naturales}

El albergue cuenta con acceso a todas las rutas y áreas naturales aledañas, ya que, tiene los permisos de operación brindados por las autoridades competentes. Así como también busca la preservación de la zona y evita la tala y minería ilegal. Cabe resaltar que este tipo de viajero basa su experiencia en la contemplación de la naturaleza y siempre busca su conservación.

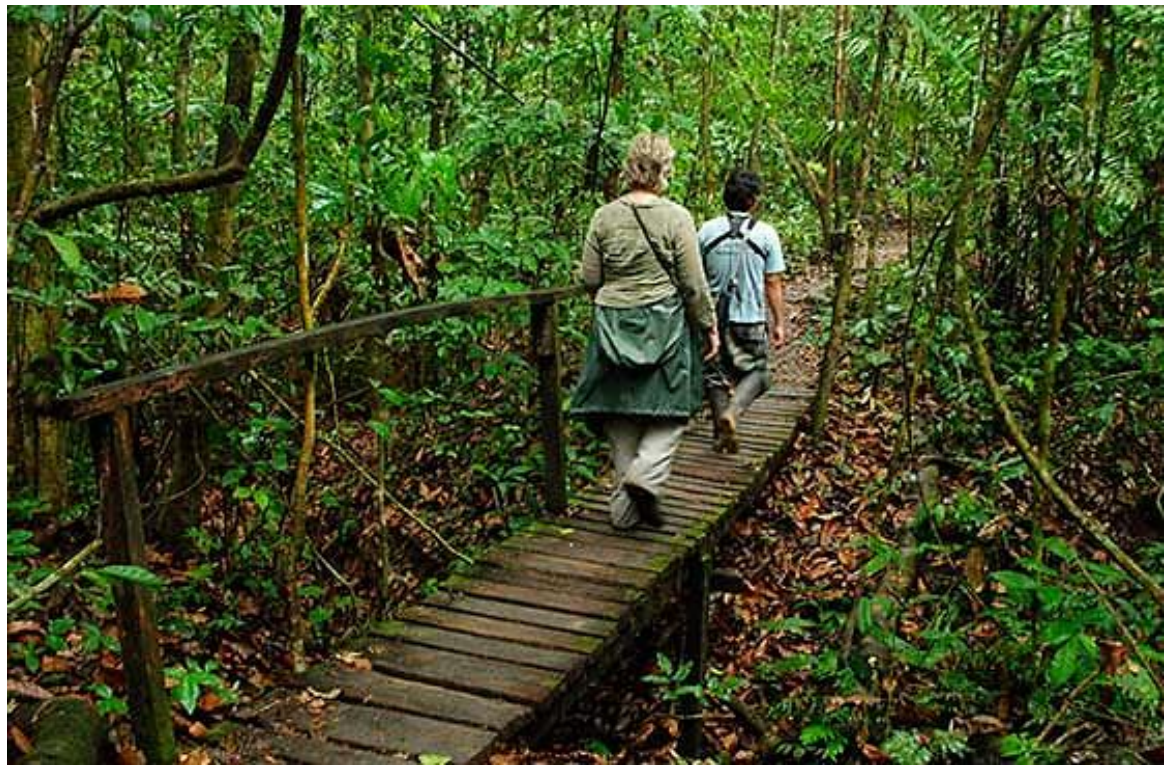

Imagen: Internet

\section{Check-list}

Todos los huéspedes serán provistos de un cuadernillo (Check-list) que contará con el nombre e imágenes de las aves que se pueden avistar dentro del albergue y en la reserva.

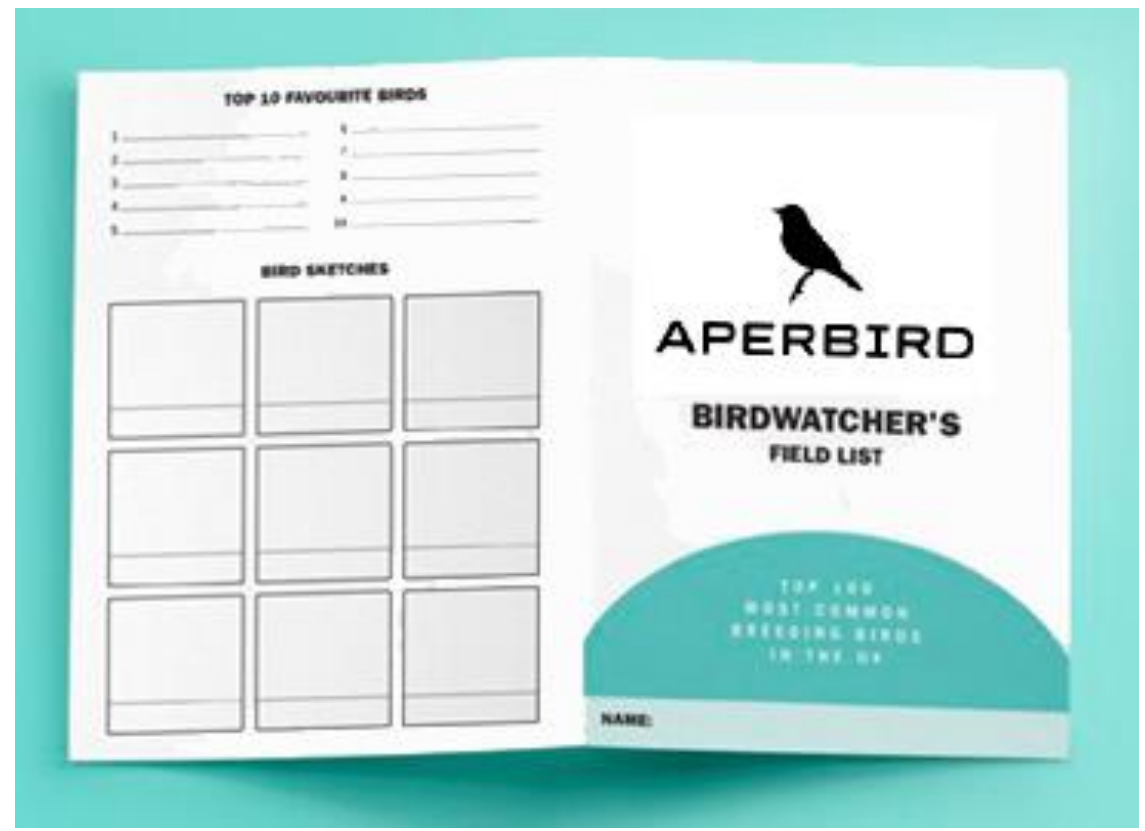




\section{Estrategia de precios (Análisis de costos, precios de mercado)}

Al tratarse de un producto nuevo y especializado dirigido a un público con alto poder adquisitivo, se utilizará la estrategia de precios descreme, basado en la colocación de un precio inicial en el nivel más alto posible, de acuerdo con el máximo que estarían dispuestos a pagar los consumidores más interesados (leads/early adopters).

\section{Estrategia comunicacional}

Podríamos utilizar 4 tipos de estrategias de promoción como herramienta para la difusión de su producto.

- Eventos

- Documentales, se gestiona press tours invitando a periodistas de medios de comunicación reconocidos como National Geographic y Audovon

- Revistas Especializadas, a través de relacionistas públicos en diversos países, se gestiona y/o contrata publicación de artículos en revistas especializadas como Bird Watching, Magazine, Rob Report, entre otros.

- Ferias Especializadas, participación en diferentes ferias especializadas con un stand. Una de ellas es la Birdfair ${ }^{l}$, en Reino Unido.

- Redes sociales, como Facebook e Instagram.
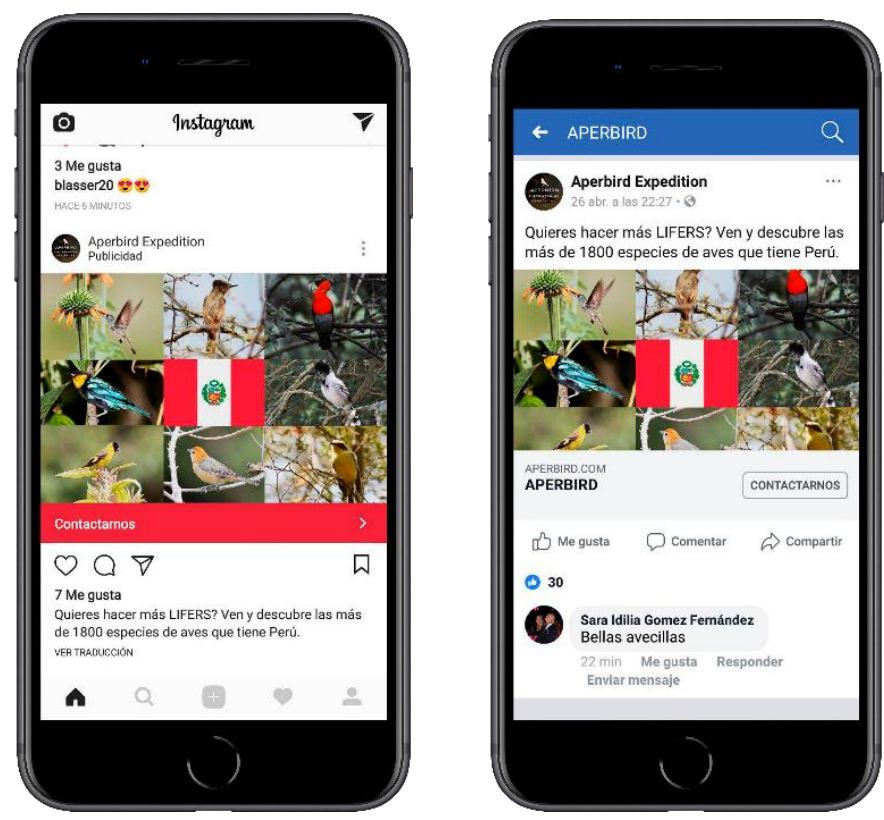

\footnotetext{
${ }^{1}$ Cfr. BirdFair
} 


\section{Estrategia de distribución}

La venta del servicio se realizará a través de 2 canales de distribución:

- Página Web: Se incluirá un sistema de reservas y pasarela de pago en línea que permitirá al cliente realizar su compra desde cualquier dispositivo con conexión a internet.

- Stands en ferias: La marca se dará a conocer a través de presencia en diversos eventos y ferias turísticas, buscando obtener posicionamiento y apertura de mercado. Estos módulos estarán habilitados para realizar la venta aceptando pagos en efectivo o tarjeta de crédito.

Página web
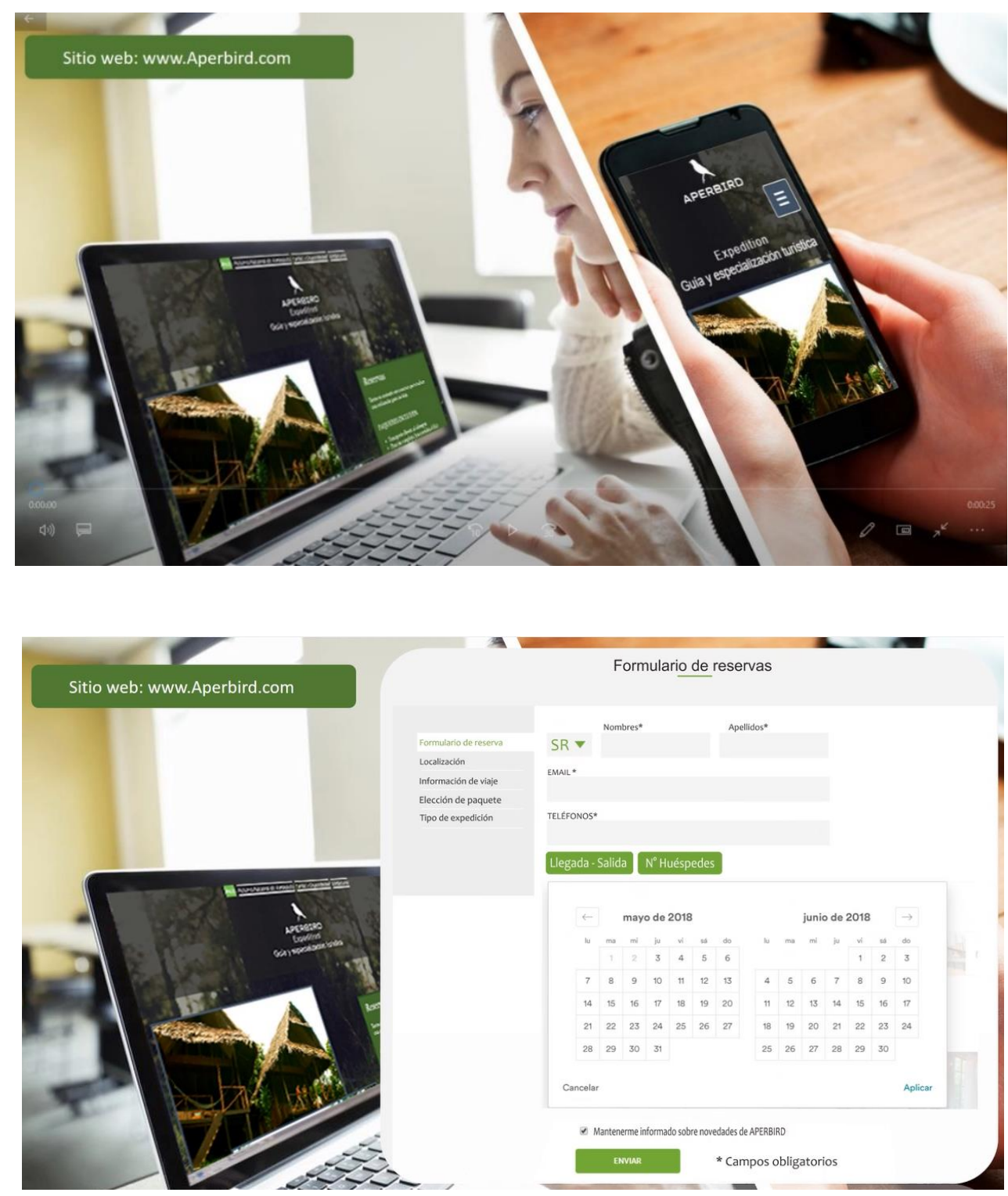
Ferias en el extranjero

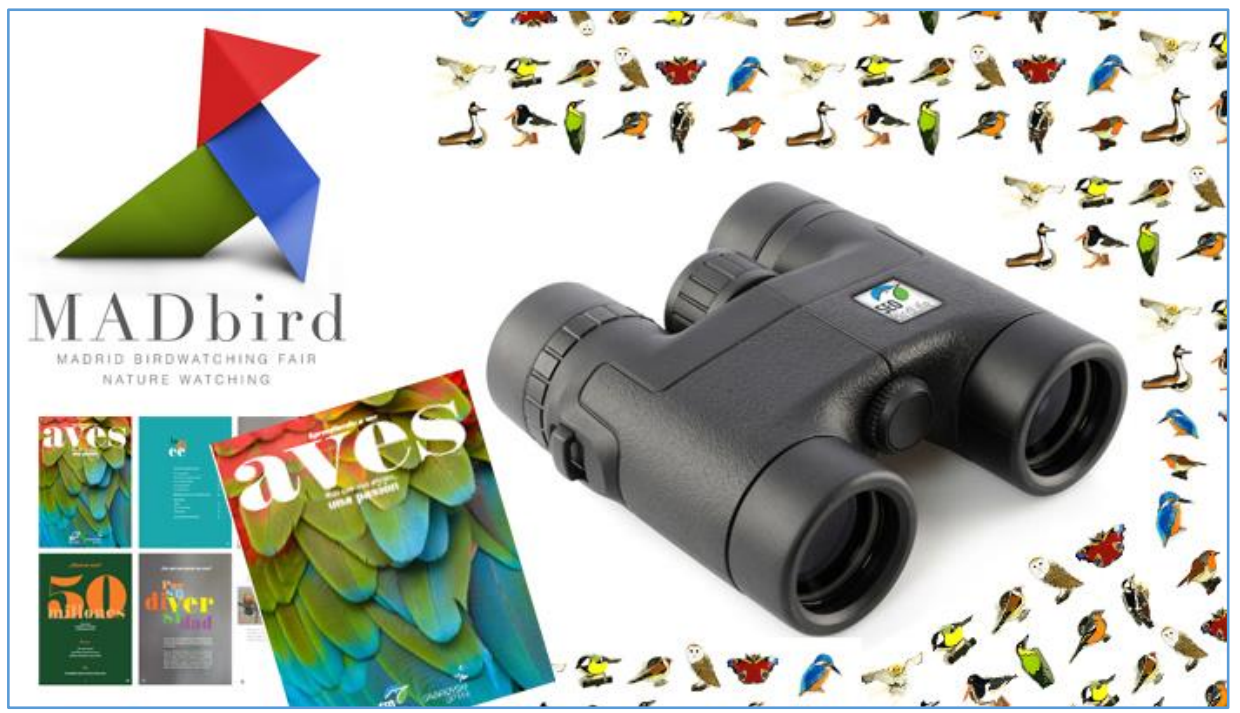

Fuente: MADbird Fair

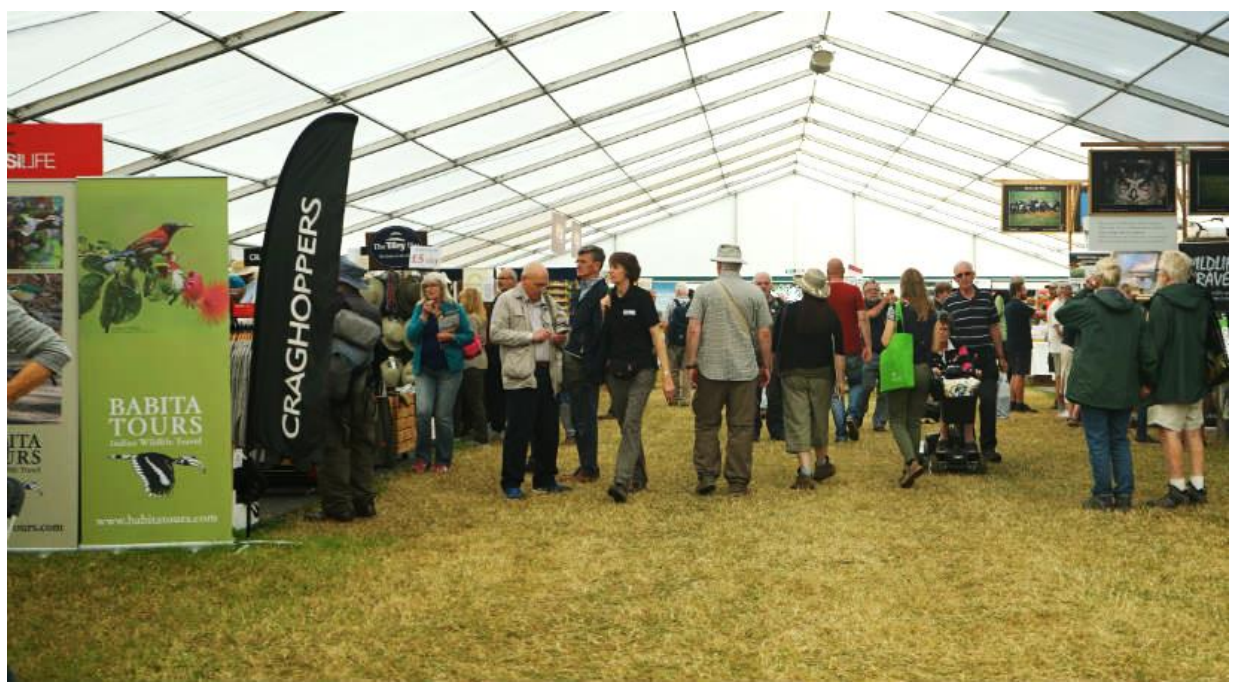

Fuente: blueskywildlife 


\section{Plan de Ventas y Proyección de la Demanda}

Tabla Nº3 : Proyección de ventas

\begin{tabular}{|c|c|c|c|c|c|c|}
\hline I Módulo de Premisas - Estandar & M1 & $\mathrm{M} 2$ & M3 & M4 & M5 & M6 \\
\hline Precio por paquete - 5D4N & $S / .3,960.00$ & S/.3,960.00 & $S / .3,960.00$ & S/.3,960.00 & $S / .3,960.00$ & $S / .3,960.00$ \\
\hline Cantidad & 0 & 5 & 5 & 10 & 10 & 10 \\
\hline Ingresos & $\mathrm{S} / .0 .00$ & $\mathrm{~S} / .19,800.00$ & $\mathrm{~S} / .19,800.00$ & $S / .39,600.00$ & $\mathrm{~S} / .39,600.00$ & $S / .39,600.00$ \\
\hline & M7 & M8 & M9 & M10 & M11 & M12 \\
\hline & $S / .3,960.00$ & $S / .3,960.00$ & $S / .3,960.00$ & $S / .3,960.00$ & $S / .3,960.00$ & $S / .3,960.00$ \\
\hline & 12 & 12 & 12 & 11 & 15 & 12 \\
\hline & $\mathrm{S} / .47,520.00$ & $\mathrm{~S} / .47,520.00$ & $\mathrm{~S} / .47,520.00$ & $\mathrm{~S} / .43,560.00$ & $\mathrm{~S} / .59,400.00$ & $\mathrm{~S} / .47,520.00$ \\
\hline
\end{tabular}

Hemos proyectado las ventas en base al conocimiento del rubro hotelero y tomando en cuenta que este segmento turístico se maneja de manera estacional. Adicional a ello, hemos considerado el impacto de las actividades de marketing que se realizaran en abril y noviembre

\begin{tabular}{|c|c|c|c|c|c|c|}
\hline I Módulo de Premisas - Especializado & M1 & $\mathrm{M} 2$ & M3 & M4 & M5 & M6 \\
\hline Precio por paquete $-12 \mathrm{D} 11 \mathrm{~N}$ & $S / .9,240.00$ & $\mathrm{~S} / .9,240.00$ & $\mathrm{~S} / .9,240.00$ & $S / .9,240.00$ & S/.9,240.00 & $\mathrm{S} / .9,240.00$ \\
\hline Cantidad & 0 & 1 & 1 & 1 & 2 & 2 \\
\hline Ingresos & $\mathrm{S} / .0 .00$ & $S / .9,240.00$ & S/.9,240.00 & $S / .9,240.00$ & $\mathrm{~S} / .18,480.00$ & $S / .18,480.00$ \\
\hline
\end{tabular}




\begin{tabular}{|r|r|r|r|r|r|}
\hline \multicolumn{1}{|c}{ M7 } & \multicolumn{2}{c}{ M 8} & \multicolumn{1}{c|}{ M10 } & M11 & \multicolumn{1}{c|}{ M12 } \\
\hline$S / .9,240.00$ & $S / .9,240.00$ & $S / .9,240.00$ & $S / .9,240.00$ & $S / .9,240.00$ & $S / .9,240.00$ \\
\hline 3 & 3 & 3 & 3 & 4 & 3 \\
\hline$S / .27,720.00$ & $S / .27,720.00$ & $S / .27,720.00$ & $S / .27,720.00$ & $S / .36,960.00$ & $S / .27,720.00$ \\
\hline
\end{tabular}

\section{Presupuesto de Marketing}

Tabla N²4: Presupuesto de marketing

\begin{tabular}{|c|c|c|c|c|c|c|c|c|c|c|c|c|c|c|c|c|c|c|c|c|c|}
\hline \multirow{2}{*}{$\begin{array}{c}\text { Unidad de } \\
\text { negocio }\end{array}$} & \multirow[b]{2}{*}{$\begin{array}{l}\text { Clase de } \\
\text { Coste }\end{array}$} & \multirow[b]{2}{*}{ Denominación } & & \multirow{2}{*}{\multicolumn{2}{|c|}{$\begin{array}{l}\text { Enero } \\
\text { Ppto. }\end{array}$}} & \multirow{2}{*}{$\frac{\text { Febrero }}{\text { Ppto. }}$} & \multirow{2}{*}{$\begin{array}{l}\text { Marzo } \\
\text { Ppto. }\end{array}$} & \multirow{2}{*}{\multicolumn{2}{|c|}{$\begin{array}{l}\text { Abril } \\
\text { Ppto. }\end{array}$}} & \multirow{2}{*}{\multicolumn{2}{|c|}{$\frac{\text { Mayo }}{\text { Ppto. }}$}} & \multirow{2}{*}{\multicolumn{2}{|c|}{$\begin{array}{l}\text { Junio } \\
\text { Ppto. }\end{array}$}} & \multirow{2}{*}{\multicolumn{2}{|c|}{$\frac{\text { Julio }}{\text { Ppto. }}$}} & \multirow{2}{*}{$\frac{\text { Agosto }}{\text { Ppto. }}$} & \multirow{2}{*}{$\frac{\text { Setiembre }}{\text { Ppto. }}$} & \multirow{2}{*}{$\frac{\text { Octubre }}{\text { Ppto. }}$} & \multirow{2}{*}{$\frac{\text { Noviembre }}{\text { Ppto. }}$} & \multirow{2}{*}{\multicolumn{2}{|c|}{$\frac{\text { Diciembre }}{\text { Ppto. }}$}} \\
\hline & & & Concepto & & & & & & & & & & & & & & & & & & \\
\hline \multirow{10}{*}{ Corporativo } & \multirow{10}{*}{ Corporativo } & \multirow[b]{3}{*}{ Aseosría Digital } & Asesoría Creativa & $\mathrm{S} /$. & $2,500.00$ & S/. $2,500.00$ & S/. $\quad 2,500.00$ & $\mathrm{~S} /$. & $2,500.00$ & $\mathrm{~S} /$. & $2,500.00$ & $\mathrm{~S} /$. & $2,500.00$ & $\mathrm{~S} /$. & $2,500.00$ & S/. $\quad 2,500.00$ & S/. $\quad 2,500.00$ & S/. $\quad 2,500.00$ & S/. $\quad 2,500.00$ & S/. & $2,500.00$ \\
\hline & & & Redes Sociales (Freelance) & S/. & 850.00 & $\begin{array}{|lr|}\text { S/. } & 850.00 \\
\end{array}$ & $\begin{array}{ll}\text { S/. } & 850.00 \\
\end{array}$ & $\mathrm{~S} /$. & 850.00 & S/. & 850.00 & S/. & 850.00 & S/. & 850.00 & \begin{tabular}{ll|} 
S/. & 850.00 \\
\end{tabular} & $\begin{array}{ll}\text { S/. } & 850.00 \\
\end{array}$ & $\begin{array}{ll}\text { S/. } & 850.00 \\
\end{array}$ & $\begin{array}{ll}\text { S/. } & 850.00 \\
\end{array}$ & $\mathrm{~S} /$. & 850.00 \\
\hline & & & \begin{tabular}{|c|} 
Otros digitales (Fotógrafos, \\
elaboración de videos, \\
testimonalias, dominios, pautas, \\
redes, etc.)
\end{tabular} & $\mathrm{S} /$. & $1,500.00$ & S/. $\quad 1,500.00$ & S/. $\quad 1,500.00$ & $\mathrm{~S} /$. & $1,500.00$ & S/. & $1,500.00$ & S/. & $1,500.00$ & $\mathrm{~S} /$. & $1,500.00$ & S/. $\quad 1,500.00$ & S/. $\quad 1,500.00$ & S/. $\quad 1,500.00$ & S/. $\quad 1,500.00$ & S/. & $1,500.00$ \\
\hline & & \multirow{3}{*}{$\begin{array}{c}\text { Eventos } \\
\text { Internacionales }\end{array}$} & Ferias al exterior & & & & S/. $13,328.00$ & & & & & & & & & & & S/. $13,328.00$ & & & \\
\hline & & & Press Tour & & & & & S/. & $10,000.00$ & & & & & & & & & & & & \\
\hline & & & Fam Trips & & & & & $\mathrm{S} /$. & $15,000.00$ & & & & & & & & & & & & \\
\hline & & \multirow{3}{*}{$\begin{array}{c}\text { Material } \\
\text { Publicitario }\end{array}$} & Impresos & S/. & 500.00 & & & & & $\mathrm{~S} /$. & 500.00 & & & & & & $\begin{array}{ll}\text { S/. } & 500.00 \\
\end{array}$ & & & & \\
\hline & & & Merchandising & $\mathrm{S} /$. & 420.00 & $\begin{array}{|ll|}\text { S/. } & 420.00 \\
\end{array}$ & 420.00 & $\mathrm{~S} /$. & 420.00 & $\mathrm{~S} /$. & 420.00 & S/. & 420.00 & $\mathrm{~S} /$. & 420.00 & \begin{tabular}{ll|} 
S/. & 420.00 \\
\end{tabular} & S/. 420.00 & 420.00 & \begin{tabular}{ll|} 
S/. & 420.00 \\
\end{tabular} & $\mathrm{~S} /$. & 420.00 \\
\hline & & & Videos & S/. & 500.00 & & & & & & & & 500.00 & & & & & & & & \\
\hline & & RSE & \begin{tabular}{|c} 
Festividades con la población \\
local
\end{tabular} & & & & S/. $\quad 2,000.00$ & & & & & & & & & & & & & & 2000 \\
\hline \multicolumn{4}{|c|}{ TOTAL } & S/. & $6,270.00$ & S/. $\quad 5,270.00$ & S/. $20,598.00$ & $\mathrm{~S} /$. & $30,270.00$ & $\mathrm{~S} /$. & $5,770.00$ & S/. & $5,770.00$ & S/. & $5,270.00$ & S/. $\quad 5,270.00$ & S/. $\quad 5,770.00$ & S/. $18,598.00$ & S/. $\quad 5,270.00$ & S/. & $7,270.00$ \\
\hline
\end{tabular}

Presupuesto Total : S/. 121,396.00 


\section{Capítulo 5. Plan de Operaciones}

\section{Políticas Operacionales}

\section{Captación de clientes}

Al ser un servicio especializado que atiende un nicho y siendo nuestro mercado objetivo birdwatchers de USA, Europa y Latinoamérica debemos contar con políticas bien definidas de captación de clientes.

Una de nuestras primeras acciones será participar en las principales ferias especializadas de Birdwatchers como Birdfair la cual se realiza en diferentes ciudades del mundo y acoge a diversas empresas relacionadas con el rubro. La actividad principal será contar con un stand en la categoría de viajes y turismo donde se podrán ofrecer los servicios del albergue, así como promocionar a Perú como destino de observación de aves basados en las investigaciones científicas. Cabe resaltar que Birdfair promueve la conservación de lugares y especies año tras año por ende la exposición con la que cuenta es de alto impacto.

Así mismo, se contratará una publicación de manera intercalada en cada edición de las dos revistas más importantes del gremio (Birdwatching Magazine y Robb Report), ya que, al ser un albergue nuevo necesitamos lograr la recordación y asociación positiva de la marca.

Como tercera acción se promoverá la realización de documentales de Tambopata y de las especies endémicas del Perú realizado por periodistas de medios reconocidos como National Geographic, esto a través de invitaciones de Aperbird logrando así un publirreportaje.

Todas estas actividades se sumarán a nuestra presencia en los principales medios digitales, redes sociales y nuestra página web a través de la cual esperamos captar un número importante de clientes.

\section{Procesos}

Para lograr la satisfacción de nuestros clientes es necesario contar con una política de procesos clara y entendible, es por ello que trabajaremos en:

- Sensibilizar a todos nuestros trabajadores en cuanto a la identidad de la marca y valores de la organización. 
- Capacitar de forma permanente en la aplicación de los manuales de procedimientos en cada área y evaluar el cumplimiento de los procesos de forma continua.

- Trabajar en un programa de empoderamiento y toma de decisiones.

- Identificar procesos, clasificarlos, evaluar los puntos críticos e interacción con nuestro cliente.

- Alimentar y mejorar cada proceso de forma permanente. Se tomará como insumo los resultados de las encuestas de satisfacción de nuestros clientes y el "cliente oculto".

\section{Planificación}

La planificación de este proyecto se basa en el análisis del sector realizada previamente y en la investigación científica que nos da como resultado el tipo, la cantidad y la calidad del recurso primordial que en este caso es el ave. Todo esto es trasladado a los objetivos y a las estrategias planteadas para alcanzarlos. El planeamiento se alinea con las políticas de servicio y valores de la empresa.

Al ser una empresa formada recientemente la planificación de operaciones está basada en el proyectado de ventas, el cual será medido de manera frecuente para continuar su rumbo o modificarlo según la coyuntura actual.

Nuestra política de planificación busca conducir las acciones y los planes hacia un escenario de constante colaboración y aprendizaje para así poder garantizar una mejora continua de los procesos internos.

\section{Post - Venta}

Como una oportunidad de incrementar las visitas y también el retorno de anteriores visitantes, utilizaremos la información de nuestros cliente actuales (base de datos) que vamos recolectando mediante los registros que se realizan al llegar al albergue (Check-in) como también los que dejan mediante nuestra web como correo, teléfono, dirección para el envío de información sobre novedades de nuevas investigaciones, descubrimientos de nuevas especies, migraciones, como también eventos, entre otros con el fin de incentivar el retorno de anteriores viajeros y a la vez sirva de apoyo para recomendaciones con amistades cercanas y las de sus gremios.

El modelo por utilizar será un boletín informativo que enviaremos de manera virtual cuatrimestralmente a las personas que hayan aceptado el uso de su información para el envío de ofertas e información. 
Ejemplo:

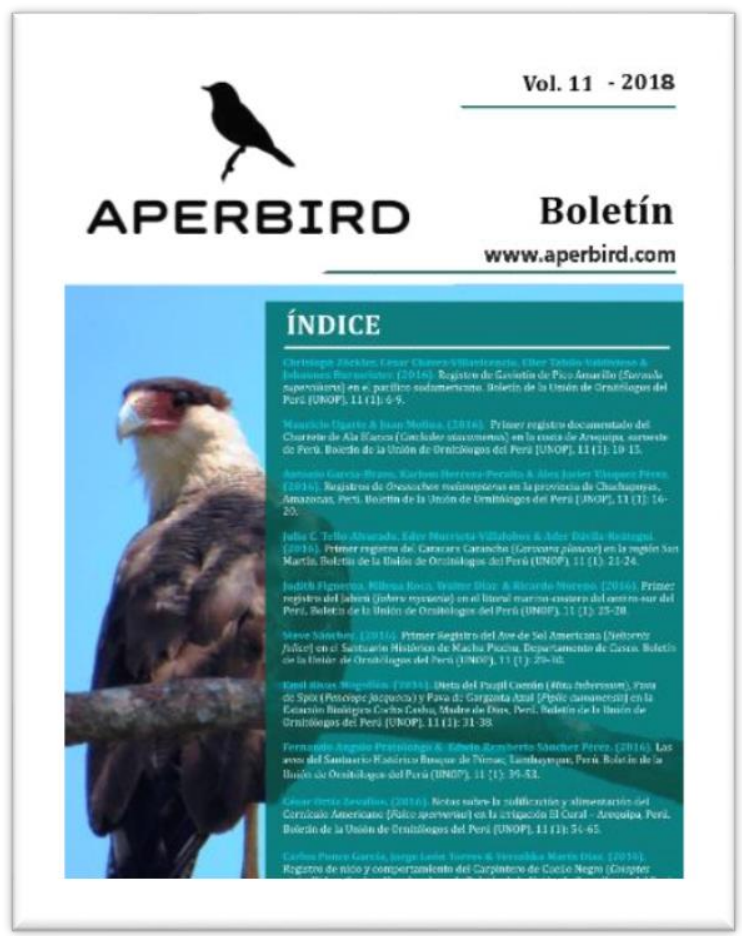

\section{Diseño de Instalaciones}

\section{Localización de las instalaciones}

País: Perú

Región: Madre de Dios

Provincia: Tambopata

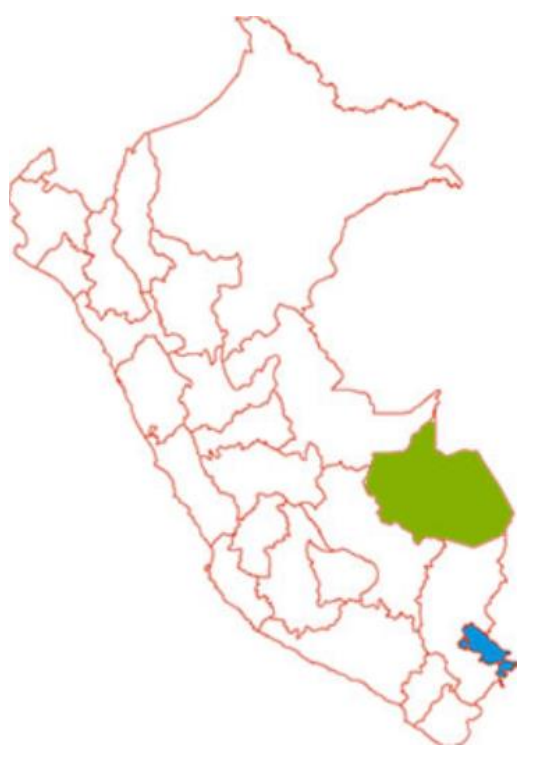




\section{Capacidad de las instalaciones}

Aperbird es un albergue que ofrece un servicio y no un producto tangible por lo que mediremos nuestra capacidad de acuerdo con la infraestructura en el albergue para recibir a los Birdwatcher.

El albergue contará con los siguientes espacios:

- Comedor con capacidad para 42 persona.

- Sala de recepción para realizar el Check in / Check out

- Cocina y almacén de $5 \mathrm{~m} 2$ con conexión al comedor.

- 10 cabañas, cada una con capacidad para 4 personas. Con baño incorporado.

- Oficina de $10 \mathrm{~m} 2$ en donde operará el Gerente de operaciones del albergue.

- 2 cabañas adicionales como vivienda para el personal (una de hombres y una para mujeres), con baño incorporado cada una.

- Horarios de atención:

- Se atenderán los 365 días del año.

- La atención de servicio en recepción, será de 24 horas

- La atención de servicio en el comedor será de 6:00 am a 10 pm

- La atención de servicios de guiado del 1er turno inicia a las 4:30am y finalizan a las 2:00pm, el segundo turno es de 3:00pm a 11:00pm. Se trabajarán horarios diversos de acuerdo con factores de clima y del tipo de expedición que busque el birdwatcher. Estos recorridos también estarán sujetos al servicio que se tome (grupal o individual).

Gráfico de capacidad instalada de huéspedes del 1er año en base a proyectado 
Figura $\mathrm{N}^{\circ} 5$ Capacidad instalada

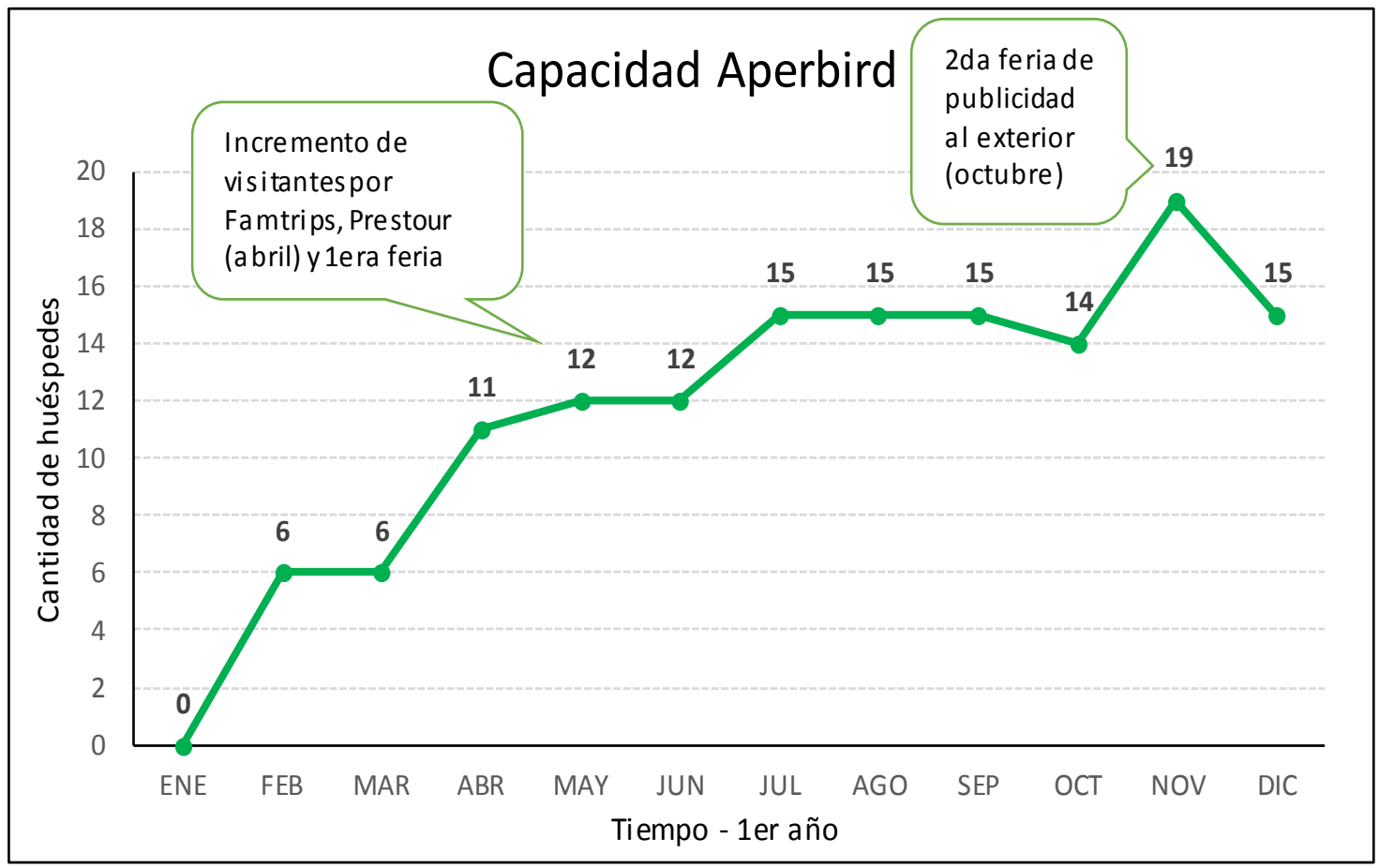

\section{Distribución de las instalaciones}

Distribución del terreno:

1. Recepción

2. Comedor (Cocina y almacén)

3. Cabañas (10)

4. Centro de estudios

5. Oficinas

6. Cuartos de empleados 


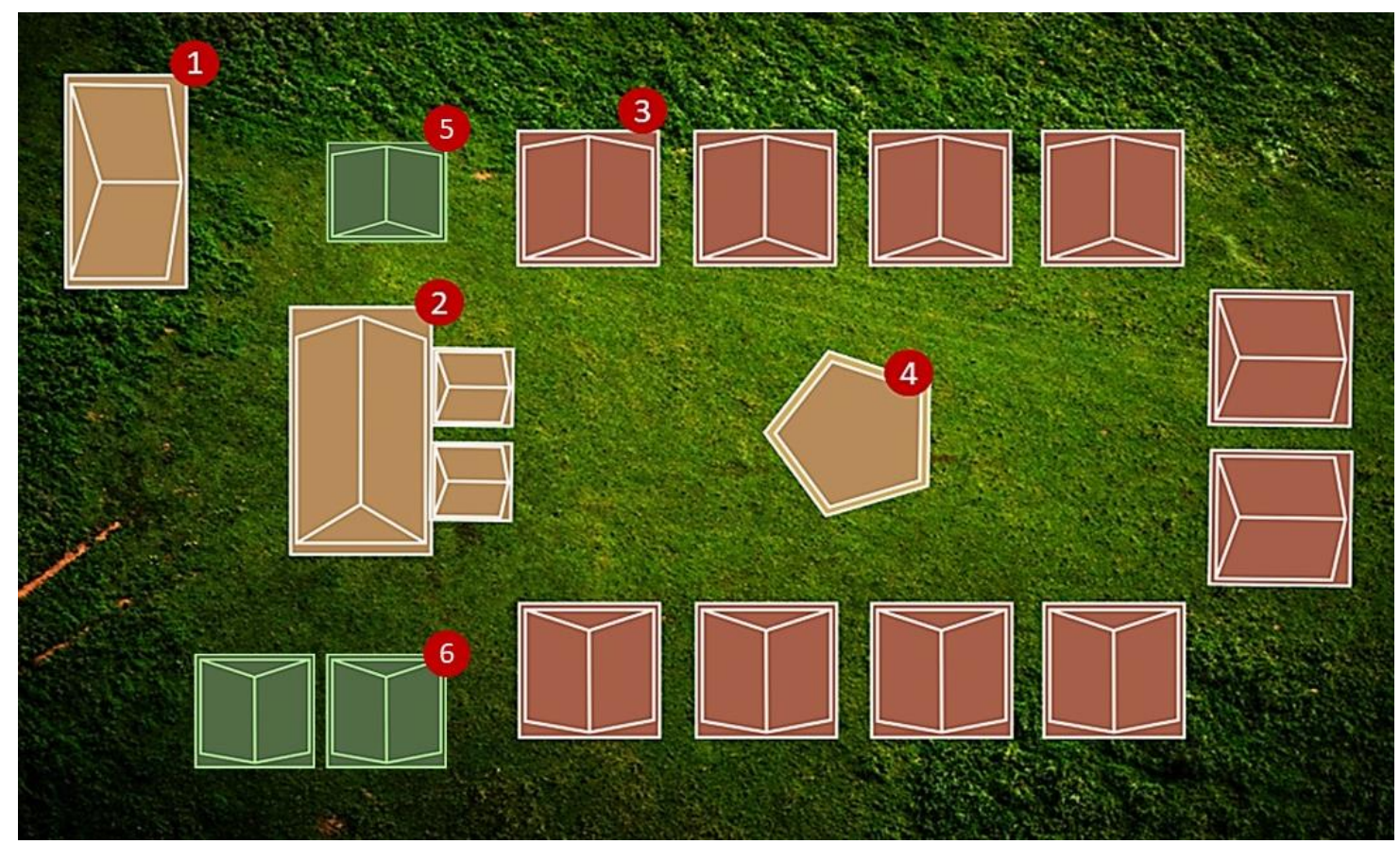

Recepción: contará con una entrada principal donde se recibirán a los huéspedes los cuales realizarán el Check in y Check out y una puerta posterior para el ingreso al albergue. Este espacio contará con 6 sofás, un baño para uso general y con una laptop para la recepcionista que se encargaría de la gestión.

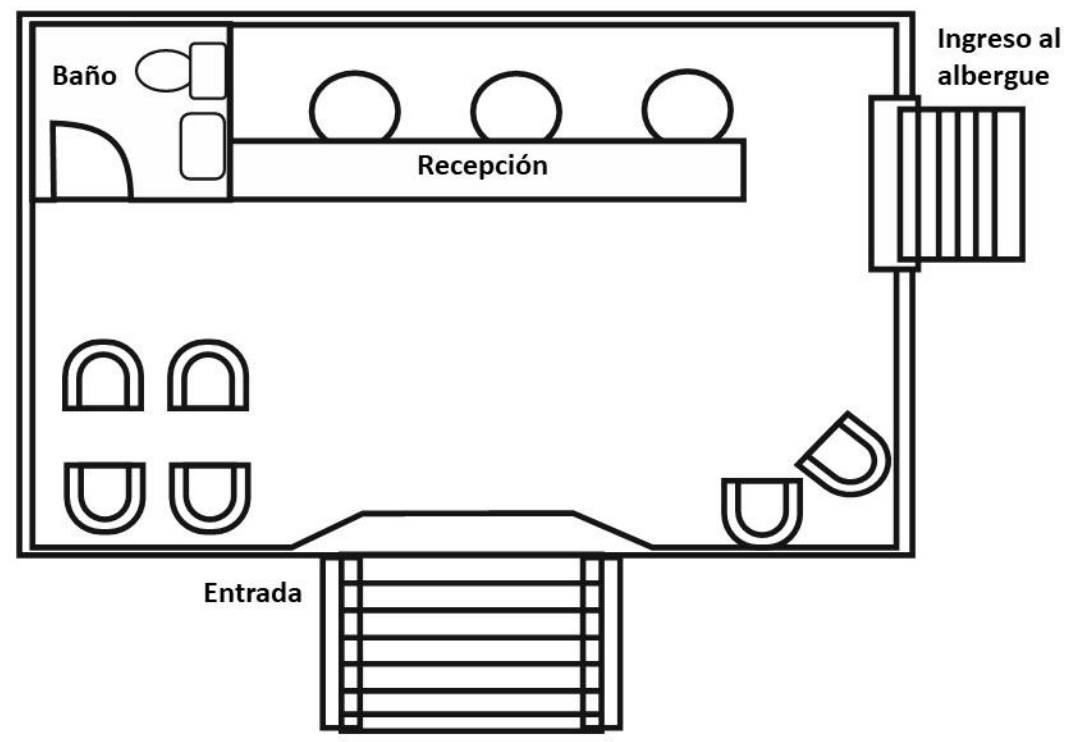


Comedor: Este espacio contará con 4 ambientes, conformados por la cocina, un almacén con suministros, dos baños y la zona de despacho que contará con 7 mesas que se utilizarán por los huéspedes para la hora del desayuno, almuerzo y cena.

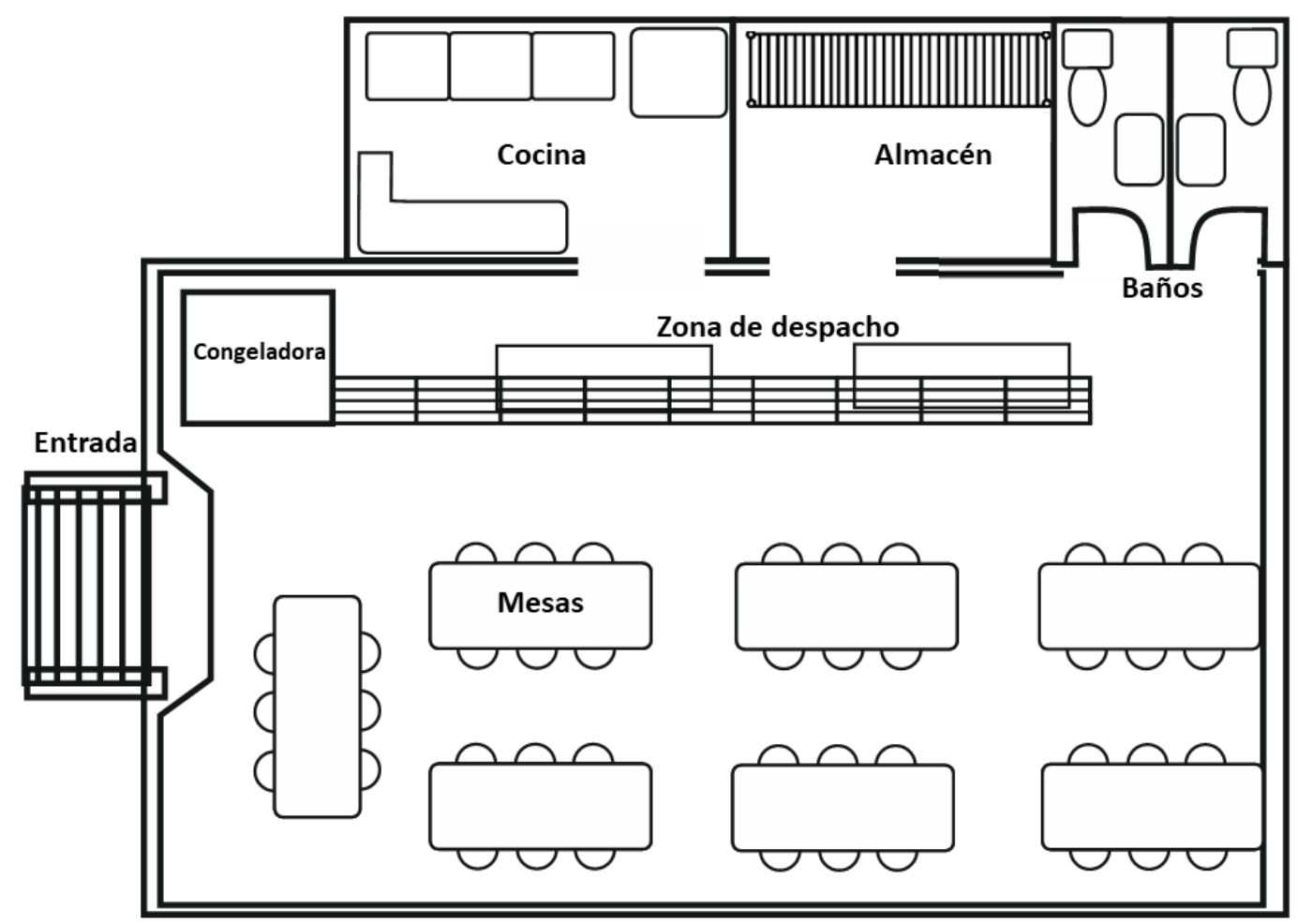

Cuarto de huésped: Cada cuarto cuenta con dos camarotes para albergar a 4 personas en total, este espacio contará con dos armarios, un escritorio y un sofá. El baño está divido en dos espacios que son el de la ducha y otra que comprende el lavadero y water.

Son 10 cabañas en total.

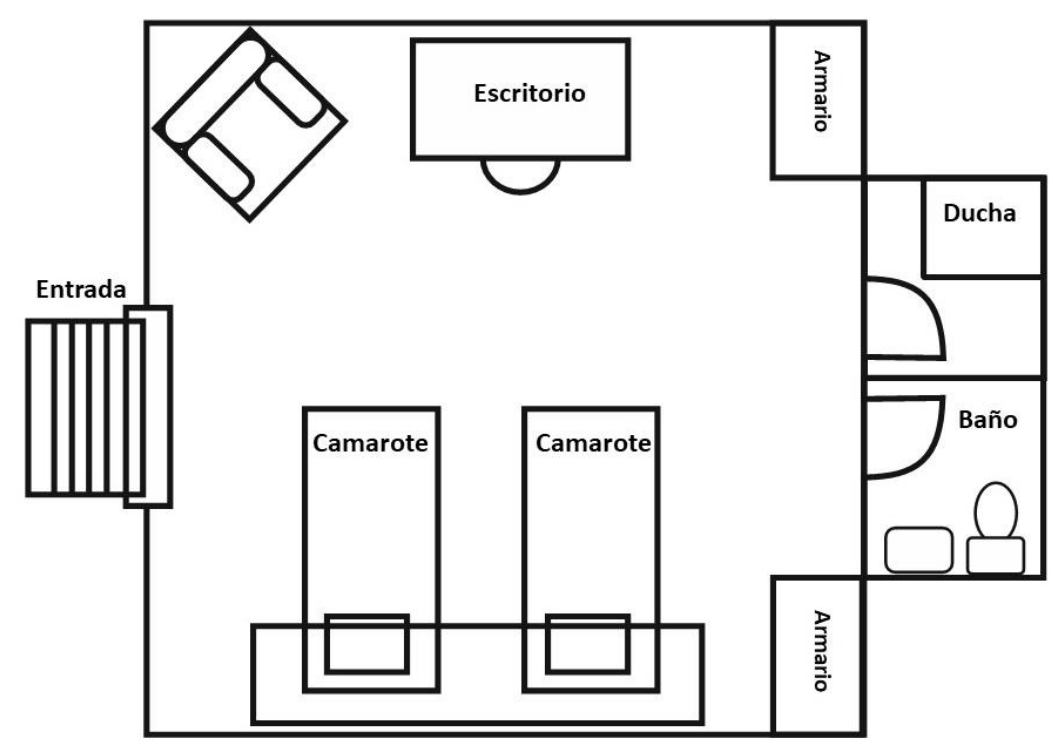


Oficinas: Espacio utilizado por el Gerente de operaciones del albergue, contará con dos escritorios, un archivero donde se contará con la documentación del albergue, de los huéspedes, etc. Tendrá un baño, un botiquín de primeros auxilios, dos laptops para uso laboral y un almacén para utensilios.

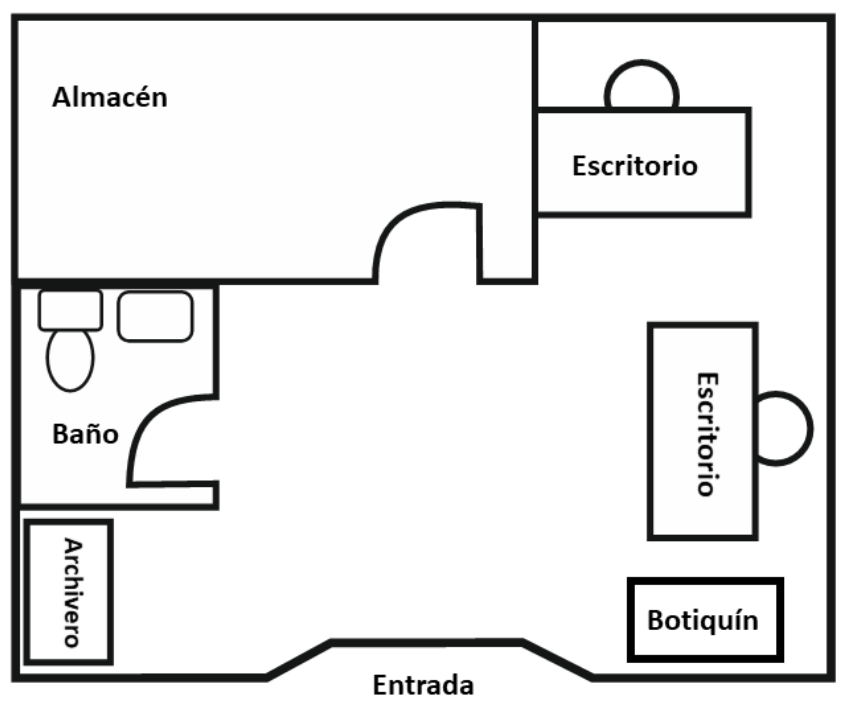

Centro de estudios: Lugar ubicado en el centro del alberque, será utilizado por los huéspedes para actividades. Cuenta con 6 escritorios, una biblioteca con libros, un estante con laptops para la revisión de información que se cuelga sobre la zona (la cual contará con 2 laptops a disposición de los huéspedes) y estudios realizados, adicional a ello también contará con espacios con muebles para descansar o realizar lectura.

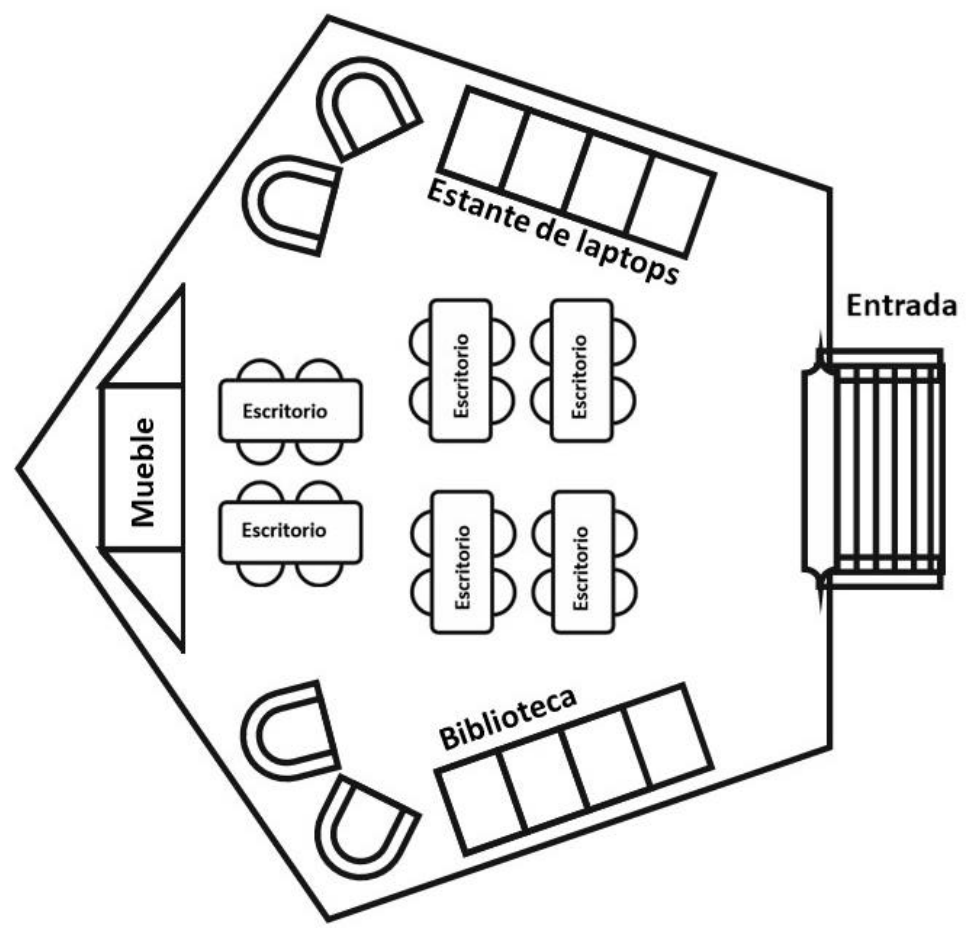


Cuarto de empleados: Se contará con 2 cabañas especiales para los empleados del albergue, uno para hombres y otro para mujeres respectivamente. Cada uno cuenta con 6 camarotes, 2 armarios y un baño divido para uso de la ducha u otro donde estará el lavadero y water.

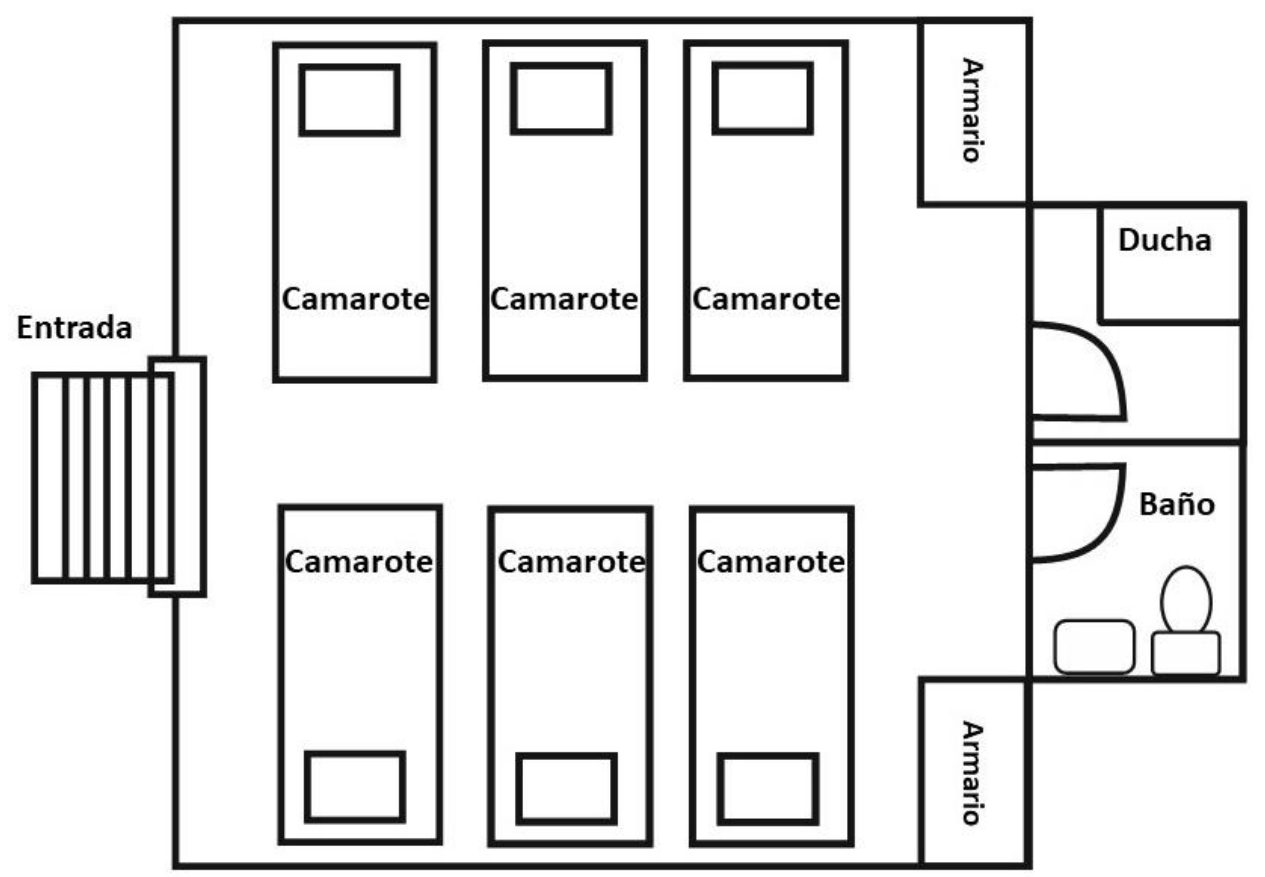

\section{Especificaciones Técnicas del Producto / servicio}

El servicio se ofrecerá por nuestra página web como canal directo. Esta web podrá abrirse desde cualquier plataforma como PC, celulares, tables y laptops. Por otro lado, también se podrá acceder desde todos los sistemas operativos como Android, iOS, Windows, Linux y Mac Os. Características de la página web:

- Plataforma multi-idioma.

- La plataforma permite el registro automático, formulación de BBDD. Protección de usuarios registrados. Ley de Datos Personales 29733.

- Integración con nuestro software interno para disponibilidad de servicios al año.

- Integración con nuestro software interno para e-mailing marketing.

- Integración con redes sociales.

- Galería de imágenes y videos testimoniales sobre los servicios que ofrecemos.

- Integración con Google Maps para ubicación. 


\section{Mapa de Procesos y PERT}

Figura $\mathrm{N}^{\circ} 6$ Mapa de procesos - Cliente Directo

Mapa de Procesos - Cliente Directo

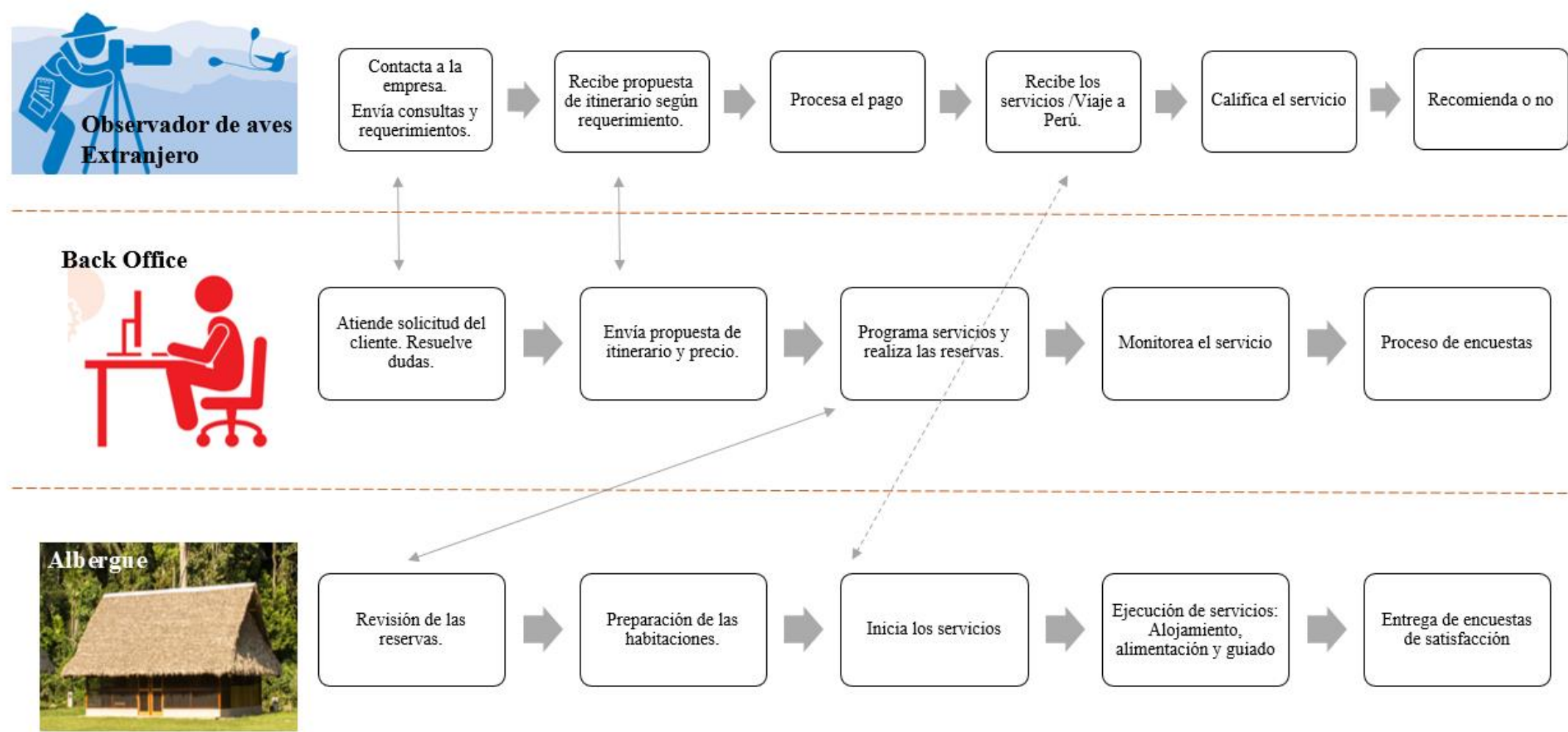




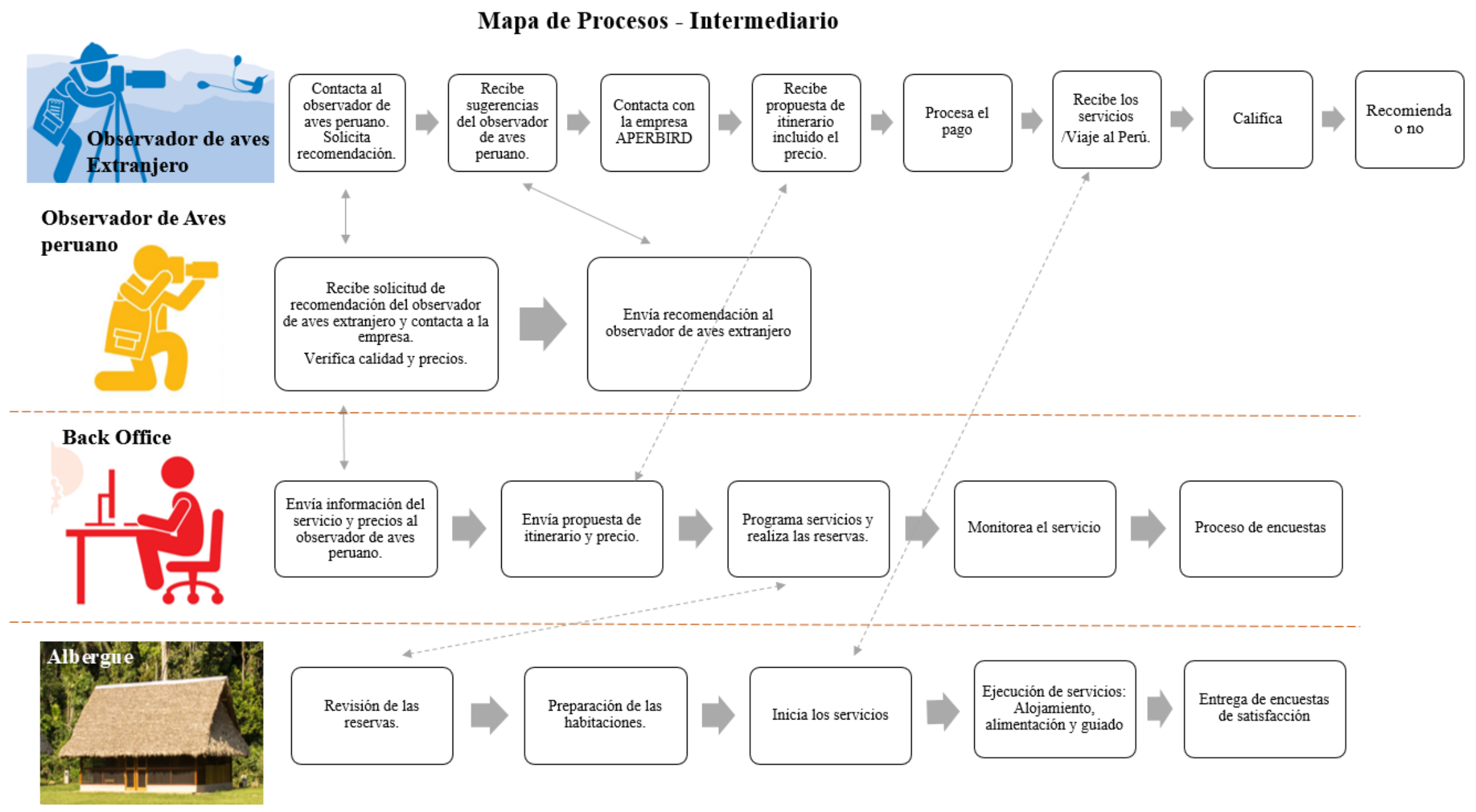


A continuación, se muestra el diagrama Pert que permite entender los tiempos y orden de los procesos de los servicios que brinda APERBIRD.

Tabla $\mathrm{N}^{\circ} 5$ Diagrama PERT

\begin{tabular}{|l|l|l|}
\hline & Actividad & Tiempo de Ejecución \\
\hline A & Investigación de gabinete de la zona & 45 días \\
\hline B & Viaje de campo, investigación de la zona. & 20 días \\
\hline C & Compra del terreno & 15 días \\
\hline D & $\begin{array}{l}\text { Planificación de construcción y programa de } \\
\text { investigación científica }\end{array}$ & 20 días \\
\hline E & Trámite de licencias de funcionamiento & 45 días \\
\hline F & Construcción del albergue e instalaciones & 45 días \\
\hline G & $\begin{array}{l}\text { Implementación del programa de investigación } \\
\text { científica }\end{array}$ & 60 días \\
\hline H & $\begin{array}{l}\text { Requerimiento, recepción de presupuestos } \\
\text { evaluación de compra de los bienes y equipos del } \\
\text { albergue y de la oficina en Lima. }\end{array}$ & 10 días \\
\hline I & Compra & 10 días \\
\hline J & Envío de los equipos y bienes a Puerto Maldonado & 10 días \\
\hline K & Implementación y decoración & 30 días \\
\hline L & Reclutamiento de los trabajadores locales & 15 días \\
\hline M & Capacitación & 10 días \\
\hline N & Diseño y confección de uniformes & Inicio del Plan de marketing y difusión \\
\hline O & Inicio de las operaciones - Periodo de prueba \\
\hline
\end{tabular}

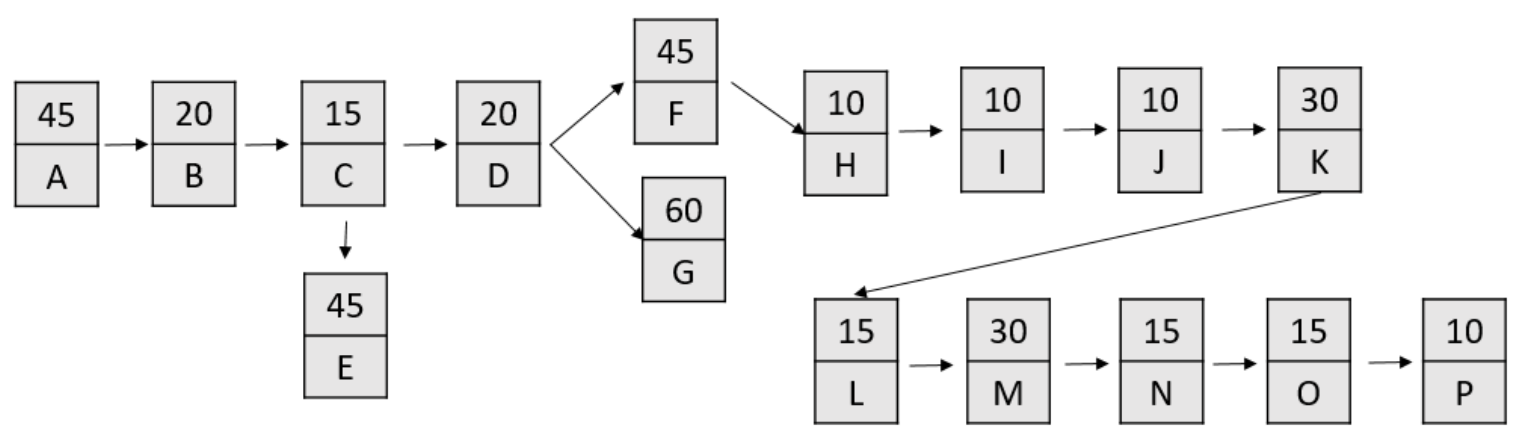




\section{Planeamiento de la Producción}

\section{Gestión de compras y stock}

Figura $\mathrm{N}^{\circ} 8$ Mapa de proceso de compras

Nuestra gestión de compra se dará en 6 pasos:

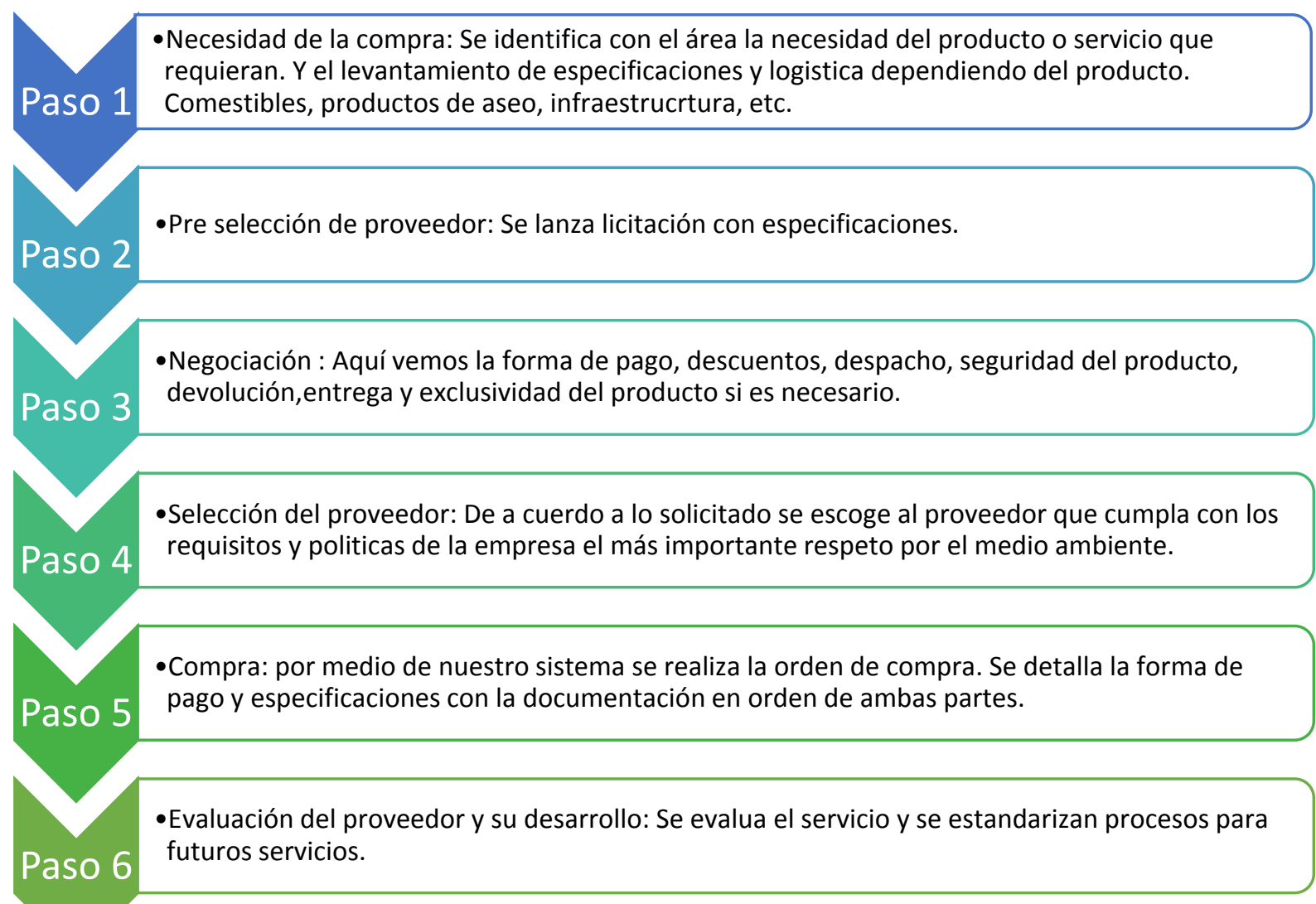

Como proceso complementario se creará un historial de compras para poder elaborar un registro de stock y detectar los tiempos de durabilidad del producto o servicio que se adquiera y así poder estar siempre abastecidos.

Nuestro proceso de compra en el albergue sería para los siguientes productos:

- Insumos de comida

- Servicio técnico

- Muebles/inmuebles

- Equipos y accesorios

- Material POP/ Merchandising 
- Textiles (uniformes, lencería de cuarto y textiles de baño)

\section{Gestión de la calidad}

Al estar enfocados en un nicho especializado nuestra calidad de servicio es una de nuestras mayores preocupaciones por este motivo hemos diseñado Manuales de atención y de guiado para que nuestro personal cuente con las herramientas necesarias para brindar el servicio de excelencia al que estamos apuntando. Estos manuales serán diseñados por expertos en atención al cliente donde se detallarán los valores de la empresa, las guías que el personal debe seguir en cada interacción tanto con el cliente externo como con el interno. Así mismo, se elaborarán patrones de experiencia que ayuden al personal a tener pauteados ciertos momentos claves en los que se puede dar un valor agregado al cliente.

Protocolo de servicio:

El contacto se inicia desde que el cliente llega al aeropuerto de Puerto Maldonado. Nuestro personal, un chofer y guía, irán a recoger al cliente, desde el primer contacto con el cliente se emplearán los protocolos en la comunicación, seguridad y traslado.

Los procesos de atención continuaran al momento de que el cliente llegue al albergue, se registre, utilice los servicios de alimentación y de guiado con los expertos.

Todo esto será posible a través de capacitaciones en todas las etapas, desde la contratación del personal, así como las que realizaran periódicamente en busca de la mejora continua y la actualización de procedimientos para mantener altos estándares de calidad. El personal también estará calificado y preparado para manejar problemas de seguridad que se puedan presentar como: incendios, picaduras de animales y primeros auxilios.

Sistema de valorización:

Debido a que nos dirigimos a un segmento A-1 nuestro servicio tiene que ser impecable y utilizaremos 2 actividades para medir y evaluar constantemente.

1. Se realizará una encuesta de satisfacción digital presencial al cliente al momento de realizar el Check-out. La encuesta se presentará en tablets para guardar la coherencia con nuestra política eco-amigable. Será un total de 5 preguntas en donde 2 evaluaran el servicio en general, 1 será sobre la infraestructura y las últimas 2 preguntas evaluarán el servicio de guiado con el experto. Esta encuesta final será una sola y se brindará a todos clientes independientemente del servicio que haya tomado (Estándar o Especializado). 
2. Emplearemos la experiencia de un viajero oculto para que pueda calificar y medir si nuestro servicio está cumpliendo con los protocolos de atención y brindando el servicio que buscamos. El viajero oculto, será una persona externa contratada por la misma empresa, se quedará en el albergue como un cliente más accediendo a todos los servicios que ofrece el paquete. Este viajero oculto contará con un check-list para realizar la evaluación y todos sus gastos serán cubiertos por nuestra empresa. Esta evaluación se realizará de forma trimestral.

\section{Inversión en activos fijos vinculados al proceso productivo}

Nuestros activos fijos están distribuidos en muebles, enseres, equipos e inmuebles.

- Muebles y enseres:

Tabla $N^{\circ} 6$ Lista de equipamiento

\begin{tabular}{|c|c|c|c|c|c|}
\hline \multicolumn{6}{|c|}{ Equipamiento } \\
\hline Muebles/Enseres & Cantidad & \multicolumn{2}{|c|}{ Costo Unitario } & \multicolumn{2}{|c|}{ Costo Total } \\
\hline Sofá recepción & 6 & $\mathrm{~S} /$. & 400.00 & $\mathrm{~S} /$. & $2,400.00$ \\
\hline Sofá de cuarto & 10 & $\mathrm{~S} /$. & 300.00 & $\mathrm{~S} /$. & $3,000.00$ \\
\hline Sofá centro de estudio & 4 & $\mathrm{~S} /$. & 280.00 & $\mathrm{~S} /$. & $1,120.00$ \\
\hline Escritorio grande recepción & 1 & $\mathrm{~S} / \mathrm{.}$ & 600.00 & $\mathrm{~S} /$. & 600.00 \\
\hline Escritorio pequeño oficina & 2 & $\mathrm{~S} /$. & 400.00 & $\mathrm{~S} /$. & 800.00 \\
\hline Escritorio pequeño cabaña & 10 & $\mathrm{~S} /$. & 250.00 & $\mathrm{~S} /$. & $2,500.00$ \\
\hline Escritorio mediano bipersonales & 6 & $\mathrm{~S} /$. & 370.00 & $\mathrm{~S} /$. & $2,220.00$ \\
\hline Muebles almacen comedor & 2 & $\mathrm{~S} /$. & 700.00 & $\mathrm{~S} /$. & $1,400.00$ \\
\hline Mueble tabla de comida comedor & 1 & S/. & 300.00 & S/. & 300.00 \\
\hline Vitrina fria cerrada comedor & 1 & S/. & $1,200.00$ & $\mathrm{~S} /$. & $1,200.00$ \\
\hline Cocina comedor & 2 & $S /$. & $1,000.00$ & $\mathrm{~S} /$. & $2,000.00$ \\
\hline Refrigedora Comedor & 1 & $\mathrm{~S} / \mathrm{.}$ & $1,400.00$ & $\mathrm{~S} /$. & $1,400.00$ \\
\hline Mesas Comedor & 7 & $\mathrm{~S} /$. & 500.00 & $\mathrm{~S} /$. & $3,500.00$ \\
\hline Sillas Comedor & 42 & $\mathrm{~S} / \mathrm{.}$ & 50.00 & $\mathrm{~S} /$. & $2,100.00$ \\
\hline Camarotes & 32 & $\mathrm{~S} /$. & $1,600.00$ & $\mathrm{~S} /$. & $51,200.00$ \\
\hline Armarios Closet de cabaña & 24 & $\mathrm{~S} /$. & 300.00 & $\mathrm{~S} /$. & $7,200.00$ \\
\hline Archiviero/stand & 1 & $\mathrm{~S} /$. & 400.00 & $\mathrm{~S} /$. & 400.00 \\
\hline Mueble Librero & 1 & $\mathrm{~S} / \mathrm{.}$ & 350.00 & $\mathrm{~S} /$. & 350.00 \\
\hline Estante de laptos & 1 & $\mathrm{~S} /$. & 500.00 & $\mathrm{~S} /$. & 500.00 \\
\hline Grifería para baños (ducha dormitorio) & 12 & S/. & 400.00 & $\mathrm{~S} /$. & $4,800.00$ \\
\hline Grifería para baños (Lavadero, inodoro) & 16 & S/. & 300.00 & $\mathrm{~S} /$. & $4,800.00$ \\
\hline Botiquin completo & 1 & $\mathrm{~S} /$. & 120.00 & $\mathrm{~S} /$. & 120.00 \\
\hline TOTAL & & & & $\mathrm{S} /$. & $93,910.00$ \\
\hline
\end{tabular}


- Equipos:

- Inmuebles: Nuestro albergue en Tambopata:

Tabla $\mathrm{N}^{\circ} 7$ Costo de infraestructura

\begin{tabular}{|c|c|c|c|}
\hline \multicolumn{4}{|c|}{ Infraestructura } \\
\hline Inmueble & Cantidad & Costo Unitario & Costo Total \\
\hline Edificación e infraestructura & 1 & S/.630,000.00 & S/.630,000.00 \\
\hline \multicolumn{2}{|c|}{ TOTAL } & S/.630,000.00 \\
\hline
\end{tabular}

\section{Estructura de costos y gastos operativos}

Hemos considerado los gastos directos de la operación, es decir no se consideran los gastos de back office (Administración).

Tabla $\mathrm{N}^{\circ} 8$ Estructura de costos operativos

\begin{tabular}{|l|c|c|c|c|c|}
\hline \multicolumn{7}{|c|}{ ESTRUCTURA DE COSTOS OPERATIVOS } \\
\hline \multicolumn{1}{|c|}{ Concepto } & $\mathrm{N}^{\circ}$ de personas & Mensual & Anual & Essalud (9\%) & Total Anual \\
\hline Pago de guia local 1 & 1 & $\mathrm{~S} / 1,200.00$ & $\mathrm{~S} / 16,800.00$ & $\mathrm{~S} / 1,512.00$ & $\mathrm{~S} / 18,312.00$ \\
\hline Pago de Guia local 2 & 1 & $\mathrm{~S} / 1,200.00$ & $\mathrm{~S} / 16,800.00$ & $\mathrm{~S} / 1,512.00$ & $\mathrm{~S} / 18,312.00$ \\
\hline Pago del cocinero del albergue & 1 & $\mathrm{~S} / 2,000.00$ & $\mathrm{~S} / 28,000.00$ & $\mathrm{~S} / 2,520.00$ & $\mathrm{~S} / 30,520.00$ \\
\hline Totales & 3 & $\mathrm{~S} / 4,400.00$ & $\mathrm{~S} / 61,600.00$ & $\mathrm{~S} / 5,544.00$ & $\mathrm{~S} / 67,144.00$ \\
\hline
\end{tabular}

Tabla $\mathrm{N}^{\circ} 9$ Estructura de gastos operativos

\begin{tabular}{|l|c|c|}
\hline \multicolumn{3}{|c|}{ ESTRUCTURA DE GASTOS OPERATIVOS } \\
\hline \multicolumn{1}{|c|}{ Concepto } & Mensual & Total Anual \\
\hline Agua & $\mathrm{S} / 600.00$ & $\mathrm{~S} / 7,200.00$ \\
\hline Luz & $\mathrm{S} / 600.00$ & $\mathrm{~S} / 7,200.00$ \\
\hline Comunicaciones & $\mathrm{S} / 800.00$ & $\mathrm{~S} / 9,600.00$ \\
\hline \multirow{2}{*}{ Total } & $\mathrm{S} / 24,000.00$ \\
\hline
\end{tabular}

Tabla $\mathrm{N}^{\circ} 10$ Lista de maquinarias

\begin{tabular}{|c|c|c|c|}
\hline \multicolumn{4}{|c|}{ Maquinarias y equipos } \\
\hline Equipos de computo & Cantidad & Costo Unitario & Costo Total \\
\hline Laptop & 5 & S/. $\quad 1,800.00$ & S/. $9,000.00$ \\
\hline \multicolumn{3}{|c|}{ TOTAL } & S/. $\quad 9,000.00$ \\
\hline
\end{tabular}




\section{Capítulo 6. Estructura organizacional y recursos humanos}

\section{Objetivos Organizacionales}

Nuestros objetivos están alineados a la misión, visión y objetivos estratégicos:

- Crear una cultura organizacional que genere valor para los colaboradores y los clientes.

- Motivar a los colaboradores con el fin de que se identifiquen con la empresa y se sientan parte importante de ella.

- Mantener un buen clima laboral que genere un desempeño más eficiente.

- Desarrollar personal y profesionalmente a los colaboradores en busca de cumplir sus objetivos alineados al propósito común de la empresa.

\section{Naturaleza de la Organización}

Aperbird será una empresa con fines de lucro y con capital propio mas financiamiento externo. Contará con 4 accionistas y se creará como Sociedad Anónima Cerrada. Se elige esta forma societaria debido a la facilidad de negociación de las acciones, los límites de responsabilidad personal que los socios tienen ante los acreedores o daños a terceros.

Tendrá en planilla a diez personas, que contarán con todos los beneficios que se exigen por ley. Asimismo, también se contarán con guías especializados adicionales con la modalidad de prestador de servicios y que emitirá recibo por honorarios para las épocas de full house. Con respecto a la distribución de las utilidades será a los socios fundadores quienes con su aporte lograron la constitución de la empresa. En ese sentido el tipo de empresa es horizontal debido a que todos participan de manera colaborativa e integrada, dado que cada función no trabaja de forma independiente por eso es imprescindible el compromiso y la responsabilidad de cada miembro de la organización. 


\section{Organigrama}

Figura $\mathrm{N}^{\circ} 9$ Organigrama

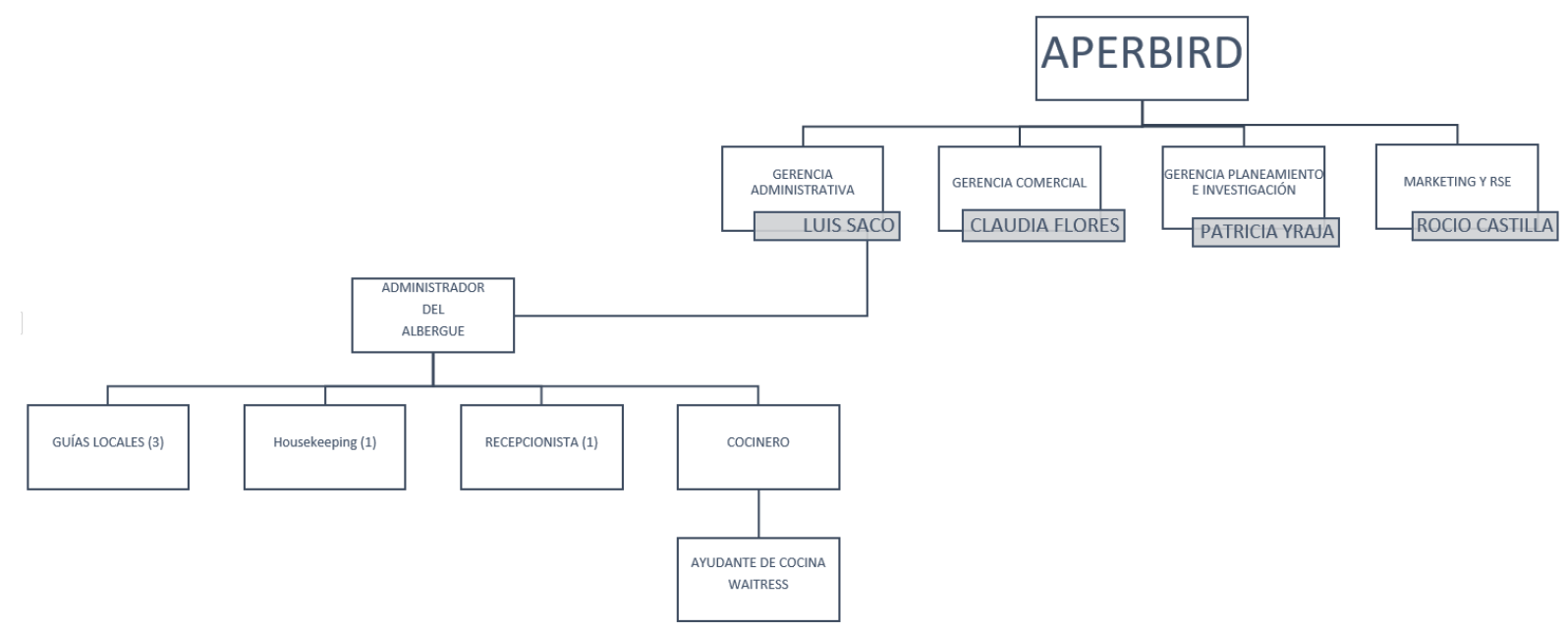

\section{Diseño de Puestos y Funciones}

Describiremos el puesto y las funciones del Gerente Administrativo:

Tabla $N^{\circ} 11$ Diseño de puesto - Gerencia administrativa

\begin{tabular}{|l|l|}
\hline \multicolumn{2}{|l|}{ Datos del cargo } \\
\hline$\underline{\text { Cargo: }}$ Gerencia Administrativa & Unidad / Sede/ Área: Lima \\
\hline
\end{tabular}

\begin{tabular}{|c|c|c|}
\hline Dependencia Jerárquica & & \\
\hline $\begin{array}{l}\text { ¿A qué puesto/s reporta? } \\
\text { - Consejo Directivo }\end{array}$ & $\begin{array}{l}\text { ¿Con qué puestos coordina?: } \\
\text { - Con las Gerencias: Comercial, } \\
\text { Planeamiento e Investigación, } \\
\text { Marketing y Responsabilidad } \\
\text { Social Empresarial }\end{array}$ & $\begin{array}{l}\text { A qué puestos supervisa: (si aplica): } \\
\text { - Recursos Humanos }\end{array}$ \\
\hline
\end{tabular}

Misión del puesto (objetivo de la posición. El propósito general o misión describe la contribución del puesto a la consecución de los objetivos de la empresa. Indica la razón de ser del puesto en la organización y debe responder a la pregunta: ¿Para qué está el puesto en la organización? ¿Qué resultados se esperan de él? Administración general, garantizando óptimos resultados de la operación y sostenibilidad financiera de la empresa.

Gestión del talento humano, velar por el continuo desarrollo de nuestros colaboradores, tanto personal como profesional.

\begin{tabular}{|c|l|}
\hline \multicolumn{2}{|l|}{$\begin{array}{l}\text { Funciones Enumere y describa sus funciones (inicie por la que considera su principal función). También podría } \\
\text { agruparlas en funciones de dirección, coordinación y operativas. }\end{array}$} \\
\hline 1 & Planificación financiera de la empresa. \\
\hline 2 & Supervisión contable de la empresa. \\
\hline 3 & Control de los ingresos y egresos de dinero en la empresa, rendiciones, desembolsos, entre otros. \\
\hline 4 & $\begin{array}{l}\text { Gestión del talento humano. Reclutar, seleccionar, capacitar y monitorear el desempeño de los } \\
\text { trabajadores. }\end{array}$ \\
\hline 5 & Elaborar los procedimientos, políticas y demás normas que deberán de cumplir los colaboradores. \\
\hline 6 & $\begin{array}{l}\text { Coordinaciones logísticas que se relacionan directamente con la operación. Provisión de alimentos por } \\
\text { ejemplo. }\end{array}$ \\
\hline 7 & Negociación permanente con proveedores, generación de órdenes de compra y servicios. \\
\hline
\end{tabular}


Toma de Decisiones Describa el límite de la autoridad conferida a su puesto indicando qué decisiones se espera que usted tome y cuáles se espera que recomiende.

Tosas las relacionadas a la realización de sus funciones.

Relaciones Internas Señale con que otros puestos dentro de la empresa (otras áreas, unidades, etc.) se relacionan principalmente y qué actividad realiza con dichos puestos.

\begin{tabular}{|l|l|}
\hline \multicolumn{1}{|c|}{ ¿Con quién? (Áreas) } & \multicolumn{1}{c|}{ Actividad } \\
\hline Comercial & $\begin{array}{l}\checkmark \text { Coordinación de la ocupabilidad en el albergue para coordinaciones } \\
\text { logísticas. }\end{array}$ \\
\hline Marketing & $\checkmark$ Coordinaciones de pagos a proveedores. \\
\hline
\end{tabular}

Relaciones Externas Señale con que otros puestos fuera de la empresa (otras empresas, organismos gubernamentales, gremios) se relacionan principalmente el puesto y qué tipo de relación mantiene.

\begin{tabular}{|c|c|c} 
¿Con quién? (Áreas) & Actividad \\
\hline Poveedores & $\checkmark$ Coordinación y negociación con los proveedores.
\end{tabular}

\begin{tabular}{|c|c|}
\hline \multicolumn{2}{|l|}{ Perfil del puesto } \\
\hline $\begin{array}{c}\text { Educación (formación, tipo de estudios universitarios o } \\
\text { técnicos) }\end{array}$ & Experiencia (años, lugares, tipo de exp) \\
\hline Administración y/o Marketing de empresas & Al menos con 5 años de experiencia \\
\hline $\begin{array}{l}\text { Competencias técnicas obligatorias (¿Qué conocimientos } \\
\text { debe poseer para desarrollar sus funciones?) } \\
\text { Incluir idiomas si es necesario para desarrollar sus } \\
\text { funciones. }\end{array}$ & Grado esperado (básico, intermedio, avanzado) \\
\hline $\begin{array}{l}\text { Entorno office y outlook } \\
\text { Inglés }\end{array}$ & $\begin{array}{l}\text { Intermedio } \\
\text { Intermedio }\end{array}$ \\
\hline $\begin{array}{c}\text { Competencias Personales (¿Qué rasgos psicológicos } \\
\text { debe poseer para desarrollar apropiadamente sus } \\
\text { funciones?) }\end{array}$ & $\begin{array}{l}\text { Competencias técnicas deseables (conocimientos } \\
\text { deseados pero no es excluyente si no lo posee) }\end{array}$ \\
\hline $\begin{array}{l}\text { Proactivo } \\
\text { Responsable } \\
\text { Empatía } \\
\text { Trabajo en equipo }\end{array}$ & Finanzas \\
\hline
\end{tabular}

\begin{tabular}{|c|c|}
\hline \multicolumn{2}{|l|}{ Condiciones adicionales del puesto } \\
\hline ¿En qué horario trabaja? & L-V 9:00 am a 7:00 pm con 1 hora de refrigerio \\
\hline \multicolumn{2}{|l|}{ Condiciones adicionales del puesto } \\
\hline $\begin{array}{l}\text { Tiene dinero a su cargo, ¿de qué materiales, bienes } \\
\text { muebles e inmuebles, equipo, actividades y trámites es } \\
\text { responsable? }\end{array}$ & Todo los activos de la empresa \\
\hline $\begin{array}{l}\text { ¿Qué otras características se debe poseer para } \\
\text { desarrollar apropiadamente sus funciones? }\end{array}$ & $\begin{array}{l}\text { Liderazgo } \\
\text { Comunicación }\end{array}$ \\
\hline
\end{tabular}




\section{Describiremos el puesto y las funciones del Gerente Comercial:}

\section{Tabla N 12 Diseño de puesto - Gerencia comercial}

\begin{tabular}{|l|l|}
\hline \multicolumn{2}{|l|}{ Datos del cargo } \\
\hline$\underline{\text { Cargo: }}$ Gerencia Comercial & Unidad/Sede/Área: Lima \\
\hline
\end{tabular}

\begin{tabular}{|l|l|l|}
\hline Dependencia Jerárquica & ¿Con qué puestos coordina?: & A qué puestos supervisa: (si aplica): \\
\hline ¿A qué puesto/s reporta?: & - Con las Gerencias: & \\
- Consejo Directivo & Administración, Planeamiento e & \\
& Investigación, Marketing y & \\
& Responsabilidad Social & \\
& Empresarial & \\
& & \\
\hline
\end{tabular}

Misión del puesto (objetivo de la posición. El propósito general o misión describe la contribución del puesto a la consecución de los objetivos de la empresa. Indica la razón de ser del puesto en la organización y debe responder a la pregunta: ¿Para qué está el puesto en la organización? ¿Qué resultados se esperan de él?

Coordinar las actividades relacionadas al cumplimiento de los objetivos de ventas y los planes de comercialización y marketing, a fin de maximizar beneficios de la empresa.

Funciones Enumere y describa sus funciones (inicie por la que considera su principal función). También podría aqruparlas en funciones de dirección, coordinación y operativas

1 Planificación comercial de la empresa.

2 Captación de clientes.

3 Participación en ferias nacionales e internacionales

4 Relación con los clientes, negociación de tarifas, términos y condiciones.

5 Diseñar, ejecutar y monitorear el proceso de post venta.

6 Velar por la calidad de los servicios ofrecidos de acuerdo a los estándares definidos y sistemas establecidos

7 Impulsar la apertura de nuevos mercados.

8 Gestión de quejas, reclamos y recomendaciones de nuestros clientes. Implementación de mejoras.

Toma de Decisiones Describa el límite de la autoridad conferida a su puesto indicando qué decisiones se espera que usted tome y cuáles se espera que recomiende.

Tosas las relacionadas a la realización de sus funciones.

\begin{tabular}{|l|l|}
\hline \multicolumn{2}{|l|}{$\begin{array}{l}\text { Relaciones Internas Señale con que otros puestos dentro de la empresa (otras áreas, unidades, etc.) se } \\
\text { relacionan principalmente y qué actividad realiza con dichos puestos. }\end{array}$} \\
\hline \multicolumn{1}{|c|}{ ¿Con quién? (Áreas) } & \multicolumn{1}{c|}{ Actividad } \\
\hline Administración & $\checkmark$ Coordinación logística. \\
\hline Marketing & $\begin{array}{l}\checkmark \text { Coordinación de actividades: Famtrip, Press tour, participación en } \\
\text { ferias nacionales e internacionales, manejo de redes sociales, estudios de } \\
\text { mercado, entre otros. }\end{array}$ \\
\hline
\end{tabular}




\begin{tabular}{|l|l|}
\hline \multicolumn{2}{|l|}{$\begin{array}{l}\text { Relaciones Externas Señale con que otros puestos fuera de la empresa (otras empresas, organismos } \\
\text { qubernamentales, gremios) se relacionan principalmente el puesto y qué tipo de relación mantiene. }\end{array}$} \\
\hline \multicolumn{2}{|c|}{ ¿Con quién? (Áreas) } \\
\hline \multirow{3}{*}{ Clientes } & $\checkmark$ Negociación de tarifas, términos y condiciones. \\
& $\checkmark$ Servicio post venta \\
& $\checkmark$ Atención de quejas y sugerencias \\
\hline
\end{tabular}

\begin{tabular}{|c|c|}
\hline \multicolumn{2}{|l|}{ Perfil del puesto } \\
\hline $\begin{array}{l}\text { Educación (formación, tipo de estudios universitarios o } \\
\text { técnicos) }\end{array}$ & Experiencia (años, lugares, tipo de exp) \\
\hline Administración y/o Marketing de empresas & Al menos con 5 años de experiencia \\
\hline $\begin{array}{l}\text { Competencias técnicas obligatorias (¿Qué conocimientos } \\
\text { debe poseer para desarrollar sus funciones?) } \\
\text { Incluir idiomas si es necesario para desarrollar sus } \\
\text { funciones. }\end{array}$ & Grado esperado (básico, intermedio, avanzado) \\
\hline $\begin{array}{l}\text { Entorno office y outlook } \\
\text { Inglés }\end{array}$ & $\begin{array}{l}\text { Intermedio } \\
\text { Avanzado }\end{array}$ \\
\hline $\begin{array}{c}\text { Competencias Personales (¿Qué rasgos psicológicos } \\
\text { debe poseer para desarrollar apropiadamente sus } \\
\text { funciones?) }\end{array}$ & $\begin{array}{l}\text { Competencias técnicas deseables (conocimientos } \\
\text { deseados pero no es excluyente si no lo posee) }\end{array}$ \\
\hline $\begin{array}{l}\text { Proactivo } \\
\text { Responsable } \\
\text { Empatía } \\
\text { Trabajo en equipo }\end{array}$ & Idiomas \\
\hline
\end{tabular}

\begin{tabular}{|l|l|}
\hline \multicolumn{2}{|l|}{ Condiciones adicionales del puesto } \\
\hline ¿En qué horario trabaja? & L-V 9:00 am a 7:00 pm con 1 hora de refrigerio \\
\hline Condiciones adicionales del puesto \\
\hline $\begin{array}{l}\text { Tiene dinero a su cargo, ¿de qué materiales, bienes } \\
\text { muebles e inmuebles, equipo, actividades y trámites es } \\
\text { responsable? }\end{array}$ & Dinero para el cumplimiento del plan de ventas \\
\hline $\begin{array}{l}\text { ¿Qué otras características se debe poseer para } \\
\text { desarrollar apropiadamente sus funciones? }\end{array}$ & $\begin{array}{l}\text { Liderazgo } \\
\text { Comunicación } \\
\text { Empatía }\end{array}$ \\
\hline
\end{tabular}

Describiremos el puesto y las funciones del Gerente de Marketing y Responsabilidad Social Empresarial:

Tabla $N^{\circ} 13$ Diseño de puesto - Gerencia de marketing y RSE

\begin{tabular}{|c|c|c|c|}
\hline \multicolumn{4}{|l|}{ Datos del cargo } \\
\hline \multicolumn{2}{|c|}{ Cargo: Gerencia de Marketing y RSE } & \multicolumn{2}{|c|}{ Unidad / Sede/Área: Lima } \\
\hline \multicolumn{4}{|l|}{ Dependencia Jerárquica } \\
\hline $\begin{array}{l}\text { ¿A qué puesto/s reporta?: } \\
\text { - Consejo Directivo }\end{array}$ & \multicolumn{2}{|c|}{$\begin{array}{l}\text { ¿Con qué puestos coordina?: } \\
\text { - Con las Gerencias: } \\
\text { Administración, Planeamiento e } \\
\text { Investigación, Comercial }\end{array}$} & A qué puestos supervisa: (si aplica) \\
\hline
\end{tabular}

Misión del puesto (objetivo de la posición. El propósito general o misión describe la contribución del puesto a la consecución de los objetivos de la empresa. Indica la razón de ser del puesto en la organización y debe responder a la pregunta: ¿Para qué está el puesto en la organización? ¿Qué resultados se esperan de él?

Generar, desarrollar e implementar estrategias de marketing a corto y largo plazo con el objetivo de maximizar los beneficios de la empresa y conseguir el posicionamiento deseado en el mercado.

Funciones Enumere y describa sus funciones (inicie por la que considera su principal función). También podría agruparlas en funciones de dirección, coordinación y operativas.

1 Diseño ejecución y seguimiento del Plan de Marketing

2 Análisis de indicadores y datos estadísticos de los perfiles de clientes en el mercado.

3 Desarrollo de campañas estratégicas de promoción y comunicación, incluyendo los medios digitales.

4 Investigación de nuevos mercados o segmentos

5 Inteligencia competitiva: Analizar los valores competitivos de la empresa, establecer la estrategia de

diferenciación frente a nuestra competencia. Incluir los análisis de precios.

6 Desarrollar y definir la marca: Logotipo, artefactos, etc.

7 Analizar los canales de distribución.

8 Desarrollar acciones de RSE cumpliendo los principios de desarrollo sostenible

9 Relación con comunidades locales cercanas a nuestro albergue. 
Toma de Decisiones Describa el límite de la autoridad conferida a su puesto indicando qué decisiones se espera que usted tome y cuáles se espera que recomiende.

Tosas las relacionadas a la realización de sus funciones.

\begin{tabular}{|l|l|}
\hline \multicolumn{2}{|l|}{$\begin{array}{l}\text { Relaciones Internas Señale con que otros puestos dentro de la empresa (otras áreas, unidades, etc.) se } \\
\text { relacionan principalmente y qué actividad realiza con dichos puestos. }\end{array}$} \\
\hline \multicolumn{1}{|c|}{ ¿Con quién? (Áreas) } & \multicolumn{1}{c|}{ Actividad } \\
\hline Administración & $\begin{array}{l}\checkmark \text { Pagos relacionados a las actividades de marketing. Por ejemplo, } \\
\text { pagos de derecho de participación en ferias. }\end{array}$ \\
\hline Comercial & $\begin{array}{l}\checkmark \text { Coordinación de actividades: Famtrip, Press tour, participación en } \\
\text { ferias nacionales e internacionales, manejo de redes sociales, estudios de } \\
\text { mercado, entre otros. }\end{array}$ \\
\hline Planeamiento e Investigación: & $\begin{array}{l}\checkmark \text { Relacionados a los programas científicos y la difusión de los } \\
\text { resultados. }\end{array}$ \\
\hline
\end{tabular}

Relaciones Externas Señale con que otros puestos fuera de la empresa (otras empresas, organismos gubernamentales, gremios) se relacionan principalmente el puesto y qué tipo de relación mantiene.

\begin{tabular}{|l|l|}
\hline \multicolumn{1}{|c|}{ ¿Con quién? (Áreas) } & \multicolumn{1}{c|}{ Actividad } \\
\hline Proveedores relacionados a las & $\checkmark$ Agencias publicitarias \\
actividades del Plan de Marketing & $\checkmark$ Asesoría digital \\
\hline \multirow{2}{*}{ Comunidades } & $\checkmark$ Proveedores de merchandising \\
\hline \multirow{2}{*}{ Entidades Gubernamentales } & $\checkmark$ Coordinación de festividades, entrega de presentes, elaboración de \\
& proyectos productivos, entre otros. \\
\hline
\end{tabular}

\begin{tabular}{|c|c|}
\hline \multicolumn{2}{|l|}{ Perfil del puesto } \\
\hline $\begin{array}{c}\text { Educación (formación, tipo de estudios universitarios o } \\
\text { técnicos) }\end{array}$ & Experiencia (años, lugares, tipo de exp) \\
\hline Administración y/o Marketing de empresas & Al menos con 5 años de experiencia \\
\hline $\begin{array}{l}\text { Competencias técnicas obligatorias (¿Qué conocimientos } \\
\text { debe poseer para desarrollar sus funciones?) } \\
\text { Incluir idiomas si es necesario para desarrollar sus } \\
\text { funciones. }\end{array}$ & Grado esperado (básico, intermedio, avanzado) \\
\hline $\begin{array}{l}\text { Entorno office y outlook } \\
\text { Inglés }\end{array}$ & $\begin{array}{l}\text { Intermedio } \\
\text { Avanzado }\end{array}$ \\
\hline $\begin{array}{l}\text { Competencias Personales (¿Qué rasgos psicológicos } \\
\text { debe poseer para desarrollar apropiadamente sus } \\
\text { funciones?) }\end{array}$ & $\begin{array}{l}\text { Competencias técnicas deseables (conocimientos } \\
\text { deseados pero no es excluyente si no lo posee) }\end{array}$ \\
\hline $\begin{array}{l}\text { Proactivo } \\
\text { Responsable } \\
\text { Empatía } \\
\text { Trabajo en equipo }\end{array}$ & $\begin{array}{l}\text { Idiomas } \\
\text { Marketing Digital } \\
\text { Relaciones Públicas }\end{array}$ \\
\hline
\end{tabular}

\begin{tabular}{|c|c|}
\hline \multicolumn{2}{|l|}{ Condiciones adicionales del puesto } \\
\hline ¿En qué horario trabaja? & L-V 9:00 am a 7:00 pm con 1 hora de refrigerio \\
\hline \multicolumn{2}{|l|}{ Condiciones adicionales del puesto } \\
\hline $\begin{array}{l}\text { Tiene dinero a su cargo, ¿de qué materiales, bienes } \\
\text { muebles e inmuebles, equipo, actividades y trámites es } \\
\text { responsable? }\end{array}$ & $\begin{array}{l}\text { Dinero para el cumplimiento del plan de } \\
\text { marketing }\end{array}$ \\
\hline $\begin{array}{l}\text { ¿Qué otras características se debe poseer para } \\
\text { desarrollar apropiadamente sus funciones? }\end{array}$ & $\begin{array}{l}\text { Liderazgo } \\
\text { Comunicación } \\
\text { Creatividad } \\
\text { Empatía }\end{array}$ \\
\hline
\end{tabular}


Describiremos el puesto y las funciones del Gerente de Planeamiento e Investigación:

Tabla N 14 Diseño de puesto - Gerencia de Planeamiento e Investigación

\begin{tabular}{|l|l|}
\hline \multicolumn{2}{|l|}{ Datos del cargo } \\
\hline Cargo: Gerente de Planeamiento e Investigación & Unidad / Sede/ Área: Lima \\
\hline
\end{tabular}

\begin{tabular}{|l|l|l|}
\hline \multicolumn{2}{|l|}{ Dependencia Jerárquica } \\
\hline $\begin{array}{l}\text { A qué puesto/s reporta?: } \\
\text {-Consejo Directivo }\end{array}$ & $\begin{array}{l}\text { Con qué puestos coordina?: } \\
\text { - Con las Gerencias: Administración, } \\
\text { Marketing y RSE, Comercial }\end{array}$ & \begin{tabular}{l} 
A qué puestos supervisa: (si \\
\hline
\end{tabular} \\
\hline
\end{tabular}

Misión del puesto (objetivo de la posición. El propósito general o misión describe la contribución del puesto a la consecución de los objetivos de la empresa. Indica la razón de ser del puesto en la organización y debe responder a la pregunta: ¿Para qué está el puesto en la organización? ¿Qué resultados se esperan de él?

Generar, desarrollar e implementar proyectos de cooperación técnica con el objetivo de ejecutar permanentemente programas de investigación científica, innovación, conservación del medio ambiente y otras con las comunidades aledañas a nuestro albergue.

\begin{tabular}{|c|l|}
\hline \multicolumn{2}{|l|}{$\begin{array}{l}\text { Funciones Enumere y describa sus funciones (inicie por la que considera su principal función). También podría } \\
\text { agruparlas en funciones de dirección, coordinación y operativas. }\end{array}$} \\
\hline 1 & Identificar y presentar proyectos relacionados a la filosofía y objetivos de la empresa. \\
\hline 2 & $\begin{array}{l}\text { Realizar el diseño, implementación y monitoreo de proyectos relacionados a mejorar los procesos, RSE e } \\
\text { investigación científica. }\end{array}$ \\
\hline 3 & $\begin{array}{l}\text { Supervisar la gestión de los programas y proyectos que son realizados directamente o en alianza con otras } \\
\text { instituciones. }\end{array}$ \\
\hline 4 & $\begin{array}{l}\text { Buscar fuentes cooperantes de financiamiento para los proyectos de innovación, calidad, productivos, investigación } \\
\text { científica y RSE. }\end{array}$ \\
\hline 5 & $\begin{array}{l}\text { Elaborar los informes técnicos correspondientes, los que pueden servir de material importante para las gerencias de } \\
\text { marketing y comercial. }\end{array}$ \\
\hline 6 & $\begin{array}{l}\text { Representar a la empresa en reuniones con otras instituciones, ya sean públicas, privadas, académicas o } \\
\text { internacionales. }\end{array}$ \\
\hline 7 & Gestión de alianzas estratégicas con instituciones que tengan el mismo interés y visión de desarrollo sostenible. \\
\hline
\end{tabular}

Toma de Decisiones Describa el límite de la autoridad conferida a su puesto indicando qué decisiones se espera que usted tome y cuáles se espera que recomiende.

Solo las relacionadas a la realización de sus funciones.

Relaciones Internas Señale con que otros puestos dentro de la empresa (otras áreas, unidades, etc.) se relacionan principalmente y qué actividad realiza con dichos puestos.

\begin{tabular}{|l|l|}
\hline \multicolumn{1}{|c|}{ ¿Con quién? (Áreas) } & \multicolumn{1}{c|}{ Actividad } \\
\hline Administración & $\begin{array}{l}\checkmark \text { Rendiciones relacionadas a las actividades de proyectos con cooperación } \\
\text { técnica. Por ejemplo, los fondos otorgados por un cooperante. }\end{array}$ \\
\hline Comercial & $\checkmark$ Compartir información relevante. \\
\hline Marketing: & $\begin{array}{l}\checkmark \text { Relacionados a los programas científicos y la difusión de resultados de los } \\
\text { proyectos. }\end{array}$ \\
\hline
\end{tabular}

Relaciones Externas Señale con que otros puestos fuera de la empresa (otras empresas, organismos gubernamentales, gremios) se relacionan principalmente el puesto y qué tipo de relación mantiene.

\begin{tabular}{|l|l|}
\hline \multicolumn{1}{|c|}{ ¿Con quién? (Áreas) } & \multicolumn{1}{c|}{ Actividad } \\
\hline $\begin{array}{l}\text { Investigadores científicos } \\
\text { (Ornitólogos por ejemplo) }\end{array}$ & $\checkmark$ Planificación y ejecución de los programas de investigación. \\
\hline Comunidades & $\checkmark$ Coordinación de potencialidades, nuevos negocios, inclusión en la cadena de \\
\hline & valor. \\
\hline & $\checkmark$ Ministerios (Comercio Exterior, Turismo. Producción, Ambiente, etc.) \\
otras instituciones & $\checkmark$ Sector académico (Universidades, ejemplo: La Agraria) \\
& $\checkmark$ Otras empresas privadas: Con intereses comunes. \\
\hline
\end{tabular}




\begin{tabular}{|c|c|}
\hline \multicolumn{2}{|l|}{ Perfil del puesto } \\
\hline $\begin{array}{c}\text { Educación (formación, tipo de estudios universitarios o } \\
\text { técnicos) }\end{array}$ & Experiencia (años, lugares, tipo de exp) \\
\hline Administración y/o Marketing de empresas & Al menos con 5 años de experiencia \\
\hline $\begin{array}{l}\text { Competencias técnicas obligatorias (¿Qué conocimientos } \\
\text { debe poseer para desarrollar sus funciones?) } \\
\text { Incluir idiomas si es necesario para desarrollar sus } \\
\text { funciones. }\end{array}$ & Grado esperado (básico, intermedio, avanzado) \\
\hline $\begin{array}{l}\text { Entorno office y outlook } \\
\text { Inglés }\end{array}$ & $\begin{array}{l}\text { Intermedio } \\
\text { Intermedio }\end{array}$ \\
\hline $\begin{array}{c}\text { Competencias Personales (¿Qué rasgos psicológicos } \\
\text { debe poseer para desarrollar apropiadamente sus } \\
\text { funciones?) }\end{array}$ & $\begin{array}{l}\text { Competencias técnicas deseables (conocimientos deseados } \\
\text { pero no es excluyente si no lo posee) }\end{array}$ \\
\hline $\begin{array}{l}\text { Proactivo } \\
\text { Capacidad de planificación y desarrollo } \\
\text { Trabajo en equipo } \\
\text { Responsable } \\
\text { Empatía } \\
\text { Buenas relaciones interpersonales }\end{array}$ & Gestión de proyectos \\
\hline
\end{tabular}

\begin{tabular}{|l|l|}
\hline \multicolumn{2}{|l|}{ Condiciones adicionales del puesto } \\
\hline ¿En qué horario trabaja? & L-V 9:00 am a 7:00 pm con 1 hora de refrigerio \\
\hline \multicolumn{2}{|l|}{ Condiciones adicionales del puesto } \\
\hline $\begin{array}{l}\text { Tiene dinero a su cargo, ¿de qué materiales, bienes } \\
\text { muebles e inmuebles, equipo, actividades y trámites es } \\
\text { responsable? }\end{array}$ & $\begin{array}{l}\text { Dinero relacionado a la ejecución de proyectos de } \\
\text { cooperación con otras instituciones. }\end{array}$ \\
\hline $\begin{array}{l}\text { ¿Qué otras características se debe poseer para } \\
\text { desarrollar apropiadamente sus funciones? }\end{array}$ & $\begin{array}{l}\text { Liderazgo } \\
\text { Comunicación } \\
\text { Creatividad } \\
\text { Empatía }\end{array}$ \\
\hline
\end{tabular}

\section{Describiremos el puesto y las funciones del Administrador del Albergue:}

Tabla $\mathrm{N}^{\circ} 15$ Diseño de puesto - Administrador de albergue

\begin{tabular}{|l|l|}
\hline \multicolumn{2}{|l|}{ Datos del cargo } \\
\hline Cargo: Administrador de albergue & Unidad / Sede/ Área: Madre de Dios \\
\hline
\end{tabular}

\begin{tabular}{|c|c|c|}
\hline \multicolumn{3}{|l|}{ Dependencia Jerárquica } \\
\hline $\begin{array}{l}\text { ¿A qué puesto/s reporta?: } \\
\text { - Gerente administrativo }\end{array}$ & $\begin{array}{l}\text { ¿Con qué puestos coordina?: } \\
\text { - Con las Gerencias: Comercial, } \\
\text { Planeamiento e Investigación, } \\
\text { Marketing y Responsabilidad } \\
\text { Social Empresarial }\end{array}$ & $\begin{array}{l}\text { A qué puestos supervisa: (si aplica): } \\
\text { - } \quad \text { Cocinero y guías locales }\end{array}$ \\
\hline
\end{tabular}

Misión del puesto (objetivo de la posición. El propósito general o misión describe la contribución del puesto a la consecución de los objetivos de la empresa. Indica la razón de ser del puesto en la organización y debe responder a la pregunta: ¿Para qué está el puesto en la organización? ¿Qué resultados se esperan de él?

Administración general del albergue, velar por la satisfacción del turista. 


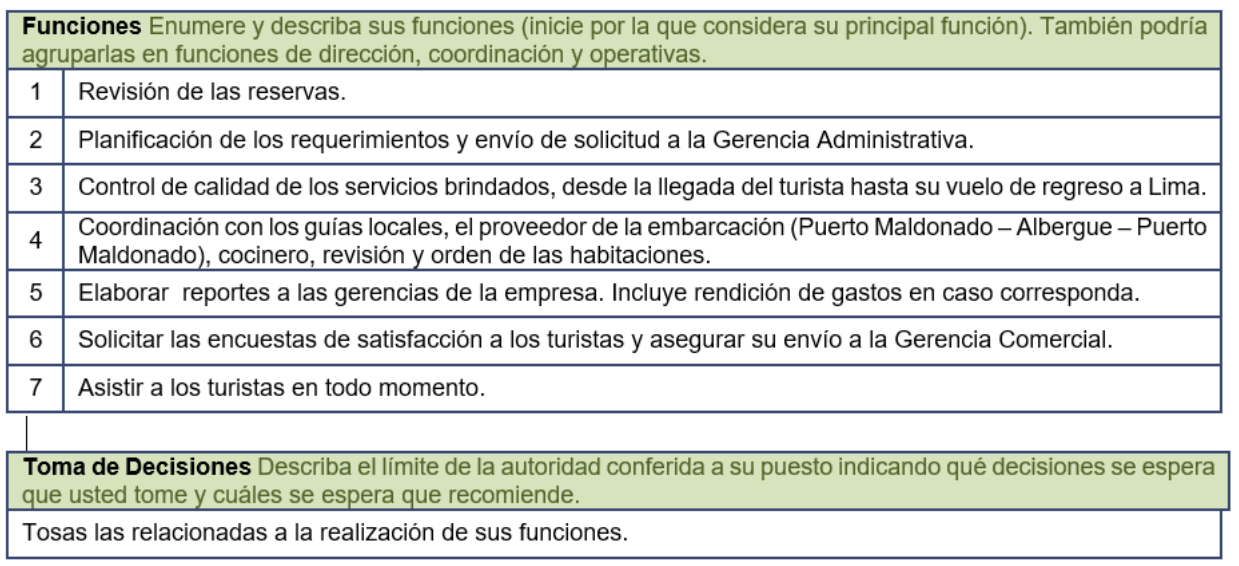

Toma de Decisiones Describa el límite de la autoridad conferida a su puesto indicando qué decisiones se espera que usted tome y cuáles se espera que recomiende.

Tosas las relacionadas a la realización de sus funciones.

\begin{tabular}{|l|l|}
\hline \multicolumn{2}{|l|}{$\begin{array}{l}\text { Relaciones Internas Señale con que otros puestos dentro de la empresa (otras áreas, unidades, etc.) se } \\
\text { relacionan principalmente y qué actividad realiza con dichos puestos. }\end{array}$} \\
\hline \multicolumn{1}{|c|}{ ¿Con quién? (Áreas) } & \multicolumn{1}{c|}{ Actividad } \\
\hline Comercial & $\begin{array}{l}\checkmark \text { Coordinación sobre la calidad de los servicios, atención de reclamos, } \\
\text { sugerencias y encuestas de satisfacción }\end{array}$ \\
\hline Guias locales & $\begin{array}{l}\checkmark \text { Coordinaciones sobre las reservas, trochas, excursiones, perfil de } \\
\text { viajeros, etc. }\end{array}$ \\
\hline
\end{tabular}

Relaciones Externas Señale con que otros puestos fuera de la empresa (otras empresas, organismos gubernamentales, gremios) se relacionan principalmente el puesto y qué tipo de relación mantiene.

\begin{tabular}{|c|c|}
\hline ¿Con quién? (Áreas) & Actividad \\
\hline Proveedores & $\begin{array}{ll}\checkmark & \text { Traslado de los turistas desde la ciudad hasta el albergue. } \\
\checkmark & \text { Compras locales }\end{array}$ \\
\hline
\end{tabular}

\begin{tabular}{|c|c|}
\hline \multicolumn{2}{|l|}{ Perfil del puesto } \\
\hline $\begin{array}{l}\text { Educación (formación, tipo de estudios universitarios o } \\
\text { técnicos) }\end{array}$ & Experiencia (años, lugares, tipo de exp) \\
\hline $\begin{array}{l}\text { Administración y/o Marketing de empresas. } \\
\text { Administración Turística - Hotelería }\end{array}$ & Al menos con 5 años de experiencia \\
\hline $\begin{array}{l}\text { Competencias técnicas obligatorias (¿Qué conocimientos } \\
\text { debe poseer para desarrollar sus funciones?) } \\
\text { Incluir idiomas si es necesario para desarrollar sus } \\
\text { funciones. }\end{array}$ & Grado esperado (básico, intermedio, avanzado) \\
\hline $\begin{array}{l}\text { Entorno office y outlook } \\
\text { Inglés }\end{array}$ & $\begin{array}{l}\text { Intermedio } \\
\text { Avanzado }\end{array}$ \\
\hline $\begin{array}{l}\text { Competencias Personales (¿Qué rasgos psicológicos } \\
\text { debe poseer para desarrollar apropiadamente sus } \\
\text { funciones?) }\end{array}$ & $\begin{array}{l}\text { Competencias técnicas deseables (conocimientos } \\
\text { deseados pero no es excluyente si no lo posee) }\end{array}$ \\
\hline $\begin{array}{l}\text { Proactivo } \\
\text { Responsable } \\
\text { Empatía } \\
\text { Trabajo en equipo }\end{array}$ & $\begin{array}{l}\text { Atención al cliente } \\
\text { Conocimiento de hoteleria y restaurante }\end{array}$ \\
\hline
\end{tabular}

Condiciones adicionales del puesto

¿En qué horario trabaja?

De $L$ - D en el albergue de Madre de Dios. Horario completo ( 24 horas)

Sistema de francos: Ejemplo, trabaja 3 semanas seguidas y 1 semana descansa.

\section{Condiciones adicionales del puesto}

Tiene dinero a su cargo, ¿de qué materiales, bienes muebles e inmuebles, equipo, actividades y trámites es responsable?

¿Qué otras características se debe poseer para desarrollar apropiadamente sus funciones?

Activos del albergue

Maneja dinero (caja chica) para las operaciones del albergue.

Liderazgo

Comunicación 
Describiremos el puesto y las funciones de los guías en el albergue:

Tabla $\mathrm{N}^{\circ} 16$ Diseño de puesto - Guía especializado de aves

Datos del cargo

Cargo: Guia especializado en aves

Unidad / Sede/ Área: Madre de Dios

\begin{tabular}{|c|c|c|}
\hline \multicolumn{3}{|l|}{ Dependencia Jerárquica } \\
\hline $\begin{array}{l}\text { ¿A qué puesto/s reporta?: } \\
\text { - Administrador del albergue }\end{array}$ & $\begin{array}{l}\text { ¿Con qué puestos coordina?: } \\
\text { - Con las Gerencias: Comercial, } \\
\text { Planeamiento e Investigación, } \\
\text { Marketing y Responsabilidad } \\
\text { Social Empresarial }\end{array}$ & A qué puestos supervisa: (si aplica): \\
\hline
\end{tabular}

Misión del puesto (objetivo de la posición. El propósito general o misión describe la contribución del puesto a la consecución de los objetivos de la empresa. Indica la razón de ser del puesto en la organización y debe responder a la pregunta: ¿Para qué está el puesto en la organización? ¿Qué resultados se esperan de él?

Guiado y asistencia al turista que se hospeda en el albergue.

Funciones Enumere y describa sus funciones (inicie por la que considera su principal función). También podría agruparlas en funciones de dirección, coordinación y operativas.

1 Revisión de las reservas y coordinación con el administrador del albergue.

2 Planificación de las excursiones de acuerdo al requerimiento del turista.

3 Cumplir con los procedimientos establecidos.

4 Asistir a los turistas en todo momento. Iniciando los servicios de guiado a la recepción del turista en el aeropuerto de Puerto Maldonado.

5 Informar al administrador del albergue cualquier inquietud, queja, reclamo y/ o sugerencia del turista

6 Coordinar con las gerencias de la empresa.

Toma de Decisiones Describa el límite de la autoridad conferida a su puesto indicando qué decisiones se espera que usted tome y cuáles se espera que recomiende.

Tosas las relacionadas a la realización de sus funciones.

Relaciones Internas Señale con que otros puestos dentro de la empresa (otras áreas, unidades, etc.) se relacionan principalmente y qué actividad realiza con dichos puestos.

\begin{tabular}{|c|c|}
\hline ¿Con quién? (Áreas) & Actividad \\
\hline Administrador del albergue & $\begin{array}{l}\checkmark \text { Coordinación sobre las reservas, la calidad de los servicios, atención } \\
\text { de reclamos y sugerencias. }\end{array}$ \\
\hline
\end{tabular}

Relaciones Externas Señale con que otros puestos fuera de la empresa (otras empresas, organismos gubernamentales, gremios) se relacionan principalmente el puesto y qué tipo de relación mantiene.

\begin{tabular}{|l|c|}
\hline \multicolumn{1}{|c|}{ ¿Con quién? (Áreas) } & Actividad \\
\hline Proveedores & $\checkmark \quad$ Traslado de los turistas desde la ciudad hasta el albergue.
\end{tabular}




\begin{tabular}{|c|c|}
\hline \multicolumn{2}{|l|}{ Perfil del puesto } \\
\hline $\begin{array}{c}\text { Educación (formación, tipo de estudios universitarios o } \\
\text { técnicos) }\end{array}$ & Experiencia (años, lugares, tipo de exp) \\
\hline $\begin{array}{l}\text { Administración Turística - Hotelería (Nivel técnico) } \\
\text { Ornitología }\end{array}$ & Al menos con 10 años de experiencia \\
\hline $\begin{array}{l}\text { Competencias técnicas obligatorias (¿Qué conocimientos } \\
\text { debe poseer para desarrollar sus funciones?) } \\
\text { Incluir idiomas si es necesario para desarrollar sus } \\
\text { funciones. }\end{array}$ & Grado esperado (básico, intermedio, avanzado) \\
\hline $\begin{array}{l}\text { Ornitología } \\
\text { Inglés }\end{array}$ & $\begin{array}{l}\text { Avanzado } \\
\text { Avanzado }\end{array}$ \\
\hline $\begin{array}{c}\text { Competencias Personales (¿Qué rasgos psicológicos } \\
\text { debe poseer para desarrollar apropiadamente sus } \\
\text { funciones?) }\end{array}$ & $\begin{array}{l}\text { Competencias técnicas deseables (conocimientos } \\
\text { deseados pero no es excluyente si no lo posee) }\end{array}$ \\
\hline $\begin{array}{l}\text { Proactivo } \\
\text { Responsable } \\
\text { Empatía } \\
\text { Trabajo en equipo }\end{array}$ & $\begin{array}{l}\text { Atención al cliente } \\
\text { Primeros auxilios }\end{array}$ \\
\hline
\end{tabular}

\begin{tabular}{|l|l|}
\hline \multicolumn{2}{|l|}{ Condiciones adicionales del puesto } \\
\hline ¿En qué horario trabaja? & $\begin{array}{l}\text { De L - D en el albergue de Madre de Dios. Horario } \\
\text { completo (24 horas). } \\
\text { Sistema de francos: Ejemplo, trabaja 3 semanas } \\
\text { seguidas y 1 semana descansa. }\end{array}$ \\
\hline Condiciones adicionales del puesto & \begin{tabular}{l} 
No aplica \\
\hline $\begin{array}{l}\text { Tiene dinero a su cargo, ¿de qué materiales, bienes } \\
\text { muebles e inmuebles, equipo, actividades y trámites es } \\
\text { responsable? }\end{array}$
\end{tabular} \\
\hline $\begin{array}{l}\text { ¿Qué otras características se debe poseer para } \\
\text { desarrollar apropiadamente sus funciones? }\end{array}$ & $\begin{array}{l}\text { Liderazgo } \\
\text { Comunicación }\end{array}$ \\
\hline
\end{tabular}

\section{Políticas Organizacionales}

Las políticas organizacionales deben ser conocidas por todos los colaboradores para mantener un orden dentro de la empresa:

- Enfoque en el servicio: brindar un servicio de excelencia para lograr la fidelización de nuestros clientes.

- Enfoque en el medio ambiente: ser respetuosos de los espacios naturales, así como también de la flora y fauna. Mantener una postura eco amigable en todas las áreas de trabajo.

- Enfoque en la investigación: es una actividad clave al ser lo que valida nuestro valor diferencial que son las aves.

- Cliente interno: el trato debe ser cordial y respetuoso entre colaboradores, de la empresa hacia ellos y viceversa.

- Ética: el comportamiento y las acciones de los colaboradores deben basarse en los valores de la empresa, ya que, son parte de la imagen de la misma. 


\section{Gestión Humana}

\section{Reclutamiento}

Al ser una sociedad recién formada, asignaremos a la junta de accionistas las posiciones administrativas. Por otro lado, para las posiciones operativas se contratará personal externo por medio de reclutamientos que realizaremos mediante publicaciones en diversas páginas de empleos como: Bumeran, Laborum y CompuTrabajo.

Al saber que nuestra cede se encuentra en Tambopata, centralizaremos la búsqueda del personal que viva en la misma ciudad o en todo caso de otras ciudades que estén dispuestos a viajar.

\section{Selección, contratación e inducción}

Para iniciar el proceso de selección del personal operativo cada jefatura se encargará de la revisión de los $\mathrm{CV}$ aplicando los filtros necesarios para que cuadre con el perfil necesario, una vez seleccionados a los candidatos pasarán por diversas evaluaciones necesarias para saber si están aptos para el puesto, estas pruebas serían de conocimientos básicos como también de una prueba psicotécnica, dinámicas para el desenvolvimiento y actitud (role-play), finalizando con una entrevista final con su futuro jefe.

Cuando la jefatura de cada área apruebe a él o los candidatos para los puestos solicitados, se realizará la contratación y para ello se solicitará algunos documentos que serán utilizados para la creación del expediente del empleado:

- Antecedentes Policiales.

- Antecedentes Penales.

- Certificado de estudios.

- Certificado de anteriores trabajos.

- Otros de ser necesarios.

Asimismo, cada candidato tendrá que llenar un formulario general de hoja de vida para mantener la uniformidad de la información.

Todo trabajador contará con un contrato de ingreso con plazo indeterminado, manteniendo un periodo de prueba de 3 meses de acuerdo con la ley.

Las inducciones se realizarán de manera independiente con cada jefatura durante la primera semana, se encargarán de enseñarles las políticas internas, el código de conducta y se organizará 
una charla para todos los nuevos trabajadores donde conocerán los beneficios que le ofrecerá Aperbird.

\section{Capacitación, desarrollo y evaluación del desempeño}

Al contar con un grupo pequeño de trabajadores se requerirá contratar personal con experiencia en el rubro y posición que cubrirán. Cada jefe revisará con cada empleado algunos temas informativos necesarios para el puesto al que están destinados, funciones, el uso de herramientas, entre otros aspectos.

Al ser una organización pequeña, en un principio no se podrá ofrecer oportunidades de crecimiento interno al personal operativo.

En los primeros 2 años de operaciones, realizaremos evaluaciones de desempeños cada semestre, con el fin de identificar las fortalezas y oportunidades para la mejora de cada trabajador. Dichas evaluaciones serán $360^{\circ}$, cada jefe se encargará de evaluar al personal que tiene a cargo y ellos también entregarán una evaluación a sus jefes generando un compromiso por ambas partes, finalmente se entregará un promedio final.

\section{Motivación}

Parte de nuestro trabajo es mantener un buen servicio y atención a nuestros clientes estando siempre a disposición de lo que necesiten y ayudarlos en lo que podamos. Debemos resaltar lo importante que será la relación y confianza entre el grupo de trabajadores para asegurar la mejor calidad de sus actividades tanto internas como con los clientes. Realizaremos charlas y talleres de motivación para mantener un buen clima y buena actitud resaltando la importancia del servicio.

Día de cumpleaños: permite que los colaboradores celebren su cumpleaños con un día libre el cual podrán escoger dentro del mes de su onomástico tomando en cuenta que este no puede cruzarse con otro día solicitado por otro trabajador.

\section{Sistema de remuneración}

APERBIRD tiene en total 10 trabajadores de los cuales, 4 son socios accionistas y desarrollan puestos gerenciales y 6 son trabajadores operativos (1 recepcionista, 1 chef de cocina. 1 waitress, 1 housekeeping, 2 guías). Todos estarán registrados en planilla recibiendo los beneficios de ley. El pago es un sueldo fijo que se acordará con cada persona, y se realizará de forma mensual con depósito en la cuenta bancaria de cada trabajador. 
A continuación, veremos en el presupuesto la planilla de los empleados

Tabla $N^{\circ} 17$ Presupuesto de recursos humanos

\begin{tabular}{|c|c|c|c|c|c|c|c|c|c|c|c|c|}
\hline \multirow[b]{2}{*}{$\begin{array}{c}\text { Unidad de } \\
\text { negocio }\end{array}$} & \multirow[b]{2}{*}{ Denominación } & \multirow[b]{2}{*}{ Concepto } & \multicolumn{2}{|l|}{ Enero } & \multicolumn{2}{|c|}{ Febrero } & \multicolumn{2}{|c|}{ Marzo } & \multicolumn{2}{|l|}{ Abril } & \multicolumn{2}{|l|}{ Mayo } \\
\hline & & & Ppto. & Real & Ppto. & Real & Ppto. & Real & Ppto. & Real & Ppto. & Real \\
\hline \multirow{10}{*}{ Corporativo } & \multirow{6}{*}{ Planilla } & Guias especialistas (2) & $2,616.00$ & & S/. $2,616.00$ & & S/. $2,616.00$ & & S/. $2,616.00$ & & S/. $3,816.00$ & \\
\hline & & Chef de cocina (1) & $2,180.00$ & & S/. $2,180.00$ & & S/. $2,180.00$ & & S/. $2,180.00$ & & $3,180.00$ & \\
\hline & & Waitress/Ayudante de cocina (1) & $1,090.00$ & & S/. $1,090.00$ & & S/. $1,090.00$ & & S/. $1,090.00$ & & $1,590.00$ & \\
\hline & & Recepcionista (1) & $1,308.00$ & & S/. $\quad 1,308.00$ & & S/. $1,308.00$ & & S/. $\quad 1,308.00$ & & $1,908.00$ & \\
\hline & & Housekeepng (1) & $1,090.00$ & & \begin{tabular}{ll|} 
S/. & $1,090.00$ \\
\end{tabular} & & S/. $1,090.00$ & & \begin{tabular}{ll|}
$\mathrm{S} /$. & $1,090.00$ \\
\end{tabular} & & $1,590.00$ & \\
\hline & & Socios accionistas (4) & \begin{tabular}{lr|} 
S/. & $10,355.00$ \\
\end{tabular} & & S/. $10,355.00$ & & S/. $10,355.00$ & & S/. $10,355.00$ & & \begin{tabular}{lr|} 
S/. & $15,105.00$ \\
\end{tabular} & \\
\hline & Uniformes & $\begin{array}{c}\text { Uniforme por estación (verano/ } \\
\text { invierno) }\end{array}$ & & & & & & & & & S/. $\quad 1,920.00$ & \\
\hline & Incentivos & $\begin{array}{c}\text { Por excelencia de servicio } \\
\text { (semestrales) }\end{array}$ & & & & & & & & & & \\
\hline & \multirow{2}{*}{ Capacitaciones } & Ecoambientalistas (Trimestral) & $1,200.00$ & & & & & & S/. $1,200.00$ & & & \\
\hline & & Habilidades blandas (Trimestral) & 400.00 & & & & & & S/. 400.00 & & & \\
\hline \multicolumn{3}{|c|}{ TOTAL } & S/. $20,239.00$ & & S/. $18,639.00$ & & S/. $18,639.00$ & & S/. $20,239.00$ & & S/. $29,109.00$ & \\
\hline
\end{tabular}

\begin{tabular}{|c|c|c|c|c|c|c|c|c|c|c|c|c|c|}
\hline \multicolumn{2}{|l|}{ Junio } & \multicolumn{2}{|l|}{ Julio } & \multicolumn{2}{|c|}{ Agosto } & \multicolumn{2}{|c|}{ Setiembre } & \multicolumn{2}{|c|}{ Octubre } & \multicolumn{2}{|c|}{ Noviembre } & \multicolumn{2}{|c|}{ Diciembre } \\
\hline Ppto. & Real & Ppto. & Real & Ppto. & Real & Ppto. & Real & Ppto. & Real & Ppto. & Real & Ppto. & Real \\
\hline S/. $2,616.00$ & & S/. $\quad 5,016.00$ & & S/. $\quad 2,616.00$ & & S/. $2,616.00$ & & S/. $2,616.00$ & & S/. $\quad 3,816.00$ & & $5,016.00$ & \\
\hline S/. $\quad 2,180.00$ & & $\begin{array}{ll}\text { S/. } & 4,180.00 \\
\end{array}$ & & S/. $\quad 2,180.00$ & & S/. $2,180.00$ & & $\begin{array}{ll}\text { S/. } & 2,180.00 \\
\end{array}$ & & S/. $\quad 3,180.00$ & & $4,180.00$ & \\
\hline $\begin{array}{ll}\text { S/. } & 1,090.00\end{array}$ & & S/. $\quad 2,090.00$ & & S/. $\quad 1,090.00$ & & $\begin{array}{ll}\text { S/. } & 1,090.00\end{array}$ & & $\begin{array}{ll}\text { S/. } & 1,090.00\end{array}$ & & S/. $1,590.00$ & & $2,090.00$ & \\
\hline S/. $1,308.00$ & & S/. $\quad 2,508.00$ & & S/. $\quad 1,308.00$ & & S/. $\quad 1,308.00$ & & S/. $\quad 1,308.00$ & & S/. $\quad 1,908.00$ & & $2,508.00$ & \\
\hline S/. $\quad 1,090.00$ & & S/. $\quad 2,090.00$ & & S/. $\quad 1,090.00$ & & S/. $1,090.00$ & & S/. $\quad 1,090.00$ & & S/. $\quad 1,590.00$ & & $2,090.00$ & \\
\hline S/. $10,355.00$ & & S/. $19,855.00$ & & S/. $10,355.00$ & & S/. $10,355.00$ & & S/. $10,355.00$ & & S/. $15,105.00$ & & $19,855.00$ & \\
\hline & & & & & & & & & & & & $1,920.00$ & \\
\hline S/. $\quad 500.00$ & & & & & & & & & & & & 500.00 & \\
\hline & & S/. $1,200.00$ & & & & & & S/. $1,200.00$ & & & & & \\
\hline & & $\begin{array}{ll}\text { S/. } & 400.00\end{array}$ & & & & & & $\begin{array}{ll}\text { S/. } & 400.00\end{array}$ & & & & & \\
\hline S/. $19,139.00$ & & S/. $37,339.00$ & & S/. $18,639.00$ & & S/. $18,639.00$ & & S/. $\quad 20,239.00$ & & S/. $27,189.00$ & & $38,159.00$ & \\
\hline
\end{tabular}




\section{Estructura de gastos de RRHH}

Detalle de planilla personal:

Contamos con 10 empleados en planilla, 4 socios accionista que tendrán funciones a cargo y 6 operativos. Todos cuentan con beneficios como Seguro Social que corresponde el 9\% del sueldo, CTS que se deposita dos veces por año en mayo y en noviembre que corresponde cada deposito a medio sueldo y 14 sueldos al año que comprenden 2 sueldos adicionales como gratificación en julio y diciembre.

Adjuntamos cuadro con presupuesto de planilla.

Tabla $N^{\circ} 18$ Presupuesto de planilla

\begin{tabular}{|c|c|c|c|c|c|c|c|c|}
\hline Item & Cantidad & Unitario & $\begin{array}{c}\text { Mensual } \\
\text { Total }\end{array}$ & Total Anual & Seguro Salud & CTS Anual & & $\begin{array}{l}\text { atificación } \\
\text { Anual }\end{array}$ \\
\hline Gerente de Operaciones & 1 & $\mathrm{~S} / 2,500.00$ & S/ $2,500.00$ & S/ $30,000.00$ & S/ $2,700.00$ & S/ $2,500.00$ & S/ & $5,000.00$ \\
\hline Gerente Comercial & 1 & $\mathrm{~S} / 2,500.00$ & S/ $2,500.00$ & S/ $30,000.00$ & S/ $2,700.00$ & S/ $2,500.00$ & S/ & $5,000.00$ \\
\hline Gerente de Planeamiento e Ivestigación & 1 & $\mathrm{~S} / 2,500.00$ & S/ $2,500.00$ & S/ $30,000.00$ & S/ $2,700.00$ & S/ $2,500.00$ & S/ & $5,000.00$ \\
\hline Gerente de Marketing y RSE & 1 & $\mathrm{~S} / 2,000.00$ & S/ $2,000.00$ & S/ $24,000.00$ & S/ $2,160.00$ & S/ $2,000.00$ & S/ & $4,000.00$ \\
\hline Recepcionista & 1 & $S / 1,200.00$ & S/ $1,200.00$ & S/ $14,400.00$ & S/ $1,296.00$ & S/ $1,200.00$ & S/ & $2,400.00$ \\
\hline Hous ekeeping & 1 & $\mathrm{~S} / 1,000.00$ & S/ $1,000.00$ & S/ $12,000.00$ & S/ $1,080.00$ & S/ $1,000.00$ & $\mathrm{~S} /$ & $2,000.00$ \\
\hline Chef de cocina & 1 & $\mathrm{~S} / 2,000.00$ & S/ $2,000.00$ & S/ $24,000.00$ & S/ $2,160.00$ & S/ $2,000.00$ & S/ & $4,000.00$ \\
\hline Waitress & 1 & $\mathrm{~S} / 1,000.00$ & S/ $1,000.00$ & S/ $12,000.00$ & S/ $1,080.00$ & S/ $1,000.00$ & S/ & $2,000.00$ \\
\hline Guía Local & 2 & $\mathrm{~S} / 1,200.00$ & S/ $2,400.00$ & S/ $28,800.00$ & S/ $2,592.00$ & S/ $2,400.00$ & S/ & $4,800.00$ \\
\hline TOTALES & & & $S / 17,100.00$ & $S / 205,200.00$ & $S / 18,468.00$ & $S / 17,100.00$ & s/ & $34,200.00$ \\
\hline \multicolumn{3}{|c|}{ * Los inversionistas desempeñan los puestos gerenciales. } & & & \multicolumn{2}{|c|}{ Total planilla } & \multicolumn{2}{|c|}{$S / 274,968.00$} \\
\hline
\end{tabular}




\section{Capítulo 7. Plan económico-financiero}

\section{Supuestos}

- El plan financiero presenta una proyección de cinco años.

- Los paquetes serán cancelados al momento de hacer la reserva.

- La moneda que rige la rentabilidad del proyecto es el sol.

- El tipo de cambio respecto a la moneda extranjera (USD) será de 3.30.

- El IGV es de $18 \%$

- El impuesto a la renta es $29.5 \%$.

- El financiamiento será de capital propio y financiado.

\section{Inversión en activos (fijos e intangibles) y depreciación}

Tabla $N^{\circ} 19$ Inversión en activos

\begin{tabular}{|c|c|c|c|c|c|c|c|c|}
\hline \multicolumn{7}{|c|}{ Equipamiento } & \multirow{3}{*}{\begin{tabular}{|c|} 
Depreciación \\
$10 \%$ \\
\end{tabular}} & \multirow[b]{2}{*}{ Dep. Anual } \\
\hline Muebles/ Enseres & Cantidad & $\cos$ & , Unitario & Costo sin IGV & & to Total & & \\
\hline Sofá recepción & 6 & S/. & 400.00 & 338.98 & $\mathrm{~S} /$. & $2,033.90$ & & 203.39 \\
\hline Sofá de cuarto & 10 & $\mathrm{~S} /$. & 300.00 & 254.24 & $\mathrm{~S} /$. & $2,542.37$ & $10 \%$ & 254.24 \\
\hline Sofá centro de estudio & 4 & $\mathrm{~S} /$. & 280.00 & 237.29 & $\mathrm{~S} /$. & 949.15 & $10 \%$ & 94.92 \\
\hline Escritorio grande recepción & 1 & $\mathrm{~S} /$. & 600.00 & 508.47 & $\mathrm{~S} /$. & 508.47 & $10 \%$ & 50.85 \\
\hline Escritorio pequeño oficina & 2 & $\mathrm{~S} /$. & 400.00 & 338.98 & $\mathrm{~S} /$. & 677.97 & $10 \%$ & 67.80 \\
\hline Escritorio pequeño cabaña & 10 & $\mathrm{~S} /$. & 250.00 & 211.86 & S/. & $2,118.64$ & $10 \%$ & 211.86 \\
\hline Escritorio mediano bipersonales & 6 & $\mathrm{~S} /$. & 370.00 & 313.56 & S/. & $1,881.36$ & $10 \%$ & 188.14 \\
\hline Muebles almacen comedor & 2 & $\mathrm{~S} /$. & 700.00 & 593.22 & $\mathrm{~S} /$. & $1,186.44$ & $10 \%$ & 118.64 \\
\hline Mueble tabla de comida comedor & 1 & $\mathrm{~S} /$. & 300.00 & 254.24 & $\mathrm{~S} /$. & 254.24 & $10 \%$ & 25.42 \\
\hline Vitrina fria cerrada comedor & 1 & $\mathrm{~S} /$. & $1,200.00$ & S/. $1,016.95$ & $\mathrm{~S} /$. & $1,016.95$ & $10 \%$ & 101.69 \\
\hline Cocina comedor & 2 & S/. & $1,000.00$ & 847.46 & S/. & $1,694.92$ & $10 \%$ & 169.49 \\
\hline Refrigedora Comedor & 1 & S/. & $1,400.00$ & $1,186.44$ & $\mathrm{~S} /$. & $1,186.44$ & $10 \%$ & 118.64 \\
\hline Mesas Comedor & 7 & $\mathrm{~S} /$. & 500.00 & 423.73 & $\mathrm{~S} /$. & $2,966.10$ & $10 \%$ & 296.61 \\
\hline Sillas Comedor & 42 & $\mathrm{~S} /$. & 50.00 & 42.37 & $\mathrm{~S} /$. & $1,779.66$ & $10 \%$ & 177.97 \\
\hline Camarotes & 32 & $\mathrm{~S} /$. & $1,600.00$ & S/. $1,355.93$ & $\mathrm{~S} /$. & $43,389.83$ & $10 \%$ & S/. $\quad 4,338.98$ \\
\hline Armarios Closet de cabaña & 24 & $\mathrm{~S} /$. & 300.00 & 254.24 & $\mathrm{~S} /$. & $6,101.69$ & $10 \%$ & 610.17 \\
\hline Archiviero/stand & 1 & $\mathrm{~S} /$. & 400.00 & 338.98 & $\mathrm{~S} /$. & 338.98 & $10 \%$ & 33.90 \\
\hline Mueble Librero & 1 & $\mathrm{~S} /$. & 350.00 & 296.61 & S/. & 296.61 & $10 \%$ & 29.66 \\
\hline Estante de laptos & 1 & S/. & 500.00 & 423.73 & S/. & 423.73 & $10 \%$ & 42.37 \\
\hline Grifería para baños (ducha dormitorio) & 12 & $\mathrm{~S} /$. & 400.00 & 338.98 & $\mathrm{~S} /$. & $4,067.80$ & $10 \%$ & 406.78 \\
\hline Grifería para baños (Lavadero, inodoro) & 16 & $\mathrm{~S} /$. & 300.00 & 254.24 & $\mathrm{~S} /$. & $4,067.80$ & $10 \%$ & 406.78 \\
\hline Botiquin completo & 1 & $\mathrm{~S} /$. & 120.00 & 101.69 & S/. & 101.69 & $10 \%$ & 10.17 \\
\hline TOTAL & & & & & S/. & $79,584.75$ & & S/. $7,958.47$ \\
\hline
\end{tabular}

\begin{tabular}{|c|c|c|c|cr|}
\hline \multicolumn{7}{|c|}{ Infraestructura } \\
\hline Inmueble & Cantidad & Costo Unitario & Costo sin IGV & \multicolumn{2}{c|}{ Costo Total } \\
\hline Edificación e infraestructura & 1 & S/.630,000.00 & S/.533,898.31 & S/. & $533,898.31$ \\
\hline \multicolumn{3}{|c|}{ TOTAL } & & S/. & $533,898.31$ \\
\hline
\end{tabular}




\begin{tabular}{|c|c|c|c|c|c|c|}
\hline \multicolumn{5}{|c|}{ Maquinarias y equipos } & \multirow[b]{2}{*}{ Depreciación } & \multirow[b]{2}{*}{ Dep. Anual } \\
\hline Equipos de computo & Cantidad & Costo Unitario & Costo sin IGV & Costo Total & & \\
\hline Laptop & 5 & $1,800.00$ & S/. $\quad 1,525.42$ & $7,627.12$ & $20 \%$ & S/. $\quad 1,525.42$ \\
\hline \multicolumn{3}{|c|}{ TOTAL } & & $7,627.12$ & & \\
\hline
\end{tabular}

\section{Proyección de ventas}

Tabla $N^{\circ} 20$ Proyección de ventas

\begin{tabular}{|c|c|c|c|c|c|}
\hline I Módulo de Premisas - Estandar & M1 & $\mathrm{M} 2$ & M3 & M4 & M5 \\
\hline Precio por paquete - 5D4N & $\mathrm{S} / .3,960.00$ & $\mathrm{~S} / .3,960.00$ & $\mathrm{~S} / .3,960.00$ & $\mathrm{~S} / .3,960.00$ & $\mathrm{~S} / .3,960.00$ \\
\hline Cantidad & 0 & 5 & 5 & 10 & 10 \\
\hline Ingresos & $\mathrm{S} / .0 .00$ & $S / .19,800.00$ & $S / .19,800.00$ & $\mathrm{~S} / .39,600.00$ & $S / .39,600.00$ \\
\hline
\end{tabular}

\begin{tabular}{|r|r|r|r|r|r|r|}
\multicolumn{1}{|c}{ M6 M7 } & \multicolumn{1}{c}{ M8 } & \multicolumn{1}{c}{ M9 10} & M11 & \multicolumn{1}{c|}{ M12 } \\
\hline $\mathrm{S} / .3,960.00$ & $\mathrm{~S} / .3,960.00$ & $\mathrm{~S} / .3,960.00$ & $\mathrm{~S} / .3,960.00$ & $\mathrm{~S} / .3,960.00$ & $\mathrm{~S} / .3,960.00$ & $\mathrm{~S} / .3,960.00$ \\
\hline 10 & 12 & 12 & 12 & 11 & & 15 \\
\hline $\mathrm{S} / .39,600.00$ & $\mathrm{~S} / .47,520.00$ & $\mathrm{~S} / .47,520.00$ & $\mathrm{~S} / .47,520.00$ & $\mathrm{~S} / .43,560.00$ & $\mathrm{~S} / .59,400.00$ & $\mathrm{~S} / .47,520.00$ \\
\hline
\end{tabular}

\begin{tabular}{|c|c|c|c|c|c|}
\hline I Módulo de Premisas - Especializado & M1 & $\mathrm{M} 2$ & M3 & M4 & M5 \\
\hline Precio por paquete -12D11N & $\mathrm{S} / .9,240.00$ & $S / .9,240.00$ & $\mathrm{~S} / .9,240.00$ & $\mathrm{~S} / .9,240.00$ & $S / .9,240.00$ \\
\hline Cantidad & 0 & 1 & 1 & 1 & 2 \\
\hline Ingresos & $\mathrm{S} / .0 .00$ & $\mathrm{~S} / .9,240.00$ & $\mathrm{~S} / .9,240.00$ & $\mathrm{~S} / .9,240.00$ & $\mathrm{~S} / .18,480.00$ \\
\hline
\end{tabular}

\begin{tabular}{|c|c|c|c|c|c|c|}
\hline M6 & M7 & M8 & M9 & M10 & M11 & M12 \\
\hline$S / .9,240.00$ & S/.9,240.00 & $S / .9,240.00$ & $S / .9,240.00$ & $S / .9,240.00$ & $S / .9,240.00$ & $S / .9,240.00$ \\
\hline 2 & 3 & 3 & 3 & 3 & 4 & 3 \\
\hline $\mathrm{S} / .18,480.00$ & $S / .27,720.00$ & $\mathrm{~S} / .27,720.00$ & $\mathrm{~S} / .27,720.00$ & $\mathrm{~S} / .27,720.00$ & $\mathrm{~S} / .36,960.00$ & $S / .27,720.00$ \\
\hline
\end{tabular}




\section{Cálculo del capital de trabajo}

Tabla $\mathrm{N}^{\circ} 21$ Capital de trabajo

\begin{tabular}{|l|r|}
\hline \multicolumn{2}{|c|}{ Calculo del Capital de Trabajo } \\
\hline Meses en negativo & \multicolumn{1}{c|}{ Monto } \\
\hline Mes 1 & $\mathrm{S} / 18,970.85$ \\
\hline Mes 2 & $\mathrm{S} / 249.43$ \\
\hline Mes 3 & $\mathrm{S} / 11,055.67$ \\
\hline Mes 4 & $\mathrm{S} / 5,590.51$ \\
\hline \multicolumn{2}{|c|}{ Total } \\
\hline
\end{tabular}

\section{Estructura de financiamiento: Tradicional y no tradicional}

Tabla $\mathrm{N}^{\circ} 22$ Estructura de financiamiento

\begin{tabular}{|l|c|l|l|}
\hline Mòdulo de Financiamiento & \multicolumn{2}{|c|}{} \\
\hline GNK & S/.656,976.62 & Monto a Financiar & S/.487,976.62 \\
\hline Capital & S/.169,000.00 & TEA & $19 \%$ \\
\hline Bancos & S/.487,976.62 & Plazo & 10 años \\
\cline { 3 - 5 }
\end{tabular}

\begin{tabular}{|r|r|r|r|r|r|}
\hline \multicolumn{1}{|l|}{ Años } & \multicolumn{1}{|l|}{ Préstamo } & \multicolumn{1}{l|}{ Amortización } & \multicolumn{1}{l}{ Cuota } & Interés & Escudo Fiscal -EF \\
\hline & $\mathrm{S} / .487,976.62$ & & & & \\
\hline 1 & $\mathrm{~S} / .487,976.62$ & $\mathrm{~S} / .19,749.05$ & $\mathrm{~S} / .112,465$ & $\mathrm{~S} / .92,715.56$ & $\mathrm{~S} / .27,351.09$ \\
\hline 2 & $\mathrm{~S} / .468,227.57$ & $\mathrm{~S} / .23,501.37$ & $\mathrm{~S} / .112,465$ & $\mathrm{~S} / .88,963.24$ & $\mathrm{~S} / .26,244.16$ \\
\hline 3 & $\mathrm{~S} / .444,726.20$ & $\mathrm{~S} / .27,966.63$ & $\mathrm{~S} / .112,465$ & $\mathrm{~S} / .84,497.98$ & $\mathrm{~S} / .24,926.90$ \\
\hline 4 & $\mathrm{~S} / .416,759.56$ & $\mathrm{~S} / .33,280.29$ & $\mathrm{~S} / .112,465$ & $\mathrm{~S} / .79,184.32$ & $\mathrm{~S} / .23,359.37$ \\
\hline $\mathrm{S}$ & $\mathrm{S} / .383,479.27$ & $\mathrm{~S} / .39,603.55$ & $\mathrm{~S} / .112,465$ & $\mathrm{~S} / .72,861.06$ & $\mathrm{~S} / .21,494.01$ \\
\hline 6 & $\mathrm{~S} / .343,875.72$ & $\mathrm{~S} / .47,128.22$ & $\mathrm{~S} / .112,465$ & $\mathrm{~S} / .65,336.39$ & $\mathrm{~S} / .19,274.23$ \\
\hline 7 & $\mathrm{~S} / .296,747.49$ & $\mathrm{~S} / .56,082.59$ & $\mathrm{~S} / .112,465$ & $\mathrm{~S} / .56,382.02$ & $\mathrm{~S} / .16,632.70$ \\
\hline 8 & $\mathrm{~S} / .240,664.91$ & $\mathrm{~S} / .66,738.28$ & $\mathrm{~S} / .112,465$ & $\mathrm{~S} / .45,726.33$ & $\mathrm{~S} / .13,489.27$ \\
\hline 9 & $\mathrm{~S} / .173,926.63$ & $\mathrm{~S} / .79,418.55$ & $\mathrm{~S} / .112,465$ & $\mathrm{~S} / .33,046.06$ & $\mathrm{~S} / .9,748.59$ \\
\hline 10 & $\mathrm{~S} / .94,508.08$ & $\mathrm{~S} / .94,508.08$ & $\mathrm{~S} / .112,465$ & $\mathrm{~S} / .17,956.53$ & $\mathrm{~S} / .5,297.18$ \\
\hline
\end{tabular}




\section{Estados Financieros (Balance General, Estado de GGPP, Flujo de}

\section{Caja)}

Tabla $N^{\circ} 23$ Balance general

\begin{tabular}{|l|r|l|r|}
\hline \multicolumn{2}{|c|}{ ESTADO DE SITUACION FINANCIERA PROYECTADO } & Año 1 \\
\hline \multicolumn{2}{|l|}{ Activos } & Pasivos y Patrimonio \\
\hline \multicolumn{2}{|l|}{ Activos Corrientes } & Pasivos Corrientes & \\
\hline Efectivo y Equivalentes al Efectivo & 83,307 & Impuestos por Pagar - IR & 25,404 \\
\hline Crédito Fiscal (IGV) & 28,409 & & \\
\hline & & Pasivos No Corrientes & 468,228 \\
\hline & & Pasivo Financiero & 493,631 \\
\hline Total Activos Corrientes & $\mathbf{1 1 1 , 7 1 6}$ & Total Pasivos & \\
\hline Activos No Corrientes & Patrimonio & 169,000 \\
\hline Propiedades, Planta y Equipo & 621,110 & Capital & 60,711 \\
\hline Depreciación Acumulada & $-9,484$ & Resultados Acumulados & $\mathbf{2 2 9 , 7 1 1}$ \\
\hline Total Activos No Corrientes & $\mathbf{6 1 1 , 6 2 6}$ & Total Patrimonio & $\mathbf{7 2 3 , 3 4 3}$ \\
\hline TOTAL DE ACTIVOS & $\mathbf{7 2 3 , 3 4 3}$ & TOTAL PASIVO Y PATRIMONIO & \\
\hline
\end{tabular}

Tabla N²4 Estado de resultados

\begin{tabular}{|l|r|}
\hline \multicolumn{1}{|c|}{ ESTADO DE RESULTADOS PROYECTADO } & \multicolumn{1}{c|}{ Año 1 } \\
\hline Ingresos de actividades ordinarias & 691,680 \\
\hline Costo de Ventas & $-83,002$ \\
\hline Ganancia (Pérdida) Bruta & 608,678 \\
\hline Gastos de Ventas y Adminitración & $-420,364$ \\
\hline Depreciación del Ejercicio & $-9,484$ \\
\hline Ganancia (Pérdida) por actividades de operación & 178,831 \\
\hline Gastos Financieros & $-92,716$ \\
\hline Resultado antes de Impuesto a las Ganancias & 86,115 \\
\hline Gasto por Impuesto a las Ganancias & $-25,404$ \\
\hline Ganancia (Pérdida) Neta del Ejercicio & 60,711 \\
\hline
\end{tabular}

Tabla $N^{\circ} 25$ Flujo de caja

\begin{tabular}{|c|c|c|c|c|c|c|}
\hline & 0 & 1 & 2 & 3 & 4 & 5 \\
\hline (t) Ingresos & & $\mathrm{S} / .691,680.00$ & $\mathrm{~S} / .788,515.20$ & S/.946,218.24 & $\mathrm{S} / .1,135,461.89$ & S/.1,362,554.27 \\
\hline (-) Costo de ventas & & $\mathrm{S} / .83,001.60$ & $\mathrm{~S} / .94,621.82$ & $\mathrm{~S} / .113,546.19$ & S/.136,255.43 & S/.163,506.51 \\
\hline (-) Costos fijos & & $S / .420,364.00$ & $S / .420,364.00$ & $\mathrm{~S} / .420,364.00$ & $S / .420,364.00$ & $S / .420,364.00$ \\
\hline$(-)$ Comisión de ventas & & $S / .0 .00$ & & & & \\
\hline (-) Depreciación & & $S / .9,483.90$ & $S / .9,483.90$ & $S / .9,483.90$ & $S / .9,483.90$ & $S / .9,483.90$ \\
\hline EBIT & & S/.178,830.50 & $S / .264,045.48$ & S/.402,824.15 & $S / .569,358.56$ & $S / .769,199.86$ \\
\hline$(-)$ IR (29.5\%) & & $\mathrm{S} / .52,755.00$ & S/.77,893.42 & $\mathrm{S} / .118,833.13$ & $\mathrm{~S} / .167,960.78$ & $S / .226,913.96$ \\
\hline (+) Depreciación & & S/.9,483.90 & S/.9,483.90 & S/.9,483.90 & S/.9,483.90 & $S / .9,483.90$ \\
\hline FEO & & $\mathrm{S} / .135,559.40$ & S/.195,635.96 & S/.293,474.93 & S/.410,881.69 & $\mathrm{S} / .551,769.80$ \\
\hline (-) Activo Fijo & $S / .621,110.17$ & & & & & \\
\hline$(-)$ CTN & $\mathrm{S} / .35,866.45$ & & & & & \\
\hline FCLD & $-\mathrm{S} / .656,976.62$ & $\mathrm{~S} / .135,559.40$ & S/.195,635.96 & S/.293,474.93 & $S / .410,881.69$ & $\mathrm{~S} / .551,769.80$ \\
\hline
\end{tabular}




\section{Flujo Financiero}

Tabla $N^{\circ} 26$ Flujo financiero

\begin{tabular}{l|r|r|r|r|r|r|}
\hline \multirow{2}{*}{$\begin{array}{l}\text { Capital } \\
\text { Amortización }\end{array}$} & $\mathrm{S} / .487,976.62$ & & & & \\
\cline { 2 - 6 } $\begin{array}{l}\text { Interés } \\
\text { Escudo tributario }\end{array}$ & & $-\mathrm{S} / .19,749.05$ & $-\mathrm{S} / .23,501.37$ & $-\mathrm{S} / .27,966.63$ & $-\mathrm{S} / .33,280.29$ & $-\mathrm{S} / .39,603.55$ \\
\cline { 2 - 6 } & & $-\mathrm{S} / .92,715.56$ & $-\mathrm{S} / .88,963.24$ & $-\mathrm{S} / .84,497.98$ & $-\mathrm{S} / .79,184.32$ & $-\mathrm{S} / .72,861.06$ \\
\cline { 2 - 6 } & & $\mathrm{S} / .27,351.09$ & $\mathrm{~S} / .26,244.16$ & $\mathrm{~S} / .24,926.90$ & $\mathrm{~S} / .23,359.37$ & $\mathrm{~S} / .21,494.01$ \\
\hline FNF & $\mathrm{S} / .487,976.62$ & $-\mathrm{S} / .85,113.52$ & $-\mathrm{S} / .86,220.46$ & $-\mathrm{S} / .87,537.71$ & $-\mathrm{S} / .89,105.24$ & $-\mathrm{S} / .90,970.60$ \\
\hline
\end{tabular}

\section{Tasa de descuento accionistas y WACC}

Tabla $\mathrm{N}^{\circ} 27$ Tasa de descuento accionistas y WACC

\begin{tabular}{|l|l|r|}
\hline Accionista & \multicolumn{1}{|c|}{ Descripción } & \multicolumn{1}{|c|}{$\%$} \\
\hline Patty & Cuenta a Plazo & $9 \%$ \\
\hline Claudia & Aporte voluntario AFP & $12 \%$ \\
\hline Rocío & Renta variable & $15 \%$ \\
\hline \multirow{2}{*}{ Luis } & Cuenta a plazo & $7 \%$ \\
\hline \multirow{5}{*}{} & Suma & $43 \%$ \\
\cline { 2 - 3 } & promedio & $10.6 \%$ \\
\cline { 2 - 3 } & COK & 5.00 \\
\cline { 2 - 3 } &
\end{tabular}

\begin{tabular}{|l|r|}
\hline FR & 5.00 \\
\hline Promedio & $11 \%$ \\
\hline COK & $53.13 \%$ \\
\hline
\end{tabular}

\begin{tabular}{|l|r|}
\hline Inversión & $\mathrm{S} / .656,976.62$ \\
\hline Aporte propio & $\mathrm{S} / .169,000.00$ \\
\hline Financiamiento & $\mathrm{S} / .487,976.62$ \\
\hline$\% \mathrm{E}$ & $26 \%$ \\
\hline$\% \mathrm{D}$ & $74 \%$ \\
\hline $\mathrm{Rd}$ & $19 \%$ \\
\hline $\mathrm{Re}$ & $53.13 \%$ \\
\hline $\mathrm{t}$ & $29.50 \%$ \\
\hline V & $100 \%$ \\
\hline WACC & $23.62 \%$ \\
\hline
\end{tabular}




\section{Indicadores de rentabilidad}

Tabla $N^{\circ} 28$ Indicadores de rentabilidad

Tasa Interna de Retorno (TIR)
\begin{tabular}{|l|r|r|}
\hline & Económico & Financiero \\
\hline Inversión & 656,977 & - \\
\hline FC1 & 169,000 \\
\hline FC2 & 195,559 & 50,446 \\
\hline FC3 & 293,475 & 109,416 \\
\hline FC4 & 410,882 & 205,937 \\
\hline FC5 & 551,770 & 421,776 \\
\hline & & 460,799 \\
\hline COK & $23.62 \%$ & $23.62 \%$ \\
\hline & & \\
\hline TIR & $29 \%$ & $74 \%$ \\
\hline VAN & S/83,491.70 & S/283,045.19 \\
\hline PRI & 3.08 & 2.04 \\
\hline
\end{tabular}




\section{Análisis de riesgo}

\section{Análisis de sensibilidad y escenarios (por variables)}

Tabla $N^{\circ} 29$ Análisis de sensibilidad y escenarios

\begin{tabular}{|l|r|r|r|}
\hline \multicolumn{1}{|c|}{ Variables críticas } & \multicolumn{1}{|c|}{ Actual } & Optimista & Pesimista \\
\hline Tipo de cambio & 3.3 & 3.5 & 3.1 \\
\hline Costo de Venta & $12 \%$ & $10 \%$ & $15 \%$ \\
\hline Precio de Paquete Premium & 2800 & 3000 & 2500 \\
\hline
\end{tabular}

\begin{tabular}{|l|r|r|r|}
\hline Análisis de Sensibilidad - Tipo de cambio & \multicolumn{3}{|}{} \\
\cline { 1 - 2 } VAN & $\$ 83,491.70$ & $\$ 103,485.13$ & $-\$ 57,780.49$ \\
\hline PIR & $29 \%$ & $28 \%$ & $19 \%$ \\
\hline PRI & 2.04 & 1.92 & 2.67 \\
\hline
\end{tabular}

\begin{tabular}{|l|r|r|r|}
\hline Análisis de Sensibilidad - Costo de Venta & \multicolumn{1}{|c|}{} \\
\hline VAN & $\$ 83,491.70$ & $\$ 55,821.80$ & $-\$ 26,601.90$ \\
\hline TIR & $29 \%$ & $25 \%$ & $21 \%$ \\
\hline PRI & 2.04 & 2.10 & 2.50 \\
\hline
\end{tabular}

\begin{tabular}{|l|r|r|r|}
\hline Análisis de Sensibilidad - Precio de Paquete Premium & \multicolumn{1}{|}{} \\
\hline VAN & $\$ 83,491.70$ & $\$ 55,859.45$ & $-\$ 26,658.38$ \\
\hline TIR & $29 \%$ & $25 \%$ & $21 \%$ \\
\hline PRI & 2.04 & 2.11 & 2.48 \\
\hline
\end{tabular}




\section{Análisis de punto de equilibro}

Tabla $N^{\circ} 30$ Punto de equilibrio

\begin{tabular}{|l|ll|lr|}
\cline { 2 - 5 } \multicolumn{1}{c|}{} & \multicolumn{2}{c|}{$\mathrm{p}$} & \multicolumn{2}{c|}{$\mathrm{Cu}$} \\
\hline Paq. Estándar & $\mathrm{S} /$ & $3,960.00$ & $\mathrm{~S} /$ & 475.20 \\
\hline Paq. Especializado & $\mathrm{S} /$ & $9,240.00$ & $\mathrm{~S} /$ & $1,108.80$ \\
\hline
\end{tabular}

\begin{tabular}{|l|l|l|}
\hline Punto de equilibro: & $\mathrm{U}=0$ & $\mathrm{C}=\mathrm{I}$ \\
\hline
\end{tabular}

\begin{tabular}{|l|lr|r|}
\hline Paq. Estándar & S/ $479,160.00$ & 121 unid. \\
\hline
\end{tabular}

$$
\begin{gathered}
420364+475.20 q=3960 q \\
420364=3484.80 q \\
q=121
\end{gathered}
$$

\begin{tabular}{|l|ll|r|}
\hline Paq. Especializado & S/ $480,480.00$ & 52 unid. \\
\hline
\end{tabular}

$$
\begin{gathered}
420364+1108.80 \mathrm{q}=9240 \mathrm{q} \\
420364=8121.20 \mathrm{q} \\
\mathrm{q}=52
\end{gathered}
$$

\begin{tabular}{|c|c|c|c|c|c|c|}
\hline & & & & \multicolumn{3}{|c|}{ Contribución Marginal } \\
\hline & \multicolumn{2}{|r|}{ Ingreso } & Costo Variable & \multicolumn{2}{|r|}{ Importe } & \multirow{2}{*}{$\%$} \\
\hline Paq. Estándar & $\mathrm{S} /$ & $451,440.00$ & S/ $\quad 54,172.80$ & S/ & $397,267.20$ & \\
\hline Paq. Especializado & S/ & $240,240.00$ & S/ $\quad 28,828.80$ & S/ & $211,411.20$ & $88.00 \%$ \\
\hline & S/ & $691,680.00$ & S/ $83,001.60$ & S/ & $608,678.40$ & $88.00 \%$ \\
\hline
\end{tabular}

\begin{tabular}{|c|r|r|r|rr|r|r|}
\cline { 5 - 7 } & \multicolumn{3}{c|}{$\%$ de Mezcla } \\
\hline Año 1 & Unidades & Precio de Venta & & \multicolumn{2}{c|}{ Ingreso } & \multicolumn{1}{c|}{ Unidades } & \multicolumn{1}{c|}{ Importe } \\
\hline Paq. Estándar & 114 & S/ & $3,960.00$ & S/ & $451,440.00$ & $81.43 \%$ & $65.27 \%$ \\
\hline Paq. Especializado & 26 & S/ & $9,240.00$ & S/ & $240,240.00$ & $18.57 \%$ & $34.73 \%$ \\
\hline TOTAL & 140 & & S/ & $691,680.00$ & $100.00 \%$ & $100.00 \%$ \\
\hline
\end{tabular}

\begin{tabular}{|l|rr|}
\cline { 2 - 3 } \multicolumn{1}{c|}{} & \multicolumn{2}{c|}{ Costo Variable } \\
\hline Paq. Estándar & S/ & 475.20 \\
\hline Paq. Especializado & S/ & $1,108.80$ \\
\hline
\end{tabular}

$\% C M=$ Importe $C M$ Total $\div$ Ingreso Total

$\% \mathrm{CM}=88 \%$

Punto de Equilibro $=C f \div \% C M$

S/ $\quad 477,686.36$

\begin{tabular}{|c|r|c|r|}
\hline \multicolumn{5}{|c|}{ Distribución de las Ventas en Punto de Equilibrio } \\
\hline Año 1 & \% de Mezcla & Ingresos & Unidades \\
\hline Paq. Estándar & $65.27 \%$ & S/ $311,772.40$ & $\mathbf{7 9}$ \\
\hline Paq. Especializado & $34.73 \%$ & S/ $165,913.97$ & 18 \\
\hline TOTAL & $\mathbf{1 0 0 . 0 0 \%}$ & S/ $\mathbf{4 7 7 , 6 8 6 . 3 6}$ & $\mathbf{9 7}$ \\
\hline
\end{tabular}




\section{Principales riesgos del proyecto (cualitativos)}

- Pérdida del personal clave (Guías especializados).

- Al ser la especialización del personal un valor agregado del negocio, nuestros guías se encontrarán en planilla desde la contratación. Así mismo, se tendrá como back up a los guías free lance.

- Fragmentación de hábitat generado por la tala y minería ilegal. (se interrumpe el corredor natural de las aves)

- Se efectuarán alianzas estratégicas con el gobierno central y regional para minimizar el impacto en nuestra zona de intervención.

- Trabas en las operaciones turísticas por influencia de las comunidades disconformes.

- Contar con un plan de responsabilidad social, el cual incluya a estas comunidades en la cadena de valor para establecer buenas relaciones.

- Proyección de la demanda no se cumple por la inseguridad en la zona (Madre de Dios) generada por el narcotráfico.

- Contar con un plan de vigilancia que refuerce las alianzas estratégicas con las autoridades competentes y comunidades locales. 


\section{Capítulo 8. Conclusiones}

- Luego de haber realizado la validación de la investigación concluimos que existe la necesidad de atender a este nicho de turismo especializado y que no se encuentra oferta de este tipo en el Perú.

- El grado de especialización para implementar este negocio es alto considerando que atendemos a un nicho especializado relacionado al avistamiento de fauna.

- Un factor sensible y clave en el proyecto es el recurso humano, específicamente las habilidades y conocimientos que deben tener los guías locales quienes son los que permanentemente están en contacto directo con el cliente.

- El presente plan de negocio propone implementar una empresa con propósito, es decir tiene una visión holística, que maximiza beneficios económicos y a la vez aporta al desarrollo social y ambiental en la zona de intervención del albergue. 


\section{Bibliografía}

Ecomanu (2018). EXPLORA LO MARAVILLOSO DEL PERU. 14/04/2018, de EcoManu Expedition Sitio web: http://www.ecomanuperu.com/es/

Wikipedia. (2017). Aves de Brasil. 14/04/2018, de Fundación Wikimedia, Inc. Sitio web: https://es.wikipedia.org/wiki/Anexo:Aves_de_Brasil

FENAMAD. (2014). Pueblos Indígenas. 24/04/2018, de Federación Nativa del Río Madre de Dios y Afluentes - FENAMAD Sitio web: http://www.fenamad.org.pe/pueblos-indigenas/

Go2Peru - COMELTUR. (2000). Observación de Aves en el Perú. 24/04/2018, de COMELTUR Sitio web: http://www.go2peru.com/spa/observacion_aves.htm

Juan Carlos Castro. (2016). Crecimiento del turismo de aventura en Perú. 15/04/2018, de Portal de turismo Sitio web: Go2Peru - COMELTUR. (2000). Observación de Aves en el Perú. 24/04/2018, de COMELTUR Sitio web: http://www.go2peru.com/spa/observacion_aves.htm

J. Mazzotti. (2000). Aves en la Reserva Nacional de Lachay. 24/04/2018, de COMELTUR Sitio web: http://www.go2peru.com/spa/guia_viajes/lima/foto_aves_reserva_nacional_lachay.htm

Go Tambopata. (2018). Aves. 05/05/2018, de Go Tambopata Sitio web: http://www.gotambopata.com/es/reserva-de-tambopata/fauna-amazonica-tambopata/aves/

GESTIÓN. (2014). Turismo de observación de aves podría mover más de US\$ 7,000 millones en el Perú. 10/05/2018, de Empresa Editora El Comercio S.A. Sitio web: https://gestion.pe/economia/turismo-observacion-aves-mover-us-7-000-millones-peru-83691 